\title{
Anatomy and physiology of the thick-tufted layer 5 pyramidal neuron
}

\author{
Srikanth Ramaswamy* and Henry Markram* \\ Blue Brain Project, Ecole Polytechnique Fédérale de Lausanne, Campus Biotech, Geneva, Switzerland
}

The thick-tufted layer 5 (TTL5) pyramidal neuron is one of the most extensively studied neuron types in the mammalian neocortex and has become a benchmark for understanding information processing in excitatory neurons. By virtue of having the widest local axonal and dendritic arborization, the TTL5 neuron encompasses various local neocortical neurons and thereby defines the dimensions of neocortical microcircuitry. The TTL5 neuron integrates input across all neocortical layers and is the principal output pathway funneling information flow to subcortical structures. Several studies over the past decades have investigated the anatomy, physiology, synaptology, and pathophysiology of the TTL5 neuron. This review summarizes key discoveries and identifies potential avenues of research to facilitate an integrated and unifying understanding on the role of a central neuron in the neocortex.

\section{OPEN ACCESS}

Edited by:

Andreas Frick, Institut National de la Santé et de la Recherche Médicale, France

Reviewed by: Robert C. Froemke, New York University School of Medicine, USA Alexander C. Jackson, University of Connecticut, USA

${ }^{*}$ Correspondence:

Srikanth Ramaswamy and Henry Markram

Blue Brain Project, Ecole Polytechnique Fédérale de Lausanne, Campus Biotech, Ch. des Mines 9, CH 1202, Geneva, Switzerland srikanth.ramaswamy@epfl.ch; henry.markram@epfl.ch

Received: 18 March 2015 Accepted: 08 June 2015 Published: 26 June 2015

Citation:

Ramaswamy S and Markram H (2015) Anatomy and physiology of the thick-tufted layer 5 pyramidal

neuron.

Front. Cell. Neurosci. 9:233 doi: 10.3389/fncel.2015.00233
Keywords: pyramidal neuron, neocortex, dendrites, axon, synaptic transmission, back-propagating action potential, spike-timing dependent plasticity

\section{Introduction}

The mammalian neocortex is endowed with a daunting diversity of neurons. These neurons are classified into excitatory pyramidal neurons and local circuit interneurons, which are predominantly inhibitory. Pyramidal neurons exist in all layers of the neocortex except layer 1 , forming the most abundant neuron type. In particular, thick-tufted layer 5 (TTL5) neurons are one of the most extensively studied cell types in the neocortex (Larkman, 1991a; DeFelipe and Fariñas, 1992; Markram et al., 1997a; for review see Spruston, 2008).

TTL5 neurons are predominantly found in lower layer 5 (layer 5B) and are characterized by a pyramid-like soma, and a stereotypical dendritic morphology with a prominent apical dendrite. In contrast to the other significant population of pyramidal neurons located in upper layer 5 (layer 5A) with slender apical dendrites, which project across hemispheres to the corpus callosum, TTL5 neurons mainly project to subcortical regions. Over the past two decades, in vitro patchclamp recordings from brain slices using IR-DIC microscopy (Stuart et al., 1993) in vivo whole cell recordings and targeted recordings in freely moving animals (Svoboda et al., 1997; Murayama et al., 2007), and biologically detailed in silico models (Hay et al., 2011; Ramaswamy et al., 2012; Reimann et al., 2013) have significantly advanced our understanding of the structure and function

\footnotetext{
Abbreviations: ACh, acetylcholine; AIS, axon initial segment; AMPAR, AMPA receptor; AMP, adenosine monophosphate; AP, action potential; bAP, back-propagating action potential; bAC, back-propagation activated $\mathrm{Ca}^{2+}$ spike; BDNF, brain-derived neurotrophic factor; $\mathrm{BK}$, big-conductance $\mathrm{Ca}^{2+}$ dependent $\mathrm{K}^{+}$channel; $\mathrm{CV}$, coefficient of variation; DA, dopamine; HCN, hyperpolarization-activated cation; IR-DIC, infrared differential interference contrast; KAR, kainate receptor; $\mathrm{KCC} 2, \mathrm{~K}^{+} / \mathrm{Cl}^{-}$cotransporter; L2/3PC, layer $2 / 3$ pyramidal neuron; TTL5, thicktufted layer 5; NMDAR, NMDA receptor; P, postnatal day; PSD, postsynaptic density; RSE, redistribution of synaptic efficacy; SK, small-conductance $\mathrm{Ca}^{2+}$ dependent $\mathrm{K}^{+}$channel; STDP, spike-timing dependent synaptic plasticity; VPA, valproic acid.
} 
of TTL5 neurons. This review attempts to consolidate the knowledge obtained from a vast body of existing literature in order to drive a unifying view of the anatomy, physiology, synaptology, and pathophysiology of the TTL5 neuron (see Figure 1).

\section{Generic Anatomy and Development}

The generic anatomy of TTL5 neurons in rodent somatosensory cortex is characterized by a triangular soma, two distinct dendritic domains emanating from the base and apex of the soma (basal and apical dendrites, respectively), and a single axon sending out several collateral branches that further bifurcate and ramify exuberantly within the neocortex. The apical dendrites further branch into oblique dendrites and terminate with a crown-like thick tuft of dendrites in layer 1 . There is a lack of quantitative data comparing the time-scales of anatomical development of TTL5 neurons across different cortical regions and species. Most of our knowledge on the development of TTL5 neurons can be attributed to studies in the frontal, parietal, temporal, and occipital lobes, in particular the visual, auditory, and somatosensory areas.

In sensory cortical areas, the anatomical development of TTL5 neurons is marked by three phases of growth; a fast growth phase of basal, oblique and apical branches from postnatal days 7 (P7) to 14 (P14), an intermediate localized growth phase of basal, apical and oblique branches growth from P14 onwards to postnatal day 21 (P21), and a slow growth phase from P21 to postnatal day 60 (P60) (Nicolai, 1981; Romand et al., 2011) We further direct the reader to exhaustive analytical studies on the overall anatomical development of TTL5 neurons (Nicolai, 1981; Kasper et al., 1994a; Zhu, 2000; Zhang, 2004) and rigorous quantifications of the morphometry of TTL5 dendrites (Larkman, 1991a,b).

\section{Somatic Development}

The somata of TTL5 neurons have been subjectively classified according to triangular, round, and oval shapes (Romand et al., 2011). The three shapes are found to occur at all ages, however, somata appear to be mostly round or triangular between P7 and P14 and are predominantly triangular from P14 onwards. The somatic surface area, height and width increase markedly from P7 to P14. Although the growth of somata slows after P14, the height and surface area still increase significantly to reach the mature adult soma size at around P21 (Zhu, 2000).

\section{Dendritic Development}

Detailed morphological analyses have revealed that the TTL5 dendritic arbor increases in size and branching complexity during the first postnatal week (Wise et al., 1979; Zhu, 2000; Romand et al., 2011; see Figure 2 for a gantt-chart like illustration of the salient features of anatomical development). This period is also marked by the growth of secondary and tertiary branches of basal dendrites, the appearance of finer oblique dendrites, and an increase in the number of spines throughout the dendritic arbor. Between P7 and P14, basal dendrites also rapidly grow to increase their radial reach and path length. Concurrently, apical dendrites are typified by the appearance of several short and thin filopodia-like structures and oblique dendrites grow rapidly increasing both in length and thickness, reaching near maximal values. Furthermore, the tuft dendrites also increase significantly in length between P7 and P14. A wide diversity of tuft shapes, a signature feature of TTL5 neurons is already observed in this early growth period. By P7, spines are sparsely and homogeneously distributed throughout the basal dendrites. Between P7 and P14, spines located on the proximal dendrites are significantly reduced in number and continue to remain relatively sparse thereafter (Romand et al., 2011; Figure 2).

By P14, TTL5 neurons develop highly branched dendritic trees. From P14 until P21, basal dendrites continue to increase in radial reach and length in a trend consistent with earlier stages of growth, without the appearance of newer branches. The apical dendrites expand in length, reaching $92 \%$ of the maximal value observed in adult animals and the number of oblique dendrites and their lengths are established (Zhu, 2000; Romand et al., 2011; Figure 2). The previously observed filopodia-like structures on apical dendrites disappear almost completely during this period. While the intermediate branches of tuft dendrites do not show a significant increase in length, the terminal segments grow prominently between P14 and P21. This period of growth also undergoes a tremendous increase in spine density, attaining levels measured in adult animals (Larkman, 1991b; Figure 2).

During adulthood, the P21 to P60 growth period witnesses the emergence of newer basal dendritic segments with a further increase in length. The terminal segments of oblique dendrites increase in length and thickness. Contrastingly, the intermediate and terminal segments of dendritic tufts are shortened in length during this growth period (Romand et al., 2011; Figure 2).

In summary, three distinct developmental periods influence the dendritic growth of TTL5 neurons. The growth rate is fastest during the first period from P7 until P14, intermediate during the second period from P14 to P21, and the slowest during the third period from P21 to P60. In the first period basal, oblique, and tuft dendrites grow rapidly (Figure 2). Specific dendritic segments are both lengthened and thickened simultaneously, while tuft segments are only lengthened. During the second period, localized changes to specific compartments takes place and maximal spine densities. Thereafter during the third period, further localized changes continue at selected compartments and terminal segments. A characteristic feature of TTL5 dendritic development is that during a given period, segments are either lengthened or thickened, but never occurring concurrently at the same segment.

\section{Axonal Development}

The TTL5 axonal arbor expands rapidly from P7 to P14, demonstrated through an increase in total length and segment number at these ages. At P7, the number of axonal collaterals is already equivalent to that of a fully mature TTL5 neuron (Romand et al., 2011; Figure 2). The radial distances from the soma to the local site of axonal collaterals increase significantly from P7 to P14, mirroring the growth of dendrites. A progressive lengthening of inter-segments between subsequent axonal stems 


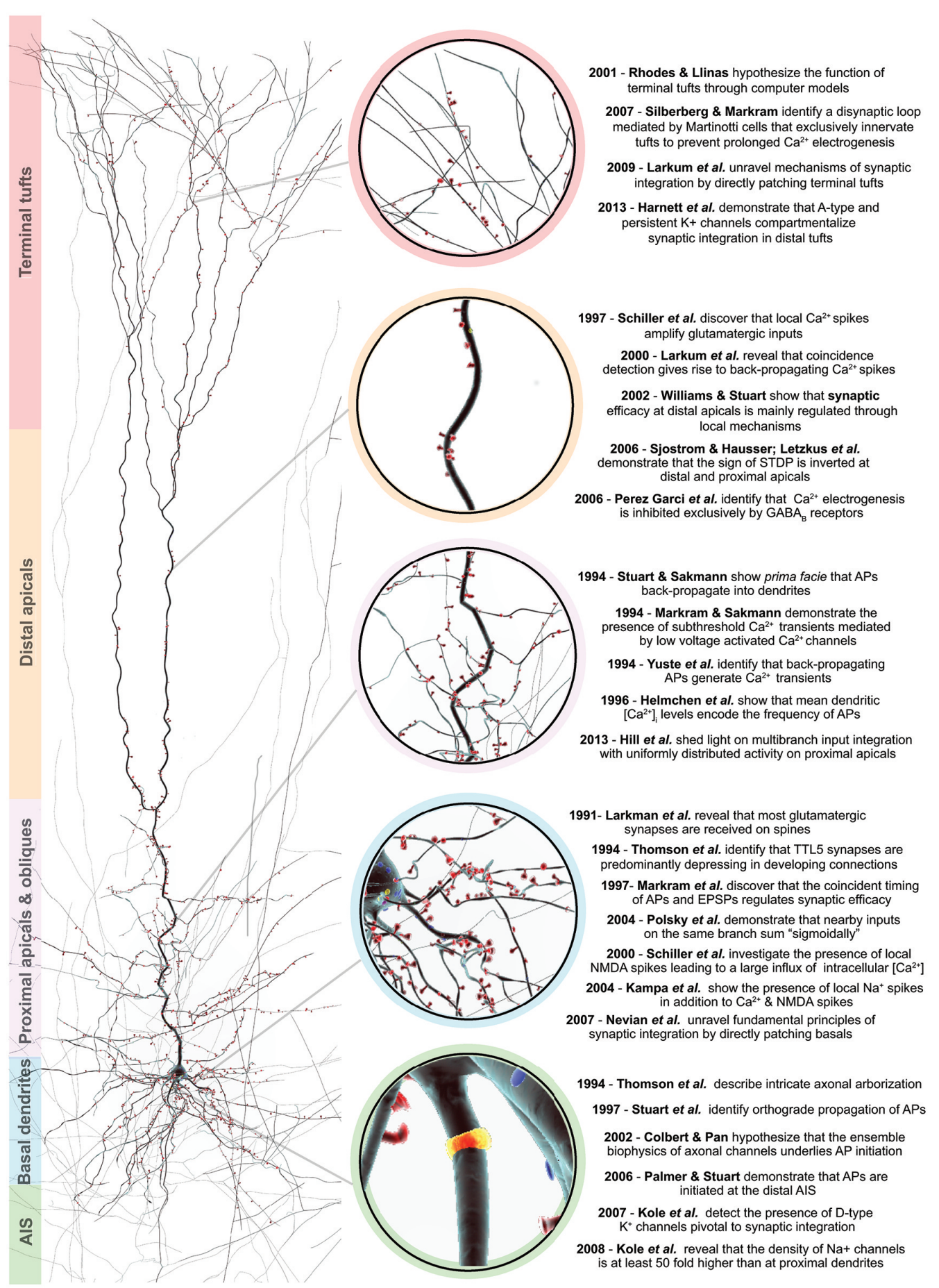

FIGURE 1 | An overview of salient discoveries in TTL5 structure and function. Right, a 3D reconstruction of a biocytin filled thick-tufted layer 5 pyramidal cell. Spines are color-coded in red and depict the afferent excitatory synapses along the dendrites. The color bars to the left indicate the various morphological domains, which are ascribed to specialized functions. Center, the colored circles zoom-in to the morphological domain of interest. Left, a chronological summary of key structural and functional discoveries pertaining to the different morphological domains. is absent at from $\mathrm{P} 7$ to $\mathrm{P} 14$, but becomes prominent during $\mathrm{P} 21$ to P36 and higher ages.

The density of small boutons (diameters between 0.2 and $0.7 \mu \mathrm{m}$ ) increases between P7 and P14 while the density of large boutons (diameters between 1.0 and $1.8 \mu \mathrm{m}$ ) significantly increases between P14 and P21 (Figure 2). Adult levels of bouton density are attained by P21 (DeFelipe and Fariñas, 1992; Romand et al., 2011; Figure 2). As animals grow older, the density of small 


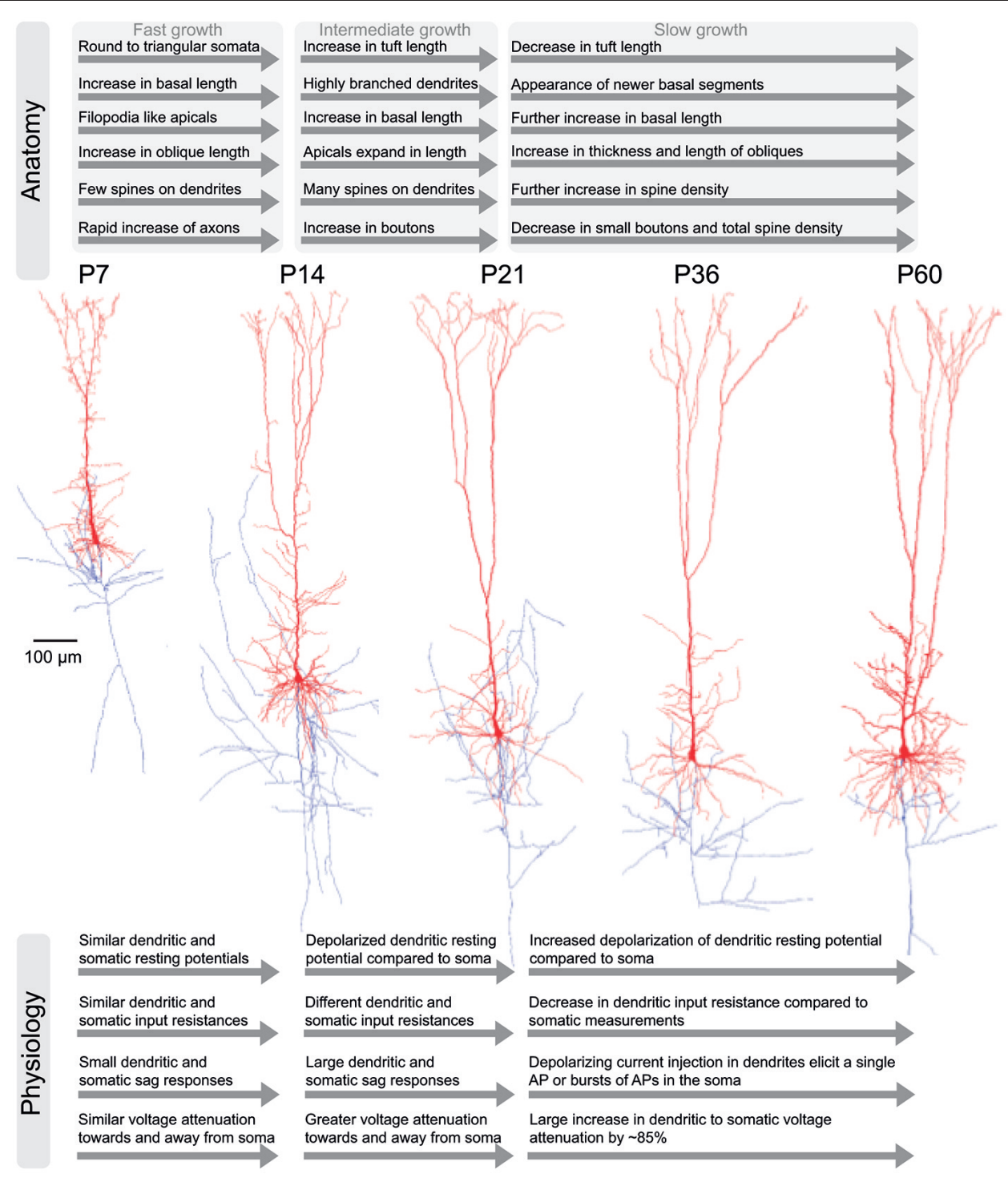

FIGURE 2 | Development of anatomical and physiological properties in TTL5 neurons. An illustration of the salient anatomical (top) and physiological (bottom) properties in TTL5 neurons across different developmental time-scales (postnatal days (P) 7, 14, 21, 36, and 60). In the corresponding morphological reconstructions (middle), axons are shown in blue; soma and dendrites are shown in red. boutons tends to decrease along with the total bouton density (Romand et al., 2011; Figure 2).

\section{Occurrence Across Different Cortical Regions and Species}

Previous studies have examined the occurrence of TTL5 neurons across different cortical regions and species (Jones et al., 1988; Rivara et al., 2003; Sherwood et al., 2003; Elston et al., 2011). These studies indicate that TTL5 neurons in different cortical regions and/or species are not merely scaled versions of a generic phenotype type, but can be structurally different while preserving fundamental stereotypical features (Elston and Jelinek, 2001; Elston, 2001; Jelinek and Elston, 2001).
The morphological complexity of TTL5 neurons progressively increases from primary sensory cortices located in the posterior occipital and temporal lobes, to primary and supplementary sensory-motor cortices situated in the parietal lobe, to the association and medial prefrontal cortices located in the frontal lobe.

In deeper layer 5B of primate visual cortex, Theodor Hermann Meynert first identified large solitary pyramidal neurons, which are distinguished by a single apical dendrite and numerous large basal dendrites. Meynert cells are known to occur in primary visual cortex of rodents, felines, higher order primates and humans (le Gros Clark, 1942; ChanPalay et al., 1974; Peters and Kara, 1985; Akiyama et al., 1990; Anderson et al., 1998; for review see Roth and Dicke, 
2005). The basal dendrites of Meynert cells bear more than $75 \%$ of spines received although they account for a much smaller proportion of the total dendritic length (Chan-Palay et al., 1974). The apical dendrite is progressively diminished of spines as it reaches the superficial layers and terminates without a prominent tuft in layer 1 . Meynert cells in primary visual cortex share a number of morphological features in common with TTL5 neurons. However, Meynert cells differ characteristically in that their basal dendritic fields show elaborate branching and apical dendrites usually do not terminate with a thick tuft (Rockland, 1996; Thomson and Bannister, 2003).

Betz cells were first identified by Vladimir Alekseyevich Betz and are found in primary sensory-motor cortex of rodents, felines, higher order primates and humans (Betz, 1874; Walshe, 1942; Phillips, 1956; Kaiserman-Abramof and Peters, 1972; Rivara et al., 2003). Considered to be one of the largest neuronal types in the mammalian cerebral cortex, Betz cells are located in the medial sensory-motor cortex and account for about $10 \%$ of TTL5 neurons in deeper layer 5B (Rivara et al., 2003). Furthermore, the morphology of Betz cells is known to vary between the rostral and caudal parts of the primary sensorymotor cortex (Rivara et al., 2003). In human sensory-motor cortex, the total neuronal arbor volume of Betz cells is on average about 20 times higher than that of TTL5 neurons in motor cortex (Rivara et al., 2003; Sherwood et al., 2003). In comparison against TTL5 neurons, Betz cells contain several more proximal basal, apical and oblique dendritic segments, which profusely branch out from the soma (Braak and Braak, 1976).

In primate anterior cingulate and medial prefrontal cortices, the total expanse of the basal dendritic arbor of TTL5 neurons exceeds that of those in primary visual cortex by about five times (Zhang, 2004; Elston et al., 2005). This suggests that the morphological structure of pyramidal neurons is remarkably different between sensory and association cortices. In mature rodent medial prefrontal cortex, there are at least two distinct types of TTL5 neurons; simple pyramidal neurons, similar to pyramidal neurons found elsewhere in the neocortex typified by a single apical dendrite that terminates with a tuft in the superficial layers, and complex pyramidal neurons distinguished by early bifurcating dual apical dendrites and elaborately branching basal dendrites (Wang et al., 2006). Complex pyramidal neurons have almost twice the total apical dendritic length and significantly more extensive and frequently branching basal dendrites than the simple pyramidal neurons (Wang et al., 2006; van Aerde and Feldmeyer, 2015). In layer 5 of medial prefrontal cortex, the complex pyramidal neuron is the most commonly occurring form of pyramidal neuron, whereas the simple pyramidal neuron is more commonly found in other primary sensory cortices (Wang et al., 2006; van Aerde and Feldmeyer, 2015).

TTL5 neurons also display a remarkable morphological variability within different regions of the prefrontal cortex of higher order primates. A recent study has demonstrated that the total area of the basal dendritic arbor and spine density and can vary by more than $50 \%$ in the "average" pyramidal neuron across dorsolateral, medial and orbital prefrontal cortices (Elston et al., 2005).

\section{Projections to Cortical and Subcortical Targets}

Long-range TTL5 axons target cortical and subcortical brain regions (Wang and McCormick, 1993; Kasper et al., 1994a; Brown and Hestrin, 2009). The elaborately branching TTL5 axon collaterals project across several neighboring neocortical microcircuits (Brown and Hestrin, 2009).

The TTL5 axon ramifies extensively in layer 5 with ascending collaterals projecting to the supragranular layers and descending collaterals projecting to infragranular layer 6 (Burkhalter, 1989; Keller, 1993; Thomson and Deuchars, 1994; Thomson and Bannister, 2003; Lübke and Feldmeyer, 2010). The supragranular layers receive targeted projections from a small number of TTL5 axon collaterals consisting of a small number of boutons (Thomson and Bannister, 2003). The innervation of pyramidal cells (PCs) in supragranular layers by ascending TTL5 axon collaterals is rather sparse, however, it is partially known that certain classes of GABAergic interneurons are targeted (Thomson and Morris, 2002).

Silver impregnation and retrograde labeling studies have indicated that the TTL5 axon projects to the superior colliculus via the cerebral peduncle, the pontine nuclei, tectal regions, the thalamic matrix, and to the striatum (Wise and Jones, 1976; Wang and McCormick, 1993; Kasper et al., 1994a; Morishima and Kawaguchi, 2006; for review see Thomson and Lamy, 2007). TTL5 axons exhibit a remarkable exactness in their projection pattern regardless of their origin from occipital, parietal or frontal regions.

TTL5 projections to different target areas are not only distinct in their anatomy but also in their physiology. A study combining neuroanatomical tract tracing with whole-cell recordings in coronal slices of adult rodent somatosensory cortex identified that TTL5 neurons projecting to thalamic and trigeminal nuclei were characterized with thick-tufts whose apical dendrites bifurcated with a wide branching pattern (Hattox and Nelson, 2007). The study by Hattox and Nelson unraveled a similarity in the physiological properties of TTL5 neurons depending on the projection area. Corticothalamic and corticotrigeminal TTL5 neurons shared similar intrinsic physiological properties, where a train of APs in response to depolarizing current injections exhibited an initial doublet, followed by insignificant or nonexistent spike frequency accommodation (Hattox and Nelson, 2007). On the other hand, most TTL5 neurons projecting to the striatum were anatomically characterized by a narrow dendritic tuft, and displayed an initial AP singlet followed by pronounced spike frenquency adaptation of a train of APs (Hattox and Nelson, 2007).

\section{Dendritic Physiology}

TTL5 neurons receive a bulk of glutamatergic synaptic inputs directly on basal, proximal apical and oblique dendrites (Thomson et al., 1993; Markram et al., 1997a) while GABAergic 
inputs are primarily received by the soma, proximal dendrites, the axon initial segment (AIS), and terminal tufts (for review see Somogyi et al., 1998). The physiological properties of TTL5 dendrites exert a profound influence in patterning synaptic input into action potential (AP) output through a highly complex transformation processes involving voltage gated ion channels, regenerative properties and integration gradients in single compartments (for reviews, see Johnston et al., 1996; Spruston, 2008; Branco and Häusser, 2010; Major et al., 2013). The physiology of TTL5 dendrites develops concurrently with anatomy.

\section{Development of Dendritic Physiology}

The physiological properties of TTL5 dendrites mature in the first six postnatal weeks (Mason and Larkman, 1990; Kasper et al., 1994b; Zhu, 2000; Zhang, 2004). Between postnatal P2 to $\mathrm{P} 14$, the resting membrane potential and input resistance measured at the soma and dendritic tufts are very similar (Zhu, 2000; see Figure 2 for a Gantt-chart like illustration of salient features of physiological development). Depolarizing step current injections in both the soma and dendrite evoke brief all or none APs of comparable amplitudes at both locations, indicating the presence of a main regenerative $\mathrm{Na}^{+}$conductance (Zhu, 2000). Hyperpolarizing step current injections elicit small sag responses at the dendrites and soma, indicating that dendrites already possess voltage gated hyperpolarization activated cation $\left(\mathrm{I}_{\mathrm{h}}\right)$ and muscarinic activated potassium $\left(\mathrm{I}_{\mathrm{M}}\right)$ conductances. The attenuation of dendritic responses measured at the soma (somatopetal) and somatic responses measured at dendrites (somatofugal) are similar, indicating that dendrites are electrotonically compact during this period (Zhu, 2000; Figure 2).

From P14 onwards to P28, the resting membrane potential and input resistance measured at dendritic tufts is significantly different from that at the soma. Suprathreshold depolarizing step current injections elicit APs at the soma. At P14, the duration of the dendritic regenerative potential outlasts the evoked somatic AP (Zhu, 2000; Figure 2). In response to hyperpolarizing current injections, the tuft and soma at P14 display pronounced sag responses (Zhu, 2000; Figure 2). Inward rectification, as shown by steady-state $I-V$ relationships in the tuft indicates a selective increase in the dendritic $\mathrm{I}_{\mathrm{h}}$ conductance (Zhu, 2000). Somatopetal and somatofugal voltage attenuation are almost $50 \%$ greater compared against the P2 period, showing that dendritic tufts increase in electrotonic distance from the soma.

In the next period between P28 to postnatal day 42 (P42), the resting potential at dendritic tufts is more depolarized than the soma. The dendritic input resistance is only slightly lower than at the soma. At P28, depolarizing step current injections at dendritic tufts are capable of eliciting either single APs or a burst of 2-3 APs at the soma (Zhu, 2000; Figure 2). The sag response to dendritic hyperpolarizing current injections appears to be more prominent at P28 as against P14 (Zhu, 2000; Figure 2). While depolarizing subthreshold dendritic current injections induce subthreshold reponses at the soma, prolonged depolarizing suprathreshold current injection results in a sustained depolarization plateau at dendritic tufts and causes bursts of APs at the soma ( $\mathrm{Zhu}, 2000)$. The increased duration of dendritic regenerative potentials at P28 indicates an increased contribution of $\mathrm{Ca}^{2+}$ conductances, showing that during this period the ionic dependence of regenerative potentials switches from predominantly $\mathrm{Na}^{+}$to $\mathrm{Ca}^{2+}$ (Zhu, 2000). Also, during this period, the dendritic tufts are remarkably isolated from the soma, causing a huge attenuation of dendritic voltage responses measured at the soma by a factor of almost $85 \%$ (Zhu, 2000; Figure 2).

Finally, between P42 and postnatal day 56 (P56), the dendritic and somatic membrane properties are similar to those measured in the previous period. The depolarizing sag response to hyperpolarizing dendritic current injection is very conspicuous and indicates further increased levels in the dendritic $\mathrm{I}_{\mathrm{h}}$ conductance. Dendritic regenerative potentials evoked by depolarizing current injections give rise to bursts with 2-4 APs at the soma. During this period, the regenerative potentials at dendritic tufts attain their final kinetics, implying that $\mathrm{Ca}^{2+}$ conductances could have reached their peak densities (Zhu, 2000). The attenuation of dendritic voltage responses measured at the soma is comparable to the previous period of P28 to P42 (Zhu, 2000).

In summary, developing TTL5 neurons share many common properties with those of mature neurons after the second postnatal week (around P14). The apical dendrites are not fully mature until P42. The dendritic tufts switch from being electrotonically close to the soma at P2 to electrotonically distant at P14 (Figure 2). The ionic dependence of regenerative potentials in the dendritic tuft is changed from being $\mathrm{Na}^{+}$ dependent to $\mathrm{Ca}^{2+}$ dependent (Zhu, 2000). At P28, the regenerative dendritic potentials are still relatively small in amplitude and duration and often fail to elicit somatic APs (Zhu, 2000). In contrast, at $\mathrm{P} 42$ the dendritic regenerative potentials are often successful in evoking one or more somatic APs (Zhu, 2000).

\section{Voltage-Gated ion Channels in Dendrites}

TTL5 dendrites express A-type and persistent $\mathrm{K}^{+}$channels, transient and persistent $\mathrm{Na}^{+}$channels, hyperpolarizationactivated cation $(\mathrm{HCN})$ channels, a plethora of $\mathrm{Ca}^{2+}$ channels, and small and large conductance (SK and BK, respectively) $\mathrm{Ca}^{2+}$ dependent $\mathrm{K}^{+}$channels, all of which influence the integration of synaptic input (Stafstrom et al., 1985; Huguenard et al., 1989; Reuveni et al., 1993; Markram and Sakmann, 1994; Stuart and Sakmann, 1994; Crill, 1996; Kang et al., 1996a; Bekkers, 2000a,b; Korngreen and Sakmann, 2000; Reyes, 2001; Benhassine and Berger, 2005, 2009; Kole et al., 2006; Schaefer et al., 2007; Almog and Korngreen, 2009; Książek et al., 2013; Harnett et al., 2015; see Figure 3 for a schematic of the diversity and distribution profiles of voltage-gated ion channels in dendrites of TTL5 neurons).

A-type $\mathrm{K}^{+}$channels decrease in density along the somatodendritic axis and thus serve in defining a distal, low threshold region for the initiation of dendritic regenerative potentials (Bekkers, 2000a; Kang et al., 2000; Korngreen and Sakmann, 2000; Schaefer et al., 2007; Figure 3). A recent study has discovered that A-type and persistent $\mathrm{K}^{+}$channels compartmentalize integration of input throughout the dendritic tuft (Harnett et al., 2013). In identifying new roles role for 


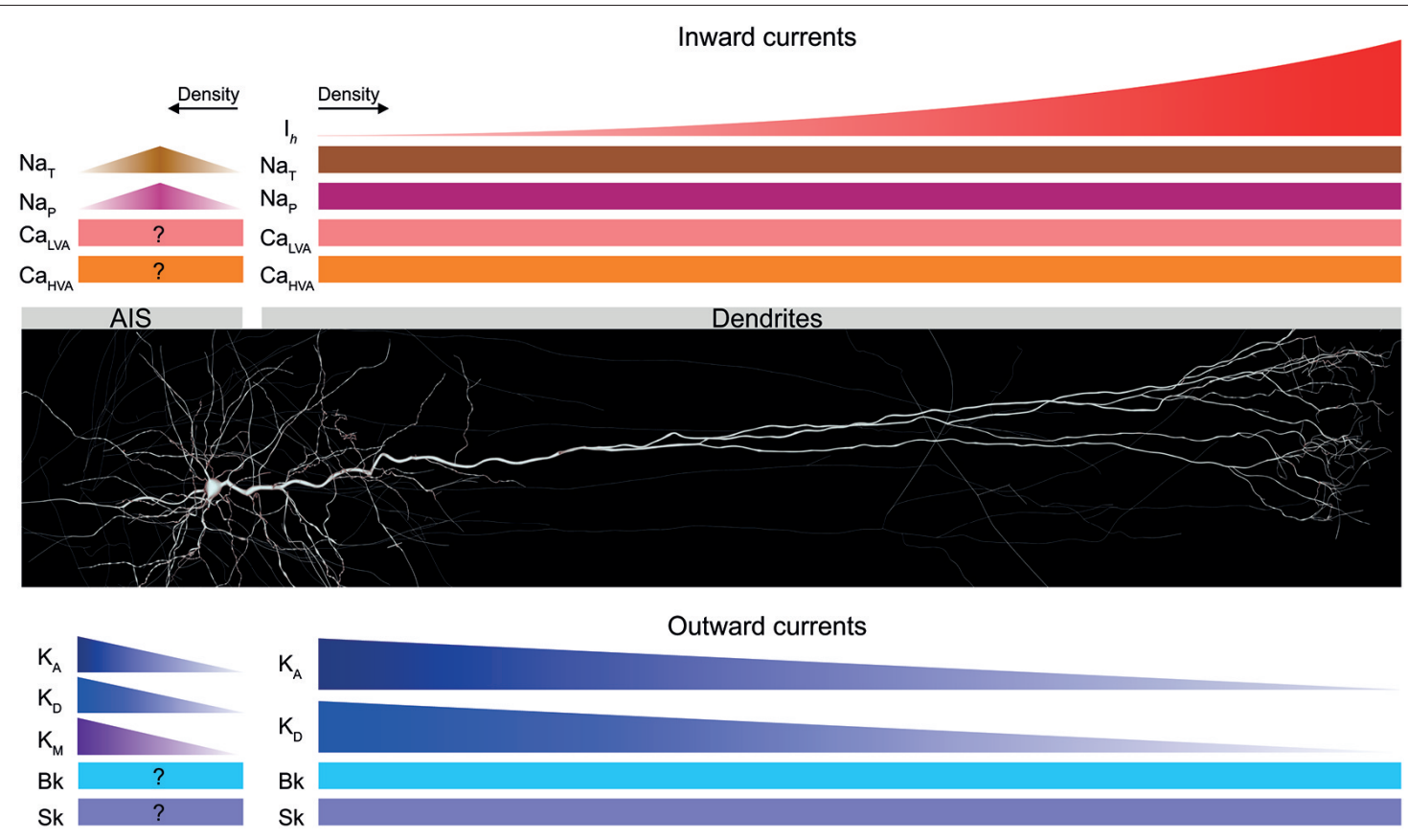

FIGURE 3 | Voltage-gated ion channels expressed in TTL5 dendrites and the axon initial segment (AIS). A schematic of the distribution profiles of different inward and outward currents expressed in the dendrites and AIS of TTL5 neurons. Inward currents are shown in shades of red; outward currents are shown in shades of blue.

$\mathrm{I}_{\mathrm{h}}$-hyperpolarization activated cation current; $\mathrm{Na}_{\mathrm{T}}$-transient sodium current; Nap - persistent sodium current; CaLvA - low voltage-activated calcium current; $\mathrm{CaHVA}_{\text {H }}$-high voltage- activated calcium current; $\mathrm{K}_{\mathrm{A}}$-transient A-type potassium current; $\mathrm{K}_{\mathrm{D}}$-delayed rectifier potassium current; $\mathrm{K}_{\mathrm{M}}$-muscarinic-activated potassium current; $\mathrm{Bk}$-big conductance calcium-activated potassium current; Sk-small conductance calcium-activated potassium current. voltage-gated $\mathrm{K}+$ channels in TTL5 dendritic tufts, the study by Harnett et al. (2013) proposes two important functional modes for $\mathrm{K}^{+}$channels. In vitro, voltage-gated $\mathrm{K}^{+}$channels act to regulate the interaction between the dendritic tuft, apical trunk, and axosomatic zones of information integration to exert influence on neuronal output. During sensory-motor behavioral tasks like active whisking, the high density of voltage-gated $\mathrm{K}^{+}$ channels in the apical dendritic arbor controls the threshold and time scale of regenerative plateau potentials. In addition, these intriguing findings also suggest that the high density of these channels perpetuate local plateau potentials in TTL5 distal dendritic compartments that are modulated by top-down excitatory inputs arriving at apical tufts (Harnett et al., 2013).

Transient $\mathrm{Na}^{+}$channels occur with a uniform density along the somato-dendritic axis and are crucial in sustaining backpropagating action potentials (bAPs) and local dendritic spikes (Huguenard et al., 1989; Stuart and Sakmann, 1994; Figure 3). Persistent $\mathrm{Na}^{+}$channels are also uniformly distributed along the somato-dendritic axis, and amplify the synaptic current in apical dendrites (Schwindt and Crill, 1995; Fleidervish and Gutnick, 1996; Mittmann et al., 1997; Astman et al., 2006; Figure 3).

HCN channels carry the depolarizing $I_{h}$ current activated by hyperpolarization and are important for dendritic excitability. HCN channels increase in density by more than 50 -fold from the soma to distal apical dendrites and shape the time course of synaptic input through spatially independent integration at apical and basal dendrites (Williams and Stuart, 2000; Berger et al., 2001, 2003; Lörincz et al., 2002; Kole et al., 2006; Harnett et al., 2015; Figure 3). Interplay between the $I_{h}$ current and the membrane capacitance endows band-pass filtering abilities to TTL5 neurons, thus favoring dendritic resonance and frequency tuning (Ulrich, 2002). Recent evidence indicates that an agedependent increase in dendritic HCN channel density ensures the development of TTL5 neurons from compact temporal integrators to compartmentalized integrators of basal and apical dendritic synaptic input (Atkinson and Williams, 2009).

A myriad of low (T-type) and high (L, N, P/Q and R types) voltage-gated $\mathrm{Ca}^{2+}$ channels also exist in TTL5 neurons (Reuveni et al., 1993; Markram and Sakmann, 1994; Almog and Korngreen, 2009). $\mathrm{Ca}^{2+}$ channels are critical in regulating neurotransmitter release, generating and sustaining regenerative dendritic events, and burst firing of APs (Schiller et al., 1997; Stuart et al., 1997a; Koester and Sakmann, 1998; Ohana and Sakmann, 1998; Williams and Stuart, 1999; Larkum et al., 2001; Figure 3).

Small and large conductance $\mathrm{Ca}^{2+}$ activated $\mathrm{K}^{+}$channels (SK and BK, respectively) channels occur with a homogeneous density along the somato-dendritic axis of TTL5 neurons, and their activation reduces the occurrence of local dendritic $\mathrm{Ca}^{2+}$ spikes thus rendering dendrites less excitable. BK channels do not influence the temporal window to initiate back-propagating $\mathrm{Ca}^{2+}$ spikes, thus actively decoupling the axo-somatic and the 
dendritic AP initiation zones during high-frequency inputs (Kang et al., 1996a,b; Benhassine and Berger, 2005, 2009; Książek et al., 2013; Figure 3).

The cell-attached patch-clamp technique has long served as the method of choice to investigate the physiology of voltage-gated ion channels with the advantage of leaving the intracellular medium unperturbed. While this modus operandi has revolutionized our understanding of the properties of voltage-gated ion channels in central neurons, it is also prone to errors. A recent study by Williams and Wozny identified errors in the measurement of the density and kinetics of several voltage-gated ion channel types through cell-attached recordings from the soma and dendrites of central neurons in rodent brain slices (Williams and Wozny, 2011). Williams and Wozny demonstrated that such errors could be directly attributed to transmembrane voltages produced by the activation of voltagegated channels attached to the tip of the recording pipette, and proposed remedial procedures to correct for associated errors (Williams and Wozny, 2011).

For further exhaustive information on the physiology of dendritic voltage gated ion channels in central neurons we guide the reader to three notable reviews (see Migliore and Shepherd, 2002; Trimmer and Rhodes, 2004; Lai and Jan, 2006).

\section{Dendritic Excitability and Local Regenerative Potentials}

A culminating point in TTL5 dendritic function came about when Greg Stuart in Bert Sakmann's laboratory performed direct patch-clamp recordings apical dendrites in vitro and demonstrated prima facie that single axo-somatic AP backpropagate into the dendritic arbor (Stuart and Sakmann, 1994). A bAP serves as a retrograde signal, conveying the level of neuronal output activity to the dendrites. Indeed, bAPs attenuate in amplitude along the somato-dendritic axis as they propagate from proximal to distal locations (Stuart and Sakmann, 1994; for reviews see Stuart et al., 1997b; Waters et al., 2005). Preliminary computational modeling studies have indicated that the morphology of the TTL5 dendritic arbor influences the backpropagation of APs (Vetter et al., 2001).

Another discovery, also in Bert Sakmann's laboratory, provided the first evidence that EPSPs caused a transient increase in $\left[\mathrm{Ca}^{2+}\right]_{\mathrm{i}}$ mediated by the opening of low voltage activated $\mathrm{Ca}^{2+}$ channels (Markram and Sakmann, 1994). This study imparted additional insights that dendrites serve to function more than mere "passive cables" during low frequency synaptic activity. Furthermore, bAPs in proximal apical dendrites were also found to evoke transient $\left[\mathrm{Ca}^{2+}\right]_{i}$ (Yuste et al., 1994; Markram et al., 1995; Schiller et al., 1995; Helmchen et al., 1996). TTL5 distal apical dendrites amplify glutamatergic inputs through local $\mathrm{Ca}^{2+}$ spikes, thus controlling the synaptic efficacy of cortico-cortical inputs (Schiller et al., 1997).

TTL5 dendrites operate as coincidence detectors by summing local spikes from individual branches with other inputs to evoke AP firing. Conventionally, this implies the coincident activation of a sufficient number of inputs to reach AP firing threshold (for reviews see Segev and London, 2000; Yuste et al., 2000; London and Häusser, 2005). A "critical frequency" of AP firing $(\sim 100 \mathrm{~Hz})$ can elicit single regenerative $\mathrm{Ca}^{2+}$ spikes in apical and basal dendrites (Larkum et al., 1999a; Kampa and Stuart, 2006). While local $\mathrm{Ca}^{2+}$ spikes are generated upon dendritic synaptic input coincident with bAPs, their initiation can be restrained by dendritic GABAB receptor mediated inhibition (Pérez-Garci et al., 2006). A hallmark discovery by Matthew Larkum showed that the coincident summation of distal synaptic input with a bAP led to a so-called back-propagation activated $\mathrm{Ca}^{2+}$ spike (BAC) causing a burst of APs at the soma as a direct consequence (Larkum et al., 1999b).

Previous studies inferring the integrative properties of thin TTL5 dendrites have either employed computational modeling or optical imaging techniques (Schiller et al., 2000; Antic, 2003; Milojkovic et al., 2004, 2005; Kampa and Stuart, 2006). Although informative, a drawback of optical imaging as an experimental technique is that it is largely qualitative and prone to ambiguity in interpreting results as opposed to quantitative characterization. In a set of ground-breaking experiments, Thomas Nevian, Matthew Larkum and Jackie Schiller pioneered direct dendritic patch-clamp recordings to reveal the elementary principles of synaptic integration in TTL5 basal dendrites (Nevian et al., 2007). Simultaneous dendritic and somatic recordings of spontaneous events in TTL5 basal dendrites revealed a dendrite to soma EPSP attenuation of up to 40 fold at locations as far as $140 \mu \mathrm{m}$ away from the soma. Contrastingly, the backward spread of EPSPs from the soma to basal dendrites experienced very little attenuation. Björn Kampa and Greg Stuart demonstrated that bAPs invading the TTL5 basal dendritic arbor depolarized the distal basal dendrites during high-frequency burst firing following the generation of local dendritic $\mathrm{Ca}^{2+}$ spikes (Kampa and Stuart, 2006). Nevian et al. (2007) further provided critical insights on the attenuation of bAPs in TTL5 basal dendrites and reported that when scaled to the relative size of apical and basal dendrites the attenuation of bAPs in both arbors were almost identical.

In addition to local $\mathrm{Ca}^{2+}$ spikes, $\mathrm{Na}^{+}$and NMDA spikes can also be initiated in the TTL5 dendritic arbor (Schiller et al., 2000; Kampa and Stuart, 2006; Rhodes, 2006; Nevian et al., 2007; Major et al., 2008; Larkum et al., 2009; Polsky et al., 2009). By means of glutamate uncaging, Jackie Schiller was the first to demonstrate that synaptically evoked potentials in basal dendrites were in fact NMDA spikes, usually followed by a large local $\mathrm{Ca}^{2+}$ influx (Schiller et al., 2000). This study also identified that localized NMDA spikes potentially confer a degree of parallel processing and independent decisionmaking in TTL5 basal dendritic branches.

\section{Dendritic Integration of Synaptic Input}

A long-standing view has held that TTL5 dendrites integrate synaptic input either linearly or supra-linearly (Cash and Yuste, 1998; Nettleton and Spain, 2000; for review see Gulledge et al., 2005). Biophysical modeling approaches have suggested that the "arithmetic" of local input summation in thin dendrites endows them with an ability to serve as independent computational subunits, which sigmoidally modulate their inputs prior to global summation (for review see Silver, 2010). An elegant study by 
Alon Polsky and Jackie Schiller combined confocal imaging and dual-site focal synaptic stimulation of TTL5 basal dendrites to reveal that nearby inputs on the same dendritic branch summed sigmoidally, whereas widely separated inputs or inputs to different branches summed linearly (Polsky et al., 2004). These findings by Polsky et al. (2004) provided experimental support for previous theoretical postulates of a two-layer neural network model of thin-branch dendritic integration in pyramidal neurons (Poirazi et al., 2003; see also Häusser and Mel, 2003).

In an extension to the above findings, Hysell Oveido and Alex Reyes further discovered that when barrages of input were injected into TTL5 apical dendrites in vitro to simulate synaptic activity, summation of inputs at proximal dendritic locations and the soma were sublinearly proportional to the intensity of synaptic barrages (Oviedo and Reyes, 2012). On the other hand, the contrary was observed at more distal dendritic locations where inputs added supralinearly to begin with and transformed to a sublinear summation regime with higher input activity (Oviedo and Reyes, 2012). More recently, experimental advances have demonstrated the integration of synaptic input in single dendritic branchlets by selectively stimulating single spines (see Branco and Häusser, 2010). Landmark experiments by Tiago Branco at Michael Häusser's laboratory brought to light the remarkable fact that single dendritic compartments are not only sensitive to the direction but also the velocity of incoming synaptic input (Branco et al., 2010). Unitary spines were progressively activated through controlled uncaging of glutamate centripetally from a single dendritic branchlet towards the soma and centrifugally away from the soma towards a selected dendritic compartment. The centripetal activation always gave rise to somatic EPSPs of larger amplitude as opposed to the centrifugal activation (Branco et al., 2010). The EPSP amplitude and AP output were unfailingly sensitive to the direction of activation and activation of NMDA receptors (Branco et al., 2010). The succession of experiments identifying modes of synaptic convergence have undoubtedly reinforced the fact that the different TTL5 dendritic domains are specially equipped to discriminate against the spatiotemporal sequence of afferent synaptic input. To facilitate synaptic integration, it appears that the multitude of active mechanisms in TTL5 dendrites have devised ingenious schemes of interplay that are highly dependent on the localization, strength, sequence, and distribution profiles of inputs.

Previous computational modeling studies have hypothesized plausible explanations for synaptic integration in terminal apical tufts (Rhodes and Llinás, 2001) yet these fine structures have proven rather evasive for direct experimental access. In another milestone for dendritic research, Matthew Larkum et al. went on to patch terminal tufts, revealing that NMDA spikes provide the basis for how distal synaptic inputs influence TTL5 neurons to reach AP firing threshold (Larkum et al., 2009). This paradigm shift not only provided the basis for parallel processing of topdown input received by terminal tufts but also led to a whole new unifying principle of TTL5 synaptic integration, where basal dendrites and terminal tufts integrate inputs through the recruitment of local NMDA spikes in AP initiation relative to the fixed apical $\mathrm{Ca}^{2+}$ and axo-somatic $\mathrm{Na}^{+}$zones of integration.
How influential are TTL5 distal synaptic inputs in AP initiation against their proximal counterparts? Distal synapses are expected to exert a lesser degree of influence on axosomatic AP initiation, mainly due to loss of charge following the flow of current from the dendrites to the soma and the axon (for review see Magee, 2000; Stuart and Spruston, 1998). This poses the following question: do distal synapses spatially scale their peak conductance to render themselves eligible to "veto" AP initiation (Häusser, 2001; Rumsey and Abbott, 2006; for reviews see Magee, 2000; Segev and London, 2000; Williams and Stuart, 2003a)? Contrary to a progressive somato-dendritic increase in synaptic conductance observed in hippocampal CA1 pyramidal neuron dendrites (Magee and Cook, 2000), Stephen Williams in Greg Stuart's laboratory provided the foremost evidence that the amplitude and time course of both excitatory and inhibitory dendritic synaptic input in TTL5 neurons are influenced by voltage-gated conductances (Williams and Stuart, 2002, 2003b). As a counteracting design strategy, distal TTL5 dendrites exhibit site dependent mechanisms to regulate synaptic efficacy. Although distal TTL5 dendrites are ineffective sources of background somatic excitation, they play a powerful transient signaling role through coincidence detection (Williams and Stuart, 2002).

Thin distal dendrites give rise to large local synaptic responses reducing the driving force for synaptic current owing to their small diameters and high input impedance. Therefore, distal dendrites can considerably influence AP initiation by activating voltage-gated conductances, which increase charge entry and consequently initiate local dendritic spikes (for reviews see Magee, 2000; Spruston, 2008).

TTL5 dendrites are bombarded with synaptic input during active network states in vivo (Borg-Graham et al., 1998; Paré et al., 1998; Destexhe et al., 2001; for review see Destexhe et al., 2003). Computational modeling has predicted that such ongoing activity attenuates synaptic potentials as they propagate across the dendritic arbor (Bernander et al., 1991; Hô and Destexhe, 2000; for review see London and Segev, 2001; Chance et al., 2002; Rudolph and Destexhe, 2003). Ensuing synaptic activity therefore dictates the efficacy of input that activates dendritic spikes through local synaptic integration to forward-propagate to the axonal AP initiation site. This regime of distributed processing is believed to have implications on the computational power of cortical pyramidal neurons (Mel, 1993; Häusser and Mel, 2003; Williams and Stuart, 2003b). The subsequent question that arises is about the prevailing state of knowledge about information processing regimes under high-conductance states during active network states in vivo. The first experiments to test the existence of such a regime by mimicking in vivo like synaptic conductance levels in vitro were performed by Stephen Williams demonstrating that synaptic conductances are highly compartmentalized in TTL5 neurons, and that the dendritic arbor is optimized to independently carry out axo-somatic and apical dendritic integration under high conductance states (Williams, 2004). Additional evidence also suggests that distal excitatory synaptic inputs decisively control the synaptic output of TTL5 neurons, powerfully influencing neocortical network activity (Williams, 2005). 
In summary, the goal of developing a model that unifies the input-output properties of TTL5 neurons appears to be within sight. In a recent review, Guy Major, Matthew Larkum and Jackie Schiller have proposed a road map towards a conceptual framework to identify fundamental abstractions marrying the principal input-output properties of TTL5 neurons (Major et al., 2013; see also Branco and Häusser, 2010). Furthermore, milestone in vivo experiments such as those by Daniel Hill et al. in Arthur Konnerth's group are beginning to shed light on a plausible model of prevalent multi-branch input integration in TTL5 dendrites where synaptic input and dendritic activity are homogeneously spread throughout the basal and apical arbors (Hill et al., 2013).

\section{Function of Dendritic Spines}

TTL5 dendrites are richly decorated with spines, which directly receive most of the excitatory synaptic input (Peters and Kaiserman-Abramof, 1970; Peters, 1987; Larkman, 1991b). Although the functional relevance of spines is not fully understood yet, computational modeling and in vitro slice experiments strongly support the notion that: (a) spines might serve to optimize the filling of a large number of afferent synapses onto a dendritic segment by increasing the available surface area (Stepanyants et al., 2002); (b) spines could check the diffusion of critical molecules away from the synaptic locus, serving as individual biochemical compartments (Koch and Zador, 1993; for review see Nimchinsky et al., 2002); (c) spines could play a regulatory role on the electrical properties of neurons (Koch and Zador, 1993; Yuste and Denk, 1995; Yuste et al., 2000; Tsay and Yuste, 2002; Araya et al., 2006, 2007, 2014; Palmer and Stuart, 2009; for review see Sala and Segal, 2014). The spine head is the site of a tiny, amorphous structure called the postsynaptic density (PSD). Prominent in excitatory synapses, the PSD houses AMPA and NMDA receptors (AMPAR and NMDAR, respectively) attached to large protein "signaling machines" that regulate the strength of synaptic transmission (Kennedy, 1997, 2000). In vivo imaging approaches have revealed the existence of spines with varying sizes in neocortical PCs, thin transient and thick persistent spines, suggesting functional roles in regulating timescales for synaptic plasticity (Trachtenberg et al., 2002; Holtmaat et al., 2005, 2006).

\section{Axonal Physiology}

The TTL5 AIS marks the origin of the axonal arbor and is exclusively innervated by GABAergic axo-axonic synapses established by Chandelier cells (Somogyi, 1977; Szabadics et al., 2006; for review see Somogyi et al., 1998). The primary collaterals of the TTL5 axon are unmyelinated and myelination progressively sets in at higher order axon branches (Palmer and Stuart, 2006; Shu et al., 2007). The principal functions of TTL5 axons involve the initiation and propagation of APs, excitationrelease coupling, and integration.

Here, we summarize the physiology of the TTL5 axon and further direct the reader to comprehensive reviews on axon physiology in central neurons (see Debanne, 2004; Rasband, 2010; Debanne et al., 2011; Kole and Stuart, 2012).

\section{Initiation and Propagation of APs}

Preliminary insights on AP initiation in the unmyelinated AIS were gained almost half a century ago (Coombs et al., 1957; Fatt, 1957; Fuortes et al., 1957; Eccles, 1964; Palay et al., 1968; Peters et al., 1968). Through the years, numerous studies have also suggested the initiation of local regenerative potentials within dendrites of neocortical pyramidal neurons (Amitai et al., 1993; Markram and Sakmann, 1994; Yuste et al., 1994; Schwindt and Crill, 1995; Schiller et al., 1997, 2000; Stuart et al., 1997b; Larkum et al., 1999b, 2001, 2009; Zhu, 2000; Polsky et al., 2004; Gordon et al., 2006; Kampa and Stuart, 2006; Nevian et al., 2007; Major et al., 2008). However, a growing body of evidence conclusively indicates that TTL5 APs are often initiated in the low threshold axon rather than at the site of dendritic synaptic input (Stuart et al., 1997a; Colbert and Pan, 2002; Palmer and Stuart, 2006; Kole et al., 2007b; Shu et al., 2007; Fleidervish et al., 2010). Lucy Palmer and Greg Stuart were foremost to demonstrate that AP initiation in TTL5 neurons occurs at the distal site of the AIS, about $35 \mu \mathrm{m}$ away from the axon hillock (Palmer and Stuart, 2006).

How do APs propagate in TTL5 neurons following their initiation? APs in TTL5 neurons orthogradely propagate into the axonal arbor, and retrogradely propagate to invade the dendritic arbor (Stuart et al., 1997a). The retrograde propagation of APs signals the level of neuronal output to the dendritic tree (see Dendritic excitability and local regenerative potentials; (Amitai et al., 1993; Markram et al., 1995; Schiller et al., 1995; Stuart et al., 1997b; Larkum et al., 1999a,b, 2009; Kampa and Stuart, 2006; Nevian et al., 2007).

The occurrence of axonal APs have also been reported to precede somatic APs, with the latency difference between the onset of axonal and somatic APs increasing at distal axonal locations (Stuart et al., 1997a). The latency difference between the peak of somatic and axonal APs increase with axonal recordings more distal from the soma, leading to an AP conduction velocity estimate of about $300 \mu \mathrm{m} / \mathrm{ms}$ (Stuart et al., 1997a). Axonal APs back-propagating into the TTL5 dendritic tree undergo distance and frequency dependent attenuation (Stuart and Sakmann, 1994; Stuart et al., 1997a). The latency difference between the onset and peak of somatic and dendritic bAPs have also been found to increase as a function of distance from the soma (Stuart et al., 1997a).

Several unique features distinguish AP initiation in TTL5 neurons. One such prominent feature is the characteristic rapid rise at the foot of the somatic AP, which manifests as a "kink" (Naundorf et al., 2006; McCormick et al., 2007). Detailed axonal recordings and computational modeling have revealed that this kink in the AP is exclusive to TTL5 neurons (Shu et al., 2007) and could be attributed to axonal AP initiation, owing in part to the high density of $\mathrm{Na}^{+}$channels housed in the AIS (Inda et al., 2006; McCormick et al., 2007). The structural evidence for a high $\mathrm{Na}^{+}$channel density in the AIS of cortical pyramidal neurons is both plentiful and conclusive (Inda et al., 2006; Kole et al., 2008; Lörincz and Nusser, 2010). However, what functional relevance does this high density confer? Although it is tempting to subscribe to the interpretation that a high $\mathrm{Na}^{+}$channel density renders a low threshold in the AIS to facilitate AP initiation, the 
dilemma remains far from resolved. Previous studies by Colbert and Pan suggested that the biophysics of axonal channels and not a high $\mathrm{Na}^{+}$channel density underlies AP initiation in TTL5 neurons, whereas several recent studies have tried to affirm that AP initiation is aided by a high $\mathrm{Na}^{+}$channel density in the AIS of TTL5 neurons (Colbert and Pan, 2002; Kole et al., 2008; Dulla and Huguenard, 2009; Hu et al., 2009). The density estimation of $\mathrm{Na}^{+}$channels in the AIS has been rigorously pursued for the past several years and consistent interpretations have surfaced only recently. Independent studies by Kole et al. (2008), Hu et al. (2009), and Fleidervish et al. (2010) indicate that the density of $\mathrm{Na}^{+}$channels in the TTL5 AIS is about 30-50 times greater than at the soma.

By combining direct axonal recordings and computational modeling, a recent study by Hallermann and colleagues showed that AP initiation in the AIS is potentially inefficient as it involves high metabolic costs necessary to restore and maintain $\mathrm{Na}^{+}$and $\mathrm{K}^{+}$gradients (Hallermann et al., 2012). In the same study, predictions derived from in silico models indicate that although the AIS and node of Ranvier together showed the highest metabolic cost per unit membrane area, APs backpropagating into the dendrites and forward-propagating into the AIS display the highest energy consumption levels in TTL5 neurons (Hallermann et al., 2012). Greater metabolic costs of AP initiation and propagation down the TTL5 axon are potential trade-off towards minimizing energy and maximizing the reliability and fidelity of high-frequency AP transmission (Hallermann et al., 2012).

\section{Voltage-Gated ion Channels in the TTL5 Axon}

The TTL5 axon expresses an assortment of voltage-gated ion channels, which are essential for AP initiation and propagation, influencing the kinetics of APs, release of neurotransmitters and reliability of synaptic transmission (for review see Debanne et al., 2011). The myriad of $\mathrm{Na}^{+}, \mathrm{Ca}^{2+}$ and $\mathrm{K}^{+}$conductances has been extensively studied in axon collaterals and terminals of central neurons (see Figure 3 for a schematic of the diversity and distribution profiles of voltage-gated ion channels characterized in the AIS of TTL5 neurons).

Voltage-gated $\mathrm{Na}^{+}$channels $\left(\mathrm{Na}_{\mathrm{v}}\right)$ in the AIS of TTL5 neurons encode for the fast-inactivating transient $\left(\mathrm{I}_{\mathrm{NaT}}\right)$ and slow-inactivating persistent $\left(\mathrm{I}_{\mathrm{NaP}}\right)$ currents (Caldwell et al., 2000; Colbert and Pan, 2002; Astman et al., 2006; Hu et al., 2009). Recent evidence has conclusively demonstrated a higher density of functional $\mathrm{Na}^{+}$channels in the AIS of TTL5 neurons as against the soma (Kole et al., 2008; Hu et al., 2009; Fleidervish et al., 2010; Figure 3).

$\mathrm{Ca}_{\mathrm{v}} 2.1$ (P/Q-type) and $\mathrm{Ca}_{\mathrm{v}} 2.2$ (N-type) channels have been recently discovered in the AIS of TTL5 neurons (Yu et al., 2010; Figure 3). These channels determine pyramidal cell excitability through activation of large conductance calcium-activated BK channels (Knaus et al., 1996).

The AIS of TTL5 neurons supports a high density of voltage-gated $\mathrm{D}$-type $\mathrm{K}^{+}$channels, which play a pivotal role in integrating slow sub-threshold input and sculpting the AP waveform and duration (Kole et al., 2007b; Foust et al., 2011; Figure 3). Furthermore, D-type $\mathrm{K}^{+}$channels also regulate neurotransmitter release, critically modulate the efficacy of TTL5 synaptic connections, and determine the onset latency of postsynaptic responses at individual synaptic contacts (Bekkers and Delaney, 2001; Kole et al., 2007b; Boudkkazi et al., 2011; for reviews see Rasband, 2010; Debanne et al., 2011; Kole and Stuart, 2012).

Recent experiments have revealed that non-inactivating voltage-gated $\mathrm{K}^{+}$channels modulated by muscarinic receptors in the AIS of TTL5 neurons play an important role in the initiation and conduction of APs (Battefeld et al., 2014). The muscarinic receptor modulated $\mathrm{K}^{+}$current $\left(\mathrm{I}_{\mathrm{M}}\right)$, first observed in bullfrog sympathetic neurons (Brown and Adams, 1980), significantly influences neuronal excitability by virtue of being the only active current near AP threshold (Marrion, 1997). Battefeld and colleagues characterized $\mathrm{I}_{\mathrm{M}}$ in the TTL5 AIS and found that this current is mediated by voltage-gated $\mathrm{K}_{\mathrm{v}} 7.2 / 7.3$ (KCNQ2/KCNQ3) heteromultimers (Battefeld et al., 2014). In addition, Battefeld et al. (2014) also discovered that $\mathrm{K}_{\mathrm{v}} 7.2 / 7.3$ co-clustered with $\mathrm{Na}_{\mathrm{v}}$ in nodes of Ranvier. The co-clustering mechanism increased the availability of the transient $\mathrm{Na}_{\mathrm{v}}$ current, and accelerated the upstroke of the AP as a result (Battefeld et al., 2014). Furthermore, staining and imaging experiments revealed that although $\mathrm{K}_{\mathrm{v}} 7.2, \mathrm{~K}_{\mathrm{v}} 7.3$, and $\mathrm{Na}_{\mathrm{v}}$ were all concentrated within the AIS, $K_{v} 7$ subunits were restricted to the distal portion of the AIS, whereas $\mathrm{Na}_{\mathrm{v}}$ occurred throughout the AIS (Battefeld et al., 2014; Figure 3).

\section{Intrinsic Firing Properties}

Voltage-gated axonal conductances contribute to AP initiation and influence the intrinsic properties of TTL5 neurons, such as the threshold for AP initiation, AP after-hyperpolarization and after-depolarization, and the firing mode. TTL5 neurons mostly respond to depolarizing somatic current injections through a distinctive firing pattern with spike-frequency adaptation, but can also discharge a burst of APs (Connors et al., 1982; McCormick et al., 1985; Chagnac-Amitai et al., 1990; Connors and Gutnick, 1990; Mason and Larkman, 1990; Silva et al., 1991; Amitai, 1994; Kasper et al., 1994b; Schwindt et al., 1997; Williams and Stuart, 1999; Schubert et al., 2001; Steriade, 2004; Groh et al., 2009).

Experiments and computational modeling have demonstrated that bursts of APs are generated through the activation of $\mathrm{Ca}^{2+}$ channels, prior to the back-propagation of APs into the TTL5 dendritic arbor (Rhodes and Gray, 1994; Mainen and Sejnowski, 1996; Williams and Stuart, 1999). The importance of burst firing is critically dependent upon the fidelity of information transfer (Lisman, 1997; Williams and Stuart, 1999). A pertinent question here is if all APs during a burst propagate reliably into the TTL5 axonal arbor resulting in neurotransmitter release, and then what are the postsynaptic changes following such release? It is unambiguous that postsynaptic responses between TTL5 neurons exhibit frequency-dependent depression during a low frequency train of APs less than $100 \mathrm{~Hz}$ (Thomson and West, 1993; Markram and Tsodyks, 1996).

The next question that arises is about the significance of burst firing in TTL5 neurons. Preliminary work by Stephen Williams and Greg Stuart revealed the significance of burst 
firing, indicating that bursts served to enhance synaptic coupling between TTL5 neurons through distinct and synergistic pre and postsynaptic amplification mechanisms during bursts of APs (Williams and Stuart, 1999). The activation of dendritic $\mathrm{Ca}^{2+}$ channels by bAPs was found to be crucial in the generation of burst firing in TTL5 neurons (Williams and Stuart, 1999). Recent studies have also shown that the distal axon, beyond the AIS influences the intrinsic excitability of TTL5 neurons (Kole, 2011). $\mathrm{Na}^{+}$channels that generate a persistent current in the node of Ranvier facilitate the probability of burst firing, and maintain a critical role for the first node of Ranvier in the generation of highfrequency bursts in TTL5 axons (Kole, 2011).

\section{Ephaptic Coupling}

In the central nervous system, ephaptic coupling broadly refers to either the coupling of adjacent axons arising due to ionic exchange between neurons or due to prevalent local electrical field potentials (Katz and Schmitt, 1940; Arvanitaki, 1942; Jefferys, 1995). Ephaptic coupling can influence AP initiation, synchronization and timing. Axon myelination is believed to inhibit ephaptic coupling.

Although widely studied in different brain regions (Taylor and Dudek, 1982; Draguhn et al., 1998; Bokil et al., 2001), the functional relevance of ephaptic coupling in TTL5 neurons has only been investigated recently (Anastassiou et al., 2011). Simultaneous somatic recordings from up to 12 TTL5 neurons revealed that extracellular electric fields generated ephapticallymediated changes of less than $0.5 \mathrm{mV}$ under subthreshold conditions. The small amplitude ephaptic changes resulted in APs, in particular for slow frequency fluctuations $(<8 \mathrm{~Hz})$ of the extracellular field (Anastassiou et al., 2011). Local field fluctuations due to ephaptic coupling in TTL5 neurons entrain both subthreshold and suprathreshold membrane potential changes to synchronize neuronal activity (Anastassiou et al., 2011).

\section{Synaptology}

The anatomical and physiological properties of TTL5 synaptic transmission influence the dynamics of electrical activity within the neocortical microcircuit. In vitro paired recordings have provided fundamental insights on the anatomical and physiological properties of TTL5 synaptic connections. More recently, data-driven unifying in silico approaches to reconstruct the neocortical microcircuit have revealed the crucial roles of the intrinsic morphological diversity of TTL5 neurons in ensuring the robustness of synaptic physiology and anatomy in the local neocortical microcircuit (Ramaswamy et al., 2012).

\section{Anatomy of Synaptic Connections}

Light and electron microscopic examinations of biocytin filled TTL5 neurons have revealed intricate details on the number and spatial innervation patterns of synaptic contacts (Markram, 1997; Markram et al., 1997a). TTL5 neurons are connected with a probability of $\sim 10 \%$ through about $4-8$ putative synaptic contacts (mean \pm S.D. of $5.5 \pm 1.1$ contacts). However, a major caveat is that this numerical information is almost entirely based on in vitro recordings from $300-400 \mu \mathrm{m}$ thick brain slices where axons and dendrites are potentially severed due to the slicing procedure, and could therefore be an underestimate. Synaptic contacts between TTL5 neurons are distributed throughout the dendritic arbor, however, despite the heterogeneity of spatial innervation, contacts are predisposed to occur at specific dendritic locations. A majority of potential synaptic contacts underlying connections between TTL5 neurons are formed on secondary and tertiary branches of basal dendrites, about $80-120 \mu \mathrm{m}$ from the soma (see Figure 2). The densities of synapses on primary, secondary and tertiary branches of basal dendrites have been found to be strikingly similar (Markram, 1997). A given TTL5 neuron can also potentially innervate its own dendritic arbor, establishing a so-called autapse (Van Der Loos and Glaser, 1972; Lübke et al., 1996). Remarkably, the spatial locations of autapses in TTL5 neurons have been found to mirror that of synapses, implying common principles of synapse formation and organization in local TTL5 microcircuits (Lübke et al., 1996).

GABAergic interneurons innervate TTL5 neurons by establishing synaptic contacts preferentially onto proximal dendrites and soma, axon, distal dendrites and tufts (Somogyi et al., 1998; Markram et al., 2004; Thomson and Lamy, 2007). While basket cells mostly target proximal dendrites and somata of TTL5 neurons (Gupta et al., 2000; Wang et al., 2002), Chandelier cells exclusively target the AIS (Somogyi, 1977; Szabadics et al., 2006), and Martinotti cells innervate apical dendrites and tufts (Somogyi et al., 1998; Pérez-Garci et al., 2006; Silberberg and Markram, 2007).

From an estimated 300-500 TTL5 neurons in a local cortical module (diameter of $300 \mu \mathrm{m}$; Szentágothai, 1975), a connection probability of $10-15 \%$, and about five potential synapses per connection, a single TTL5 neuron could be potentially innervated from as many as 40 neighboring TTL5 neurons, receiving about 200 afferent synapses (Peters, 1987; Song et al., 2005; Perin et al., 2011; Ramaswamy et al., 2012).

\section{Physiology of Synaptic Connections}

Synaptic connections between TTL5 neurons in the juvenile rodent neocortex display characteristic short-term frequency dependent depression, with a high initial probability of neurotransmitter release (Thomson and West, 1993; Thomson et al., 1993; Thomson and Deuchars, 1997; Reyes et al., 1998; Reyes and Sakmann, 1999; Berger et al., 2009). Although this phenomenon is mostly ubiquitous across several neocortical areas in juvenile animals, a notable exception is the medial prefrontal cortex where the response of monosynaptic connections between TTL5 neurons is marked by facilitating synapses with pronounced augmentation (Wang et al., 2006; Berger et al., 2009). In the rodent prefrontal cortex, pairedpulse responses have demonstrated that the physiology of monosynaptic connections between TTL5 neurons is weakly depressing between P7 and P9 (Zhang, 2004). The synaptic responses thereafter transition from being weakly facilitating around P12, with a gradual increase of facilitation until P20 and beyond Zhang (2004). The switch from depressing to 
facilitating responses appears to occur around P9 (Zhang, 2004), although the underlying mechanisms are yet to be ascertained. Similar to an increase in the morphological complexity of TTL5 neurons from the occipital to the frontal areas at least as seen in juvenile rodents (see Occurrence across different cortical regions and species), a corollary which necessitates further experiments could be that synaptic physiology switches from being predominantly depressing in the sensory areas in favor of facilitating in the association areas. It has also been observed that monosynaptic connections between TTL5 neurons in the mature somatosensory cortex are predominantly facilitating (Atkinson and Williams, 2009). However, it is not yet known if the balance of TTL5 synaptic physiology tilts from depression to facilitation with a progression of age across all cortical areas and species.

A prominent trait of depressing TTL5 synaptic connections is that once a certain "limiting" activation frequency is surpassed, postsynaptic responses display a marked decrease in amplitude inversely proportional to the activation frequency, termed the "1/f rule of synaptic depression" (Abbott et al., 1997; Tsodyks and Markram, 1997). For instance, according to this rule the average amplitude of the postsynaptic response at an activation frequency of $40 \mathrm{~Hz}$ is half the amplitude as that at $20 \mathrm{~Hz}$. The various mechanisms underlying frequency dependent synaptic depression in TTL5 neurons are not fully understood yet. However, the phenomenon of synaptic depression has been found to be independent of the activation of postsynaptic voltage-gated channels or polysynaptic dendritic inhibition or shunting (Markram and Tsodyks, 1996; for review see O'Donovan and Rinzel, 1997). Presynaptic factors could also influence depression. Some preliminary experiments with the bath application of $100 \mu \mathrm{M}$ cyclothiazide to block AMPAR desensitization could not abolish depression altogether, however, the rate of depression was slowed and the rate of recovery from depression and the EPSP amplitudes were found to increase in response to a presynaptic stimulus with a train of APs (Markram, 1997). AMPAR desensitization could therefore help in sculpting TTL5 synaptic responses mediated by frequencydependent depressing synapses (for reviews see Trussell and Fischbach, 1989; Jones and Westbrook, 1996).

Afferent GABAergic inputs onto TTL5 neurons display both frequency dependent depression and facilitation (Thomson et al., 1996; Gupta et al., 2000; Ali et al., 2007; Silberberg and Markram, 2007; for review see Thomson and Lamy, 2007). Previous studies have demonstrated that the very same axon of a TTL5 neuron innervating a neighboring TTL5 neuron through depressing synapses on one hand can also innervate a Martinotti-like GABAergic interneuron through facilitating synapses on the other (Markram et al., 1998). Alex Reyes in Bert Sakmann's laboratory observed similar synaptic transmission principles in layer 2/3 PCs of the juvenile somatosensory cortex (Reyes et al., 1998). This implies a differential signaling mechanism in neocortical information processing regulated by selective synaptic modifications. While TTL5 connections onto Martinotti cells are marked by low release probability facilitating synapses, connections onto basket cells are mediated by high release probability depressing synapses (Wang et al., 2002). Most GABAergic interneurons types in the neocortical microcircuit are known to inhibit TTL5 neurons through high release probability depressing synapses. A notable exception to this homogeneity of GABAergic innervation is seen in connections from small basket cells to TTL5 neurons, where inhibition is mediated by low release probability facilitating synapses (Gupta et al., 2000). A recent study demonstrated a depolarizing effect of inhibition from Chandelier cells onto neocortical PCs by virtue of a depolarized GABAA reversal potential in the axon relative to perisomatic compartments (Szabadics et al., 2006). While this has not yet been observed directly in TTL5 neurons, it raises interesting questions on selective inhibition of the pyramidal AIS by Chandelier cells.

Inhibition from different interneuron types to TTL5 neurons are predominantly mediated by fast GABAA receptors. However, neurogliaform cells evoke slow, and long-lasting inhibition through a mélange of GABAA and GABAB receptors in TTL5 neurons (Tamás et al., 2003). Furthermore, it appears that distinct GABAergic microcircuits connect layer 1 interneurons via layer $2 / 3$ interneurons to TTL5 neurons in rat neocortex (Jiang et al., 2013). Disynaptic circuits involving layer 1 neurogliaform cells, which formed reciprocal connections with groups of layer $2 / 3$ interneurons, inhibited the distal apical dendrites and tufts of TTL5 neurons through a combination of GABAA and GABAB receptors. This disynaptic configuration powerfully inhibited dendritic spiking in TTL5 neurons through reciprocal inhibition of layer 1 neurogliaform cells and layer 2/3 interneurons combined with an electric couplingmediated synchronizing mechanism (Jiang et al., 2013). On the other hand, single-bouquet cells in layer 1, which formed unidirectional inhibitory connections with several types of layer 2/3 interneurons, enhanced dendritic spiking in TTL5 neurons through a disynaptic disinhibitory configuration (Jiang et al., 2013). In general, TTL5 neurons receive strong inhibition form parvalbumin expressing neurons, moderate inhibition from somatostatin expressing neurons, and weak inhibition form vasoactive intestinal polypeptide expressing neurons (Pfeffer et al., 2013). Thus, an assortment of local interneuron types strategically modulates the global activity of TTL5 neurons.

The physiology of monosynaptic transmission between TTL5 neurons is extensively characterized through wholecell recordings in vitro. Unitary EPSPs evoked by a single presynaptic AP in developing TTL5 synaptic connections displayed amplitudes ranging between $0.15-5.5 \mathrm{mV}$ with a mean of $1.3 \pm 1.1 \mathrm{mV}$, a mean EPSP onset latency of $1.7 \pm 0.9 \mathrm{~ms}$, a mean $20-80 \%$ rise time of $2.6 \pm 2.3 \mathrm{~ms}$, and a mean decay time constant of $40 \pm 18 \mathrm{~ms}$ (Markram et al., 1997a). The rather wide range of EPSP amplitudes could potentially arise from the number of release sites, the probability of neurotransmitter release or the quantal size, all of which form the basis of the classical quantal model of synaptic transmission (Del Castillo and Katz, 1954; Korn and Faber, 1991). By means of statistical analysis, Alex Loebel et al. predicted that multiple release sites mediate synaptic transmission between TTL5 neurons (Loebel et al., 2009). However, further experimental corroborations are essential to ascertain this prediction. Synaptic transmission between TTL5 neurons is highly reliable with a low mean 
percentage of transmission failures of $14.3 \pm 17.6$, and a mean coefficient of variation (c.v.) of EPSP amplitude of $0.52 \pm 0.37$.

Unitary EPSPs in monosynaptic TTL5 connections are voltage dependent, with an increase in magnitude of the amplitude, decay time constant and the voltage time integral at membrane potentials higher than $-60 \mathrm{mV}$ (Markram et al., 1997a). The amplification of EPSPs at more depolarized membrane potentials could be attributed to several sources, including increased current flow through NMDA receptors (NMDAR), block of $\mathrm{I}_{\mathrm{h}}$ currents, and activation of low-threshold $\mathrm{Ca}^{2+}$ or persistent somatic $\mathrm{Na}^{+}$channels (Stuart and Sakmann, 1994; Schwindt and Crill, 1995). At hyperpolarized membrane potentials, the postsynaptic response between TTL5 neurons is mainly mediated by AMPA receptors (AMPAR) with fast kinetics, and at more depolarized membrane potentials NMDAR mediate the postsynaptic response with comparatively slow kinetics. Michael Haüsser and Arnd Roth devised a novel technique to quantitatively peel out the rise and decay time course of recorded AMPA conductances in TTL5 connections, which are estimated at about $0.2 \mathrm{~ms}$ and $1.7 \mathrm{~ms}$, respectively (Häusser and Roth, 1997).

The time course of $\mathrm{Mg}^{2+}$ block and unblock of NMDAR determines the extent of their activation by depolarization and has critical implications for spike-timing dependent synaptic plasticity (STDP) by delivering precision to the temporal window (Kampa et al., 2004). A spatial concentration of receptor "hotspots" along the TTL5 apical dendrite reveals a somato-dendritic gradient of glutamate sensitivity (Dodt et al., 1998). Interestingly, stimulation of these glutamate receptor hot spots facilitates the triggering of both $\mathrm{Na}^{+}$and $\mathrm{Ca}^{2+}$ spikes, implying that these hot spots serve as initiation zones for dendritic regenerative potentials (Dodt et al., 1998; Frick et al., 2001). The repertoire of ionotropic glutamate receptors in TTL5 neurons also includes kainate receptors (KAR), although studies confirming their functional relevance are rather scarce. KARs display kinetics on time-scales similar to AMPARs and increase in density along somato-dendritic axis (Eder et al., 2003).

Prevalent polysynaptic pathways have been identified in neocortical layer 5, where an assortment of GABAergic interneurons mediates connections between neighboring PCs. It has also been discovered that PCs in supra-granular layers exert strong inhibitory effects on neighboring PCs through the direct activation of nerve terminals of GABAergic interneurons, bypassing their somato-dendritic domain (Ren et al., 2007). The dynamics of polysynaptic pathways through the mediation of GABAergic interneurons display a rich variety of temporal and spatial patterns, ensuring a critical balance of the yin of inhibition and yang of excitation for cortical function (for review see McBain and Fisahn, 2001). In a striking dichotomy, inhibition in polysynaptic pathways is induced by discharge of local PCs and excitation is caused by specific GABAergic interneurons (Kapfer et al., 2007; Silberberg and Markram, 2007; for review see Silberberg, 2008).

Silberberg et al. discovered that inhibitory responses were evoked in TTL5 neurons following presynaptic stimulation of individual neighboring TTL5 neurons with frequency dependent trains of APs (Silberberg and Markram, 2007). Strikingly, the probability for inhibition between TTL5 neurons was more than twice that of direct excitation and inhibitory responses increased as a function of rate and duration of presynaptic discharge. Simultaneous somatic and dendritic recordings conclusively attributed the locus of inhibition to distal dendrites. Wholecell recordings from local TTL5 neurons and neighboring interneurons combined with morphological reconstructions confirmed that Martinotti cells were the GABAergic interneuron population mediating this interaction (Silberberg and Markram, 2007).

High-frequency discharge activates the Martinotti pathway rendering inhibitory interactions between TTL5 neurons, which are otherwise predominantly excitatory during low-frequency discharges. The Martinotti pathway prevents over-activation of TTL5 neurons, and is therefore crucial in preventing epileptoform activity (Pérez-Garci et al., 2006; Silberberg and Markram, 2007). By exclusively innervating distal tufts of TTL5 neurons in supra-granular neocortical layers, the Martinotti pathway serves a role akin to a fire-extinguisher by preventing the prolonged regeneration of dendritic $\mathrm{Ca}^{2+}$ spikes in TTL5 neurons and consequent high-frequency bursting, thereby maintaining cortical function by ensuring a balance of inhibition and excitation (Pérez-Garci et al., 2006). A recent study by Thomas Berger and colleagues revealed that the Martinotti pathway is not exclusive to the somatosensory cortex alone and is strikingly ubiquitous in its occurrence as a motif across a multitude of neocortical areas, however its precise role, for instance in synaptic plasticity entails further investigation (Berger et al., 2009).

Recent studies have demonstrated that the somatic depolarization of TTL5 neurons $(>5 \mathrm{mV})$ substantially increases the amplitude and shortens the latency of the disynaptic inhibitory response in neighboring TTL5 neurons (Zhu et al., 2011). Paired recordings from TTL5 neurons have revealed that sufficient depolarization increases the EPSP amplitude, elevates the firing of interneurons and inhibition, thus reflecting the analog mode of synaptic transmission between TTL5 neurons and interneurons (Zhu et al., 2011). Therefore, it appears that membrane potential-dependent modulation of inhibition is a crucial strategy to dynamically balance neocortical yin and yang under different activity regimes.

\section{Properties of Afferent Synaptic Input and Modulation of TTL5 Function}

The extensive arborization of the TTL5 dendrite facilitates the reception of synaptic connections from a medley of glutamatergic and GABAergic neurons. Descending axon collaterals from PCs originating in the lower confines of layer 2 and middle layer 3 establish synaptic contacts with oblique TTL5 dendrites (Thomson and Bannister, 1998; Reyes and Sakmann, 1999; Kampa et al., 2007). Although it is known that layer 4 spiny stellate cells form precise topographical projections to layer $5 \mathrm{~A}$, it is not completely clear whether deeper TTL5 dendrites are specifically innervated (Feldmeyer et al., 2005). The functional role of afferent inputs from layer 6 PCs on TTL5 dendrites is only superficially understood. One might speculate that the axon collaterals of cortico-thalamic PCs in layer 6 could target 
TTL5 dendrites in the upper confines of layer 5 during their ascending course towards the supragranular layers. A couple of recent studies suggest that the axons of cortico-cortical PCs in layer 6 are predisposed to form a plexus in layer 5 , however, it is inconclusive if TTL5 dendrites are included in the target specificity of this plexus (Kumar and Ohana, 2008; Marx and Feldmeyer, 2012). Recent experiments in vitro have employed laser-scanning photostimulation techniques to focally uncage glutamate to characterize functional input from layer 6 excitatory neurons to TTL5 dendrites (Zarrinpar and Callaway, 2014).

The expansive TTL5 dendritic arbor can be demarcated into distinct functional domains based on characteristic afferent inputs received from GABAergic local circuit interneurons (see Figure 4 for a schematic of the diverse sources of afferent excitatory and inhibitory input to, and targets of efferent excitatory output from TTL5 neurons). The division of the TTL5 dendritic arbor into these functional domains endows enhanced capabilities for the integration of varied streams of synaptic input. Martinotti cells preferentially target distal TTL5 dendrites and terminal tufts, while small basket cells predominantly target the proximal apical and basal dendrites and the soma (Thomson et al., 1996; Kawaguchi and Kubota, 1997; Somogyi et al., 1998; Wang et al., 2002; Silberberg and Markram, 2007; Ali and Thomson, 2008). TTL5 innervation by nest and large basket cells appears to be rather heterogeneous, covering the entire dendritic arbor (Wang et al., 2002). Synaptic contacts from bipolar, double bouquet and bitufted cells are made onto the proximal and distal dendrites for the most part (for reviews see Somogyi et al., 1998; Markram et al., 2004; Figure 4). Chandelier cells exclusively target the TTL5 AIS through axo-axonic synaptic contacts (Somogyi et al., 1982; Howard et al., 2005; Szabadics et al., 2006). Neurogliaform cells in the supragranular layers innervate distal TTL5 dendrites through metabotropic GABAB receptors mediating slow inhibition (Tamás et al., 2003; Oláh et al., 2007; Figure 4). Furthermore, terminal TTL5 dendritic tufts are innervated by a local plexus of axons from GABAergic intereneurons residing in layer 1 , also giving rise to slow inhibition through GABAB receptors (Zhu, 2000; Zhu and Zhu, 2004; Figure 4).

TTL5 dendrites directly receive thalamocortical afferents from the ventrobasal (VB) thalamus (Gottlieb and Keller, 1997; Figure 4). Furthermore, thalamic inputs involving lemniscal afferents arising from the ventroposterior medial nucleus (VPM) target proximal TTL5 dendrites (Ahissar et al., 2000; Feldmeyer et al., 2005; Lübke and Feldmeyer, 2007; Schubert et al., 2007; Figure 4). It is hypothesized that both slender and thicktufted neurons in layer 5 function as integrators of paralemiscal and lemniscal thalamic afferents through weak but reliable monosynaptic connections arising from layer 4 spiny stellates (Feldmeyer et al., 2005). In vivo whole-cell recordings have revealed that thalamic afferents innervate neurons in layers $5 \mathrm{~B}$ and 6 , concurrently to those in layer 4 (Constantinople and Bruno, 2013; Figure 4). This study discovered that a multitude of thalamic neurons innervated pyramidal neurons in the deeper layers including TTL5 neurons, and identified a bistratified model of sensory information flow from thalamus to two parallel streams, comprising of an upper stratum of layers 4 and 2/3, and a lower stratum of layers 5/6 (Constantinople and Bruno, 2013; Figure 4). This bistratified model facilitated sensory information to fully circumvent upper layers. Synaptic afferents originating in thalamus reliably elicited APs in TTL5 neurons in vivo, implicating their roles in mediating behavior by virtue of their projection to other higher-order brain areas (Constantinople and Bruno, 2013).

Recent experiments have yielded a plethora of information on the modulation of the TTL5 neurons by both excitatory and inhibitory afferents. In particular, in vivo experiments have postulated critical roles of inhibitory interneurons in controlling TTL5 function in behaving animals (for a review see Palmer et al., 2012a). The advent of optogenetic approaches to selectively manipulate populations of neurons has now made it possible to study local electrogenic properties of TTL5 neurons including the initiation and sustenance of $\mathrm{Na}^{+}, \mathrm{Ca}^{2+}$, and NMDA spikes and their spatiotemporal synergies. In particular there is a better understanding of how at least two different forms of inhibition exclusively targeting distal dendrites and terminal tufts of TTL5 neurons modulate their function in vivo (see Figure 4 for a schematic of excitatory, and inhibitory afferents, and local electrogenic properties in the context modulation of TTL5 activity).

Martinotti cells receive facilitatory synaptic input from TTL5 neurons (Pérez-Garci et al., 2006; Kapfer et al., 2007; Silberberg and Markram, 2007). Burst firing in TTL5 neurons due to network activity inhibits $\mathrm{Ca}^{2+}$ spike generation in distal dendrites through disynaptic inhibition via the recruitment of Martinotti cells (Murayama et al., 2009; also see Palmer et al., 2012a; Figure 4). Although the exact function of this disynaptic circuit is yet to be ascertained, some studies indicate that disynaptic inhibition of TTL5 neurons could serve to synchronizing TTL5 network activity (Berger et al., 2010), while others suggest a modulation of the dynamic range of TTL5 neurons (Kapfer et al., 2007; Murayama et al., 2009; see also Palmer et al., 2012a). Dendritic $\mathrm{Ca}^{2+}$ spikes directly cause burst firing in TTL5 neurons (Schwindt and Crill, 1999; Williams and Stuart, 1999), therefore disynaptic inhibition could be an operating mechanism by which TTL5 neurons in a network that are recruited first shut out other TTL5 neurons from participating in network activity (see Palmer et al., 2012a). Disynaptic inhibition in TTL5 neurons in vivo mediated by Martinotti cells are brought about wholly by GABAA receptors operating on fast time scales (Murayama et al., 2009).

Neurogliaform cells in layer 1 directly inhibit the tufts of TTL5 neurons (Chu et al., 2003; Jiang et al., 2013; Lee et al., 2014; Muralidhar et al., 2014). By virtue of their morphology with a dense local axon, neurogliaform cells also inhibit other interneurons in layer 1 (Zhu and Zhu, 2004; Oláh et al., 2007). Neurogliaform cells potently inhibit TTL5 tufts through a combination of fast GABAA, and slow GABAB receptor activation (Tamás et al., 2003; Oláh et al., 2007, 2009; Figure 4). Recent in vivo experiments by Palmer and colleagues unraveled a cellular basis for interhemispheric inhibition of layer 5 pyramidal neurons through the activation of neurogliaform cells mediating inhibition through slow GABAB receptors (Palmer et al., 2012b). Elegant in vivo experiments by Palmer and 


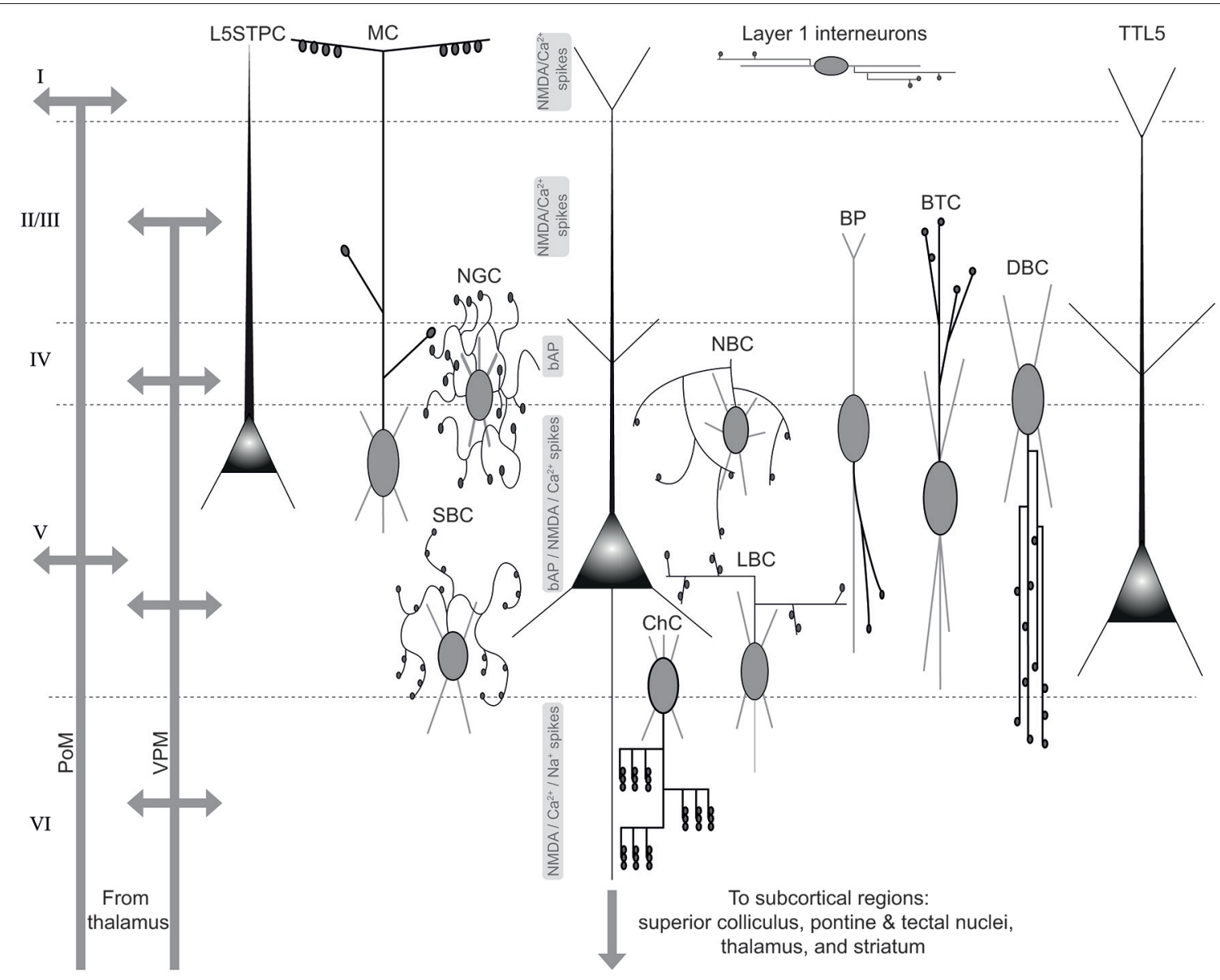

FIGURE 4 | Diverse sources of afferent excitatory and inhibitory input to, and targets of efferent excitatory output from TTL5 neurons. An illustration of the TTL5 neuron in the local neocortical microcircuit showing diverse sources of excitatory and inhibitory inputs, and targets of excitatory output. Schematic representations of the various neuron types afferent to the TTL5 neuron are shown according to their known dendritic, peri-somatic or axonal innervation domains. Local electrogenic properties, and their likely layers of origin are shown to the left of the TTL5 schematic in the center. POM-posterior medial nucleus; VPM-ventral posterior medial nucleus; L5STPC-layer 5 slender-tufted pyramidal cell; $\mathrm{MC}-$ Martinotti cell; NGC-neurogliaform cell; SBC-small basket cell; $\mathrm{ChC}$-chandelier cell; LBC-large basket cell; NBC-nest basket cell; BP-bipolar cell; BTC-bitufted cell; DBC-double bouquet cell; TTL5-thick-tufted layer 5 pyramidal neuron. colleagues revealed that $\mathrm{GABAB}$ mediated inhibition from neurogliaform cells exert a remarkable influence on the spiking activity of layer 5 pyramidal neurons, despite their confined and targeted innervation of distal dendrites (Palmer et al., 2012b). Although it is not very clear from the study if the implicated neurons were indeed TTL5 neurons with conspicuous thicktufts terminating in layer 1 , in general the local dendritic activity of layer 5 pyramidal neurons in vivo is durably suppressed through $\mathrm{GABAB}$ receptors by the activation of neurogliaform cells (Palmer et al., 2012b).

Thus, it appears that the function of TTL5 neurons in vivo is crucially governed by the selective activation of at least two distinct populations of GABAergic interneurons, which inhibit TTL5 activity across different time scales. Direct dendritic inhibition of TTL5 neurons through a combination of fast GABAA and slow GABAB receptors shuts off local electrogenic activity $\left(\mathrm{Ca}^{2+}\right.$, and NMDA spikes) and modulates global TTL5 function in vivo. Further in vivo experiments are essential to peel out the roles of specific populations of GABAergic interneurons that selectively innervate targeted parts of TTL5 dendrites, soma and axons to better understand their normative circuit function in behaving animals.

\section{Synaptic Assemblies}

Donald Hebb's pioneering theoretical contributions to learning and memory have exerted a continuing influence on neuroscience and psychology for more than half a century. Hebb postulated that when one neuron persistently drives another in its neighboring vicinity, then the connection between them is strengthened (Hebb, 1949). Futhermore, Hebb proposed that as a consequence this can lead to the development of clustered synaptic coupling of neurons into assemblies of cells where experience sculpts their constituent network arrangement. Through the past several years, an accumulation of experimental 
evidence has corroborated Hebb's postulates (see Dudai, 1989; Abeles, 1991; Kandel, 2007).

In spite of a vast body of experimental evidence for Hebb's postulates, several previous studies have indicated that Hebb's postulate of "neurons that fire together wire together" would lead to saturation of synapses within assemblies of cells, curbing their dynamic range and contracting memory storage capacity (Rochester et al., 1956; Rosenblatt, 1962; Bienenstock et al., 1982; McNaughton and Morris, 1987; Dayan and Abbott, 2001). Experimental studies have demonstrated that saturated longterm potentiation (LTP) does not foster learning and memory (Stent, 1973; Bienenstock et al., 1982). Indeed, Hebb had proposed that synaptic connections that were not utilized could weaken passively, however, several contradictions (including the ones mentioned above) indicated the necessity for an active depressive synaptic mechanism (Stent, 1973; Sejnowski, 1977; Bienenstock et al., 1982), thus paving the way for long-term depression (LTD) and bidirectional and STDP to be unraveled (Lynch et al., 1977; for review see Abbott and Nelson, 2000).

One pertinent question that arises based on these findings is in the context of cortical networks. What can be said about the topological network arrangement of cortical neurons? Through the past several years, sharp electrode and wholecell recordings from multiple neurons have indicated that not only are the connection probabilities different for the multitude of neuron types, but also the numbers and distributions of synapses can vary widely (Feldmeyer et al., 1999, 2002; Reyes and Sakmann, 1999; Thomson et al., 2002; Kampa et al., 2006a; Frick et al., 2008). At the outset, these data provide ready evidence for synaptic clustering, however, these types of clustering might likely also arise from other mechanisms attributable to topographical, genetic, and neuron-specific connectivity rules (Callaway and Katz, 1993; Stepanyants et al., 2004; Luo et al., 2008; Chédotal and Richards, 2010).

Early evidence for synaptic clustering between neurons of the same type in the microcircuit came about with the discovery that TTL5 neurons are bidirectionally more frequently connected as opposed to their unidirectional connection probability (Markram et al., 1997a,b). A rigorous and methodical study of triplets of TTL5 neurons by Sen Song in Dmitri Chklovskii's group (Song et al., 2005) demonstrated the existence of three-cell connectivity motifs in the neocortical microcircuit.

A recent study by Perin et al. demonstrated, by recording simultaneously from clusters of up to 12 TTL5 neurons, that both connection probability and synaptic strength can be predicted based on the number of common neighbors of a single TTL5 neuron (Perin et al., 2011). A rather simple clustering rule where connectivity is directly proportional to the number of common neighbors was found to account for "small world networks" of neurons, accurately predicting the connection probability between any two TTL 5 neurons. The composite neurons of each group were found to be surprisingly distributed, typically more than $100 \mu \mathrm{m}$ apart, allowing for multiple groups to be interlaced in the same space. This study led to the discovery of a synaptic organizing principle that groups neurons in a manner that is common across animals and hence, independent of individual experiences (Perin et al., 2011). The postnatal development of TTL5 neurons, however, is likely to be activity dependent and could involve mechanisms such as long-term microcircuit plasticity that has previously been identified at synaptic contacts underlying these connections (Le Bé and Markram, 2006).

\section{Synaptic Plasticity}

Synapses are plastic. Governed by temporal patterns of pre- and postsynaptic activity, the process of synaptic plasticity is widely believed to underlie learning and memory. Postsynaptic activity is shaped by the active and passive properties of the dendritic arbor. Dendritic excitability regulates the plastic properties of the synapse over several time scales and stages of development (Desai et al., 1999a,b; Sjöström et al., 2001, 2008).

\section{Plasticity in Local Microcircuits: The Ability to Rewire}

Structurally, the local neocortical microcircuit is a tabula rasa, with each TTL5 axon forming several appositions with all neighboring TTL5 dendrites (Kalisman et al., 2005). Functionally, however, the constituent neurons of the microcircuit are fickle in choosing their postsynaptic partners, with synaptic contacts established only onto a small fraction of these targets. This blueprint equips the neocortical microcircuit with a high potential for plasticity enabling the formation of a multitude of functional microcircuits, which are continually transformed owing to the activity of constituent neurons.

Nir Kalisman and colleagues discovered that in the local neocortical microcircuit the tabula rasa configuration confers an all-to-all geometrical connectivity matrix between neighboring TTL5 neurons (Kalisman et al., 2005). This enables a reconfiguration of the microcircuit without any remodeling of arbors simply by the genesis or termination of synapses (boutons and spines) at existing physical appositions (Kalisman et al., 2005). This poses pertinent questions of whether the microcircuit is in a state of spontaneous preparedness to rapidly turn connections between TTL5 neurons on or off without any further regrowing of axons or dendrites?

Le Bé and Markram (2006) demonstrated a novel form of microcircuit plasticity where multisynaptic connections between TTL5 neurons were turned on or off over a time scale of several hours (Le Bé and Markram, 2006). New connections emerged as a result of bath application and periodic puffing of glutamate, while the disappearance of connections remained unaffected. These experiments provided direct evidence that excitation mediated by glutamate catalyzed the formation of new connections. The same study also provided insights on the strength of emerging and disappearing connections, in that emergent connections were found to be weaker than the existing ones. Interestingly, the synaptic connections that disappeared over a span of time were preferentially the weaker ones (with fewer synapses), underlying a co-operative mechanism that drives the formation and maintenance of multi-synapse connections in the neocortex (Fares and Stepanyants, 2009).

The phenomenon of microcircuit plasticity is likely triggered by new experiences, which removes the weakest connections and provides a grace period to test the merit of new emergent connections for their retention or elimination, endowing 
microcircuits with the ability to choose stronger and thus "fitter" connections in a Darwinian fashion (Le Bé and Markram, 2006). TTL5 synaptic connections are rarely if ever liaised by fewer than three contacts per connection. Microcircuit plasticity is thus an attractive contender for a candidate mechanism that selectively governs the number of putative synaptic contacts in TTL5 connections within the range of 4-8 contacts, as observed in vitro.

\section{Redistribution of Synaptic Efficacy}

bAPs trigger synaptic modifications as they temporally collide with or miss incoming EPSPs, treading the "delicate" line between Hebbian and anti-Hebbian synaptic modifications (Markram et al., 1997b; Bi and Poo, 1998; Sjöström et al., 2001, 2007, 2008; Kampa et al., 2006a, 2007; Letzkus et al., 2006; Sjöström and Häusser, 2006). The consequent change in synaptic strength from Hebbian pairing is not a uniform amplification of responses at all frequencies, but arises due to a redistribution of available synaptic efficacy.

Conventionally, synaptic plasticity has been evaluated by measuring the change in the amplitude of synaptic responses evoked by single-shock extracellular electrical stimulation of afferent fibers (Bliss and Lomo, 1973). The general behavior of a synapse cannot be conclusively extrapolated by unitary responses, therefore a train of presynaptic APs is essential to monitor gain changes at a synapse (Thomson et al., 1993; Markram and Tsodyks, 1996). A first demonstration of such synaptic gain changes, now referred to as redistribution of synaptic efficacy (RSE), showed that the absolute synaptic efficacy of TTL5 connections remained unaffected following high-frequency presynaptic stimulation (Markram and Tsodyks, 1996). It was also noted that the entire synaptic response to the high-frequency presynaptic AP train was not uniformly increased, but instead the existing synaptic efficacy was redistributed (Markram and Tsodyks, 1996). The same study also suggested likely mechanisms contributing to the increased use of the existing efficacy in TTL5 synapses, through either an increase in the probability of neurotransmitter release after Hebbian-pairing or by an increase in the affinity of postsynaptic glutamatergic receptors, provided the receptors are not completely saturated.

\section{Excitability and Plasticity: Two Sides of the Same Coin}

Although the morphology of the dendritic arbor remains mostly untransformed, its electrical properties can change in an activitydependent manner over seconds to hours and perhaps even days, implying that dendritic learning rules exist in conjunction with synaptic rules (Sjöström et al., 2007; for review see Sjöström et al., 2008). Synapses convey information through the dendrites to the soma, triggering axonal APs as the final output. This process is symbiotic, where synaptic activity regulates dendritic excitability, and the dendritic arbor in turn exerts influence through the induction of synaptic plasticity.

A bAP invading the TTL5 dendritic arbor sparks synaptic modification (Markram et al., 1997b; Sjöström et al., 2001, 2007, 2008; Dan and Poo, 2004, 2006; Kampa and Stuart, 2006; Letzkus et al., 2006; Sjöström and Häusser, 2006; Kampa et al., 2007). Manipulating the relative timing of pre and postsynaptic APs led to the discovery of a watershed learning rule where the coincidence of postsynaptic APs and unitary EPSPs induced changes in EPSP amplitude in TTL5 neurons (Markram et al., 1997b). It was discovered that if the presynaptic AP preceded the postsynaptic AP by as little as $10 \mathrm{~ms}$, the connection was strengthened, leading to LTP. On the contrary, if the postsynaptic AP preceded the presynaptic AP, the connection was weakened, causing LTD. The phenomenon of the regulation of synaptic efficacy by coincidental APs and EPSPs, christened STDP has established itself as an attractive model for learning at the level of single cells across several brain regions (Magee and Johnston, 1997; Markram et al., 1997b; Bi and Poo, 1998; Abbott and Nelson, 2000; Sjöström et al., 2001; Kampa et al., 2007; also see Lisman and Spruston, 2005). The change in synaptic strength plotted as a function of the relative timing of pre- and postsynaptic APs is referred to as the STDP function or learning window and varies between synapse types (Abbott and Nelson, 2000).

In classical STD, the timing of pre and postsynaptic APs induces LTP by depolarizing and unblocking NMDA receptors (Magee and Johnston, 1997; Markram et al., 1997b; Kampa et al., 2007). Under situations wherein bAPs completely fail to invade the dendritic arbor, STDP can still be induced if the bAPs are salvaged by sufficient postsynaptic depolarization. This can either be achieved by current injection during wholecell recordings or by evoking bursts of APs (Sjöström et al., 2001; Letzkus et al., 2006; Sjöström and Häusser, 2006; Kampa et al., 2007). High-frequency bursts of APs occur naturally in TTL5 neurons and influence the initiation of dendritic spikes, consequently depolarizing the dendritic arbor (Lisman, 1997; Larkum et al., 1999a; Williams and Stuart, 1999; Kampa and Stuart, 2006). It has been demonstrated that only AP bursts above a critical firing frequency $(\sim 100 \mathrm{~Hz})$ initiate dendritic spikes (Larkum et al., 1999a; Kampa and Stuart, 2006). Compelling evidence also indicates that AP bursts are required to exceed a critical frequency to bring about STDP, implying an imperative requirement of dendritic spikes (Kampa et al., 2006b). Similarly, the induction of STDP at synapses on basal and apical dendrites of TTL5 neurons can be blocked by the inhibition of dendritic spikes by voltagegated $\mathrm{Ca}^{2+}$ channel antagonists (Kampa et al., 2006b; Letzkus et al., 2006). In summary, all these key findings strongly indicate that global dendritic spikes during AP burst firing are indispensable for the induction of LTP during low frequency pairing.

The question that arises then is how does dendritic synapse location impact the induction of STDP? Synapses onto different regions of the TTL5 dendritic arbor transmit a melange of information, which could be integrated in numerous ways. In concurrence with this notion, proximal synapses function by directly depolarizing the axo-somatic compartment, whereas information conveyed by distal synapses is mostly integrated through the initiation of regenerative dendritic spikes. Recent studies have focused on deciphering the relevance of dendritic synapse location for STDP induction in principal neocortical 
neurons. The first study by Rob Froemke et al. (2005) to address the location dependence of STDP indicated that the time window for LTD induction in layer $2 / 3$ pyramidal neurons (L2/3PCs) is broader for inputs from distal synapses (Froemke et al., 2005). It was discovered that $\mathrm{Ca}^{2+}$ dependent suppression of NMDARs in the distal dendrites led to a broadening of the time window for LTD induction. Two other studies have investigated distance dependent STDP induction exclusively in TTL5 neurons. Jesper Sjöström in Michael Häusser's laboratory demonstrated that pairing trains of APs and EPSPs led to LTP at proximal inputs (Sjöström and Häusser, 2006). In contrast, the same paradigm induced LTD at distally located inputs. Distal LTD was induced even while postsynaptic firing was absent, but could be transformed to LTP fostered by bAPs following sufficient dendritic current injection. An independent and complementary study by Letzkus et al. (2006) demonstrated that pairing unitary layer $2 / 3$ inputs with bursts of APs at positive times led to LTP at proximal synapses and LTD at distal synapses in TTL5 neurons. On the contrary, negative pairings had the opposite effect, inducing LTD at proximal inputs and LTP of distal inputs in TTL5 neurons (Letzkus et al., 2006). Recent work by Gordon et al. demonstrated that TTL5 basal dendrites manifest compartments of plasticity (Gordon et al., 2006). While synapses onto proximal basal dendrites are modified when paired with the global activity of the neuron, in distal basal dendrites NMDA spikes serve as a local postsynaptic signal for induction of LTP.

\section{Modulation of Intrinsic Excitability and Plasticity}

Several studies have investigated the influence of neuromodulators such as dopamine (DA), and acetylcholine (ACh) on neuronal excitability in the juvenile rodent neocortex (Gulledge and Jaffe, 1998; Gulledge and Stuart, 2005). Allan Gulledge and David Jaffe measured the effect of DA on the membrane properties of TTL5 neurons and discovered that over a range of concentrations, DA decreased the excitability of TTL5 neurons (Gulledge and Jaffe, 1998). In another study, Gulledge and Jaffe demonstrated that the dopaminergic modulation of TTL5 neurons occurs through at least three different mechanisms: (a) DA was found to inhibit AP generation by enhancing spontaneous inhibitory synaptic input; (b) DA decreased the input resistance of TTL5 neurons; and (c) DA triggered a delayed and prolonged enhancement of excitability (Gulledge and Jaffe, 2001). Although DA inhibits AP generation in TTL5 neurons, it does not influence the back-propagation of APs, and the initiation of local dendritic spikes in these neurons (Gulledge and Stuart, 2003). These results indicate that DA likely does not play a modulatory role on the dendritic properties of TTL5 neurons, however this entails further investigation. However, recent evidence has emerged on the selective modulation of $\mathrm{K}+$ currents at proximal unmyelinated segments of the TTL5 primary axon collateral (Yang et al., 2013). DA receptors, particularly D1 and D2 suppressed and enhanced $\mathrm{K}+$ currents respectively, owing to differential regulation in the activity of cyclic AMP-dependent protein kinase signaling pathways (Yang et al., 2013). DA modulated the time course and kinetics of APs recorded directly from the TTL5 axon. DA could therefore play a substantial role in governing neuronal signaling through the active maintenance of axonal $\mathrm{K}^{+}$ currents.

Cholinergic release modulates TTL5 neurons in a variety of ways. ACh reduces the rate of synaptic depression between TTL5 neurons without affecting the so-called stationary EPSPs following presynaptic stimulation (Tsodyks and Markram, 1997). This suggests that ACh attenuates temporal coding in TTL5 neurons. Angel Nuñez et al. (2012) provided evidence that ACh enhances EPSCs through nicotinic and M1 muscarinic receptors while diminishing IPSCs through nicotinic and M2 muscarinic receptors. Consequently, the aggregate effects contributed to increased excitability, generation of $\mathrm{Ca}^{2+}$ spikes and bursts of APs when inputs exclusive to basal dendrites were stimulated (Nuñez et al., 2012). ACh therefore exerts influence in maintaining the excitation-inhibition balance by switching TTL5 neurons into a bursting regime causing response enhancement spelling profound implications for necortical function. Activity in the medial prefrontal cortex (mPFC) is critically implicated by $\mathrm{ACh}$ which critically modulates the PFC during behavioral tasks that require intense attention and focus. It has been demonstrated that prefrontal ACh release exists across multiple time-scales altering phasic dynamics as a result (Parikh et al., 2007). In particular, during coincident presynaptic and postsynaptic activity, nicotinic acetylcholine receptors (nAChRs) enhance GABAergic synaptic transmission, profoundly impacting dendritic calcium signals and AP propagation in TTL5 neurons (Couey et al., 2007). Rapid increase of ACh exhibits laminar specificity by selectively modulating PCs in layers 2/3 and 5 (Poorthuis et al., 2013). A medley of ionotropic nAChRs modulates the dynamics of TTL5 neurons in several ways, which includes raising the threshold for the induction of spike-timing dependent plasticity (Couey et al., 2007).

The exclusive dendritic domains of TTL5 neurons can also modulate synaptic plasticity. Gordon et al. (2006) discovered that pairing of APs and EPSPs led to LTP induction in proximal basal dendrites, however, in distal basal dendrites LTP could be induced only when synaptic activation paired with the local application of brain-derived neurotrophic factor (BDNF) initiated local NMDA spikes. Although BDNF is known to have a modulatory effect on cortical synaptic plasticity (Desai et al., 1999b), experiments by Gordon et al. (2006) could, for instance, provide a basis to differentiate between synapses occurring on proximal and distal parts of the TTL5 basal dendritic arbor, aided by BDNF application which serves as a "gating molecule". Furthermore, cholinergic modulation can directly influence synaptic plasticity by shifting the polarity of plasticity, suggesting different modes for Hebbian modifications in TTL5 neurons (Stiefel et al., 2005).

In a series of recent experiments, Trevor Hamilton et al. demonstrated that neuropolypeptide Y (NPY) modulates the induction of LTD by suppressing $\mathrm{Ca}^{2+}$ influx induced by trains of bAPs (Hamilton et al., 2013). In what appears as a precise design strategy, release of NPY specifically targets the distal TTL5 dendrite occurring in the superficial layers. NPY receptors localized on distal dendritic processes selectively modulate LTD 
by regulating $\mathrm{Ca}^{2+}$ influx and regenerative potentials in TTL5 apical dendrites and tufts.

The influence of local TTL5 excitability on global network activity can be significantly altered by the use of anesthetics. In vivo experiments measuring TTL5 excitability have thus far been exclusively carried out under the use of anesthetics, particularly urethane, barbiturate, or ketamine, which can profoundly impact the active properties of TTL5 dendrites and intrinsic firing properties (Svoboda et al., 1997; Helmchen et al., 1999; Larkum and $\mathrm{Zhu}, 2002)$. It is therefore imperative that the consequences of anesthetic modulation of TTL5 excitability are well understood prior to deriving conclusions from in vivo measurements. A comprehensive study by Sarah Potez in Matthew Larkum's group identified the impact of anesthetics on TTL5 excitability both in vitro and in vivo (Potez and Larkum, 2008). In summary, while local $\mathrm{Ca}^{2+}$ dendritic spikes were not totally abolished by any of the commonly used anesthetics, urethane depolarized the firing threshold causing hyper-excitability; dose-response characteristic of barbiturate inhibited spontaneous spiking activity; ketamine caused hyper-excitability with a broadening of dendritic $\mathrm{Ca}^{2+}$ spikes and lowered the critical frequency for their induction (Potez and Larkum, 2008). Although the use of anesthetics does not impair the active propagation of dendritic spikes in vivo, their direct modulation of the kinetics and distribution of ion channels in TTL5 dendrites warrants further investigation.

\section{Pathophysiology and Disease}

Over the years, a wealth of information has accumulated on TTL5 function, what then is our current understanding on TTL5 dysfunction? TTL5 dysfunction has been strongly implicated to a host of maladies such as schizophrenia, epilepsy, autism, anxiety and depression critically disrupting cortical activity (Black et al., 2004; Traub et al., 2005; Lytton, 2008).

Schizophrenia is a neuropsychiatric disorder marked by pronounced deterioration of thinking and emotional responsiveness. The basal dendritic arbor in prefrontal cortical TTL5 neurons atrophies in size due to schizophrenia, and the consequent abnormal dendritic outgrowth leads to a reduction in cortical neuropil, thereby causing a decrease in connectivity between TTL5 neurons (Black et al., 2004). The reduced prefrontal neuropil could also be associated with less dopaminergic innervation of the deep layers of the prefrontal cortex, owing to schizophrenia (Garey et al., 1998; Black et al., 2004).

Epilepsy is one of several episodic disorders of the brain, characterized by recurrent synchronous neuronal activity. Epilepsy is not necessarily a single disorder, but manifests itself in several forms, including multiple sclerosis, transient ischemic attacks and migraine, all dynamical disorders that become apparent over time (Khosravani and Zamponi, 2006; Lytton, 2008). Recent evidence indicates that distinct forms of epilepsy are linked to changes in the efficacy of the $\mathrm{I}_{\mathrm{h}}$ current carried by HCN channels (Di Pasquale et al., 1997; for review see Santoro and Baram, 2003).

The deficit in $I_{h}$ mediated functions may contribute to the development and onset of spontaneously occurring hyper-excitability in neocortical pyramidal neurons in a rat model of absence seizures (Strauss et al., 2004). Furthermore, in a genetic rat model of absence epilepsy, Maarten Kole in Greg Stuart's group showed that a loss of dendritic $\mathrm{I}_{\mathrm{h}}$ recruits $\mathrm{Ca}^{2+}$ channels to amplify bAP triggered dendritic $\mathrm{Ca}^{2+}$ spikes leading to an increase in burst firing (Kole et al., 2007a). Therefore, the deficit of dendritic HCN channels in TTL5 neurons provides a somato-dendritic mechanism for increasing the synchronization of cortical output, and is therefore likely to play an important role in the generation of absence seizures (Kole et al., 2007a). Additionally, recent experiments have shown that sensory deprivation in neocortex increases the intrinsic excitability of TTL5 neurons through epileptic seizures from increased dendritic $\mathrm{Ca}^{2+}$ arising through a deficit of HCN expression (Breton and Stuart, 2009). These preliminary findings have contributed to a better understanding of the cortical basis of idiopathic generalized epilepsies and bolster the idea that the mechanisms involved in $\mathrm{HCN}$ expression hold promise as therapeutic targets for the treatment of absence seizures.

The $\mathrm{K}^{+} / \mathrm{Cl}^{-}$cotransporter (KCC2) is crucial in maintaining low $\left[\mathrm{Cl}^{-}\right]_{\mathrm{i}}$ resulting in hyperpolarizing GABA responses. A decrease in KCC2 after neuronal injuries resulted in increases in $\left[\mathrm{Cl}^{-}\right]_{\mathrm{i}}$ and enhanced neuronal excitability in TTL5 neurons due to depolarizing GABA responses (Jin et al., 2006). Perforatedpatch recordings revealed the functional consequence of KCC2 down-regulation in chronically injured neocortex indicating that a positive shift in the GABAergic reversal potential due to $\mathrm{Cl}^{-}$ extrusion (directly attributed to KCC2 down-regulation) caused acute epileptogenesis in pathophysiological TTL5 neurons (Jin et al., 2006).

Autism is a developmental disorder of neurological origin, primarily affecting social cognition. The etiology of autism has not been conclusively established yet, but genetic and environmental alterations are believed to confer vulnerability to this neurological disorder (Rubenstein and Merzenich, 2003). Recent studies have focussed on animal models of autism to explore changes in molecular, synaptic and cellular properties in pathological TTL5 neurons (Rinaldi et al., 2007a,b).

Rinaldi et al. investigated the postnatal effects of embryonic exposure to valproic acid (VPA) on TTL5 neurons of juvenile rat somatosensory cortex through whole cell patch-clamp recordings, and discovered that a single prenatal injection of VPA caused a significant enhancement of the local recurrent connectivity formed by TTL5 neurons (Rinaldi et al., 2007b). The connections between these pathological TTL5 neurons led to weaker synaptic responses, and their intrinsic excitability was also weakened. Furthermore, the mean number of potential synaptic contacts diminished (from an average of $\sim 5.5$ in control neurons to $\sim 3.3$ in pathological neurons) following exposure to VPA (Rinaldi et al., 2007b). In a complementary study, Rinaldi et al. (2007a) demonstrated that a single prenatal injection of VPA caused a surprisingly selective enhancement of NMDAR subunits NR2A and NR2B (Rinaldi et al., 2007a). This selective enhancement translated into enhanced NMDAR mediated synaptic currents and a marked amplification of synaptic plasticity through LTP in TTL5 neurons. These results 
provide preliminary insight on some of the potential core symptoms observed in humans prenatally exposed to VPA, and hold promise for the therapeutic treatment of autism.

\section{Five Decades of TTL5 Research: What Lies Ahead?}

We have endeavored to provide a unifying view of the dendritic, axonal, synaptic properties and plasticity of TTL5 neurons, and to a lesser extent the pathophysiology of TTL5 neurons from more than five decades of research. In this review, a degree of inevitable recurrence exists in the description of some key phenomena. A high level of interdependence is evident between dendritic excitability and synaptic plasticity and viceversa, where on the one hand activity-dependent regulation of dendritic excitability induces synaptic plasticity, and synaptic plasticity controls dendritic computations on the other.

Although we have learnt much more about the function of TTL5 neurons in the past several decades than ever before, this is still the tip of the iceberg. To reveal all anatomical and physiological aspects seems still far in the future. With the advent of newer in vivo, in vitro and in silico approaches for targeted experiments on TTL5 neurons, specific questions can be asked about their occurrence and generalization across different species and/or cortical regions,

\section{References}

Abbott, L. F., and Nelson, S. B. (2000). Synaptic plasticity: taming the beast. Nat. Neurosci. 3, 1178-1183. doi: 10.1038/81453

Abbott, L. F., Varela, J. A., Sen, K., and Nelson, S. B. (1997). Synaptic depression and cortical gain control. Science 275, 221-224. doi: 10.1126/science.275. 5297.221

Abeles, M. (1991). Corticonics: Neural Circuits of the Cerebral Cortex. Cambridge, UK: Cambridge University Press.

Ahissar, E., Sosnik, R., and Haidarliu, S. (2000). Transformation from temporal to rate coding in a somatosensory thalamocortical pathway. Nature 406, 302-306. doi: $10.1038 / 35018568$

Akiyama, H., Kaneko, T., Mizuno, N., and McGeer, P. L. (1990). Distribution of phosphate-activated glutaminase in the human cerebral cortex. J. Comp. Neurol. 297, 239-252. doi: 10.1002/cne.902970207

Ali, A. B., Bannister, A. P., and Thomson, A. M. (2007). Robust correlations between action potential duration and the properties of synaptic connections in layer 4 interneurones in neocortical slices from juvenile rats and adult rat and cat. J. Physiol. 580, 149-169. doi: 10.1113/jphysiol.2006.124214

Ali, A. B., and Thomson, A. M. (2008). Synaptic A5 subunit-containing GABAA receptors mediate IPSPs elicited by dendrite-preferring cells in rat neocortex. Cereb. Cortex 18, 1260-1271. doi: 10.1093/cercor/bhm160

Almog, M., and Korngreen, A. (2009). Characterization of voltage-gated Ca2+ conductances in layer 5 neocortical pyramidal neurons from rats. PLoS One 4:e4841. doi: 10.1371/journal.pone.0004841

Amitai, Y. (1994). Membrane potential oscillations underlying firing patterns in neocortical neurons. Neuroscience 63, 151-161. doi: 10.1016/03064522(94)90013-2

Amitai, Y., Friedman, A., Connors, B. W., and Gutnick, M. J. (1993). Regenerative activity in apical dendrites of pyramidal cells in neocortex. Cereb. Cortex 3, 26-38. doi: 10.1093/cercor/3.1.26

Anastassiou, C. A., Perin, R., Markram, H., and Koch, C. (2011). Ephaptic coupling of cortical neurons. Nat. Neurosci. 14, 217-223. doi: 10.1038/nn.2727

Anderson, J. C., Binzegger, T., Martin, K. A. C., and Rockland, K. S. (1998). The connection from cortical area V1 to V5: a light and electron microscopic study. J. Neurosci. 18, 10525-10540. robustness and redundancy in local circuit organization, gene expression changes across developmental time scales and activity patterns, protein transport and localization across different morphological regions, gene and protein networks underlying specific functions, the biophysical role of spines, possible cell assemblies based on afferent input and efferent output, the neuromodulation of plasticity, how different parts of the dendrite participate in the emergence of receptive fields, integration of translaminar, transcolumnar and transregional synaptic input, to outline a few. Gaining a grasp of a how single TTL5 neuron is actively modulated by the myriad of excitatory and inhibitory synapses impinging onto different dendritic domains is fundamental to better understand the multimodal information processing capabilities of these neurons. The pursuit to unravel the anatomy and physiology of TTL5 neurons will increase our understanding of their pivotal roles in neuronal microcircuitry and why our neuronal network is so wired to make us who we are.

\section{Acknowledgments}

We thank Sandrine Romand and Dr. Yun Wang for morphological reconstructions used in Figure 2. This work was supported by the Blue Brain Project, EPFL, Switzerland.

Antic, S. D. (2003). Action potentials in basal and oblique dendrites of rat neocortical pyramidal neurons. J. Physiol. 550, 35-50. doi: 10.1113/jphysiol. 2002.033746

Araya, R., Jiang, J., Eisenthal, K. B., and Yuste, R. (2006). The spine neck filters membrane potentials. Proc. Natl. Acad. Sci. U S A 103, 17961-17966. doi: 10. 1073/pnas.0608755103

Araya, R., Nikolenko, V., Eisenthal, K. B., and Yuste, R. (2007). Sodium channels amplify spine potentials. Proc. Natl. Acad. Sci. US A 104, 12347-12352. doi: 10. 1073/pnas.0705282104

Araya, R., Vogels, T. P., and Yuste, R. (2014). Activity-dependent dendritic spine neck changes are correlated with synaptic strength. Proc. Natl. Acad. Sci. U S A 111, E2895-E2904. doi: 10.1073/pnas.1321869111

Arvanitaki, A. (1942). Effects evoked in an axon by the activity of a contiguous one. J. Neurophysiol. 5, 89-108.

Astman, N., Gutnick, M. J., and Fleidervish, I. A. (2006). Persistent sodium current in layer 5 neocortical neurons is primarily generated in the proximal axon. J. Neurosci. 26, 3465-3473. doi: 10.1523/jneurosci.4907-05.2006

Atkinson, S. E., and Williams, S. R. (2009). Postnatal development of dendritic synaptic integration in rat neocortical pyramidal neurons. J. Neurophysiol. 102, 735-751. doi: 10.1152/jn.00083.2009

Battefeld, A., Tran, B. T., Gavrilis, J., Cooper, E. C., and Kole, M. H. P. (2014). Heteromeric Kv7.2/7.3 channels differentially regulate action potential initiation and conduction in neocortical myelinated axons. J. Neurosci. 34, 3719-3732. doi: 10.1523/JNEUROSCI.4206-13.2014

Bekkers, J. M. (2000a). Properties of voltage-gated potassium currents in nucleated patches from large layer 5 cortical pyramidal neurons of the rat. J. Physiol. 525, 593-609. doi: 10.1111/j.1469-7793.2000.t01-1-00593.x

Bekkers, J. M. (2000b). Distribution and activation of voltage-gated potassium channels in cell-attached and outside-out patches from large layer 5 cortical pyramidal neurons of the rat. J. Physiol. 525, 611-620. doi: 10.1111/j.1469-7793. 2000.t01-2-00611.x

Bekkers, J. M., and Delaney, A. J. (2001). Modulation of excitability by $\alpha$ dendrotoxin-sensitive potassium channels in neocortical pyramidal neurons. J. Neurosci. 21, 6553-6560.

Benhassine, N., and Berger, T. (2005). Homogeneous distribution of largeconductance calcium-dependent potassium channels on soma and apical 
dendrite of rat neocortical layer 5 pyramidal neurons. Eur. J. Neurosci. 21, 914-926. doi: 10.1111/j.1460-9568.2005.03934.x

Benhassine, N., and Berger, T. (2009). Large-conductance calcium-dependent potassium channels prevent dendritic excitability in neocortical pyramidal neurons. Pflugers Arch. 457, 1133-1145. doi: 10.1007/s00424-0080569-3

Berger, T., Larkum, M. E., and Lüscher, H.-R. (2001). High I(h) channel density in the distal apical dendrite of layer $\mathrm{V}$ pyramidal cells increases bidirectional attenuation of EPSPs. J. Neurophysiol. 85, 855-868.

Berger, T. K., Perin, R., Silberberg, G., and Markram, H. (2009). Frequencydependent disynaptic inhibition in the pyramidal network: a ubiquitous pathway in the developing rat neocortex. J. Physiol. 587, 5411-5425. doi: 10. 1113/jphysiol.2009.176552

Berger, T., Senn, W., and Lüscher, H.-R. (2003). Hyperpolarization-activated current Ih disconnects somatic and dendritic spike initiation zones in layer V pyramidal neurons. J. Neurophysiol. 90, 2428-2437. doi: 10.1152/jn. 00377.2003

Berger, T. K., Silberberg, G., Perin, R., and Markram, H. (2010). Brief bursts selfinhibit and correlate the pyramidal network. PLoS Biol. 8:e1000473. doi: 10. 1371/journal.pbio.1000473

Bernander, O., Douglas, R. J., Martin, K. A., and Koch, C. (1991). Synaptic background activity influences spatiotemporal integration in single pyramidal cells. Proc. Natl. Acad. Sci. U S A 88, 11569-11573. doi: 10.1073/pnas.88.24. 11569

Betz, W. (1874). Anatomischer nachweis zweier gehirncentra. Zentralbl. Med. Wiss. 12, 578-595.

Bi, G. Q., and Poo, M. M. (1998). Synaptic modifications in cultured hippocampal neurons: dependence on spike timing, synaptic strength and postsynaptic cell type. J. Neurosci. 18, 10464-10472.

Bienenstock, E. L., Cooper, L. N., and Munro, P. W. (1982). Theory for the development of neuron selectivity: orientation specificity and binocular interaction in visual cortex. J. Neurosci. 2, 32-48.

Black, J. E., Kodish, I. M., Grossman, A. W., Klintsova, A. Y., Orlovskaya, D., Vostrikov, V., et al. (2004). Pathology of layer V pyramidal neurons in the prefrontal cortex of patients with schizophrenia. Am. J. Psychiatry 161, 742-744. doi: 10.1176/appi.ajp.161.4.742

Bliss, T. V., and Lomo, T. (1973). Long-lasting potentiation of synaptic transmission in the dentate area of the anaesthetized rabbit following stimulation of the perforant path. J. Physiol. 232, 331-356. doi: 10. 1113/jphysiol.1973.sp010273

Bokil, H., Laaris, N., Blinder, K., Ennis, M., and Keller, A. (2001). Ephaptic interactions in the mammalian olfactory system. J. Neurosci. 21:RC173.

Borg-Graham, L. J., Monier, C., and Frégnac, Y. (1998). Visual input evokes transient and strong shunting inhibition in visual cortical neurons. Nature 393, 369-373. doi: 10.1038/30735

Boudkkazi, S., Fronzaroli-Molinieres, L., and Debanne, D. (2011). Presynaptic action potential waveform determines cortical synaptic latency. J. Physiol. 589, 1117-1131. doi: 10.1113/jphysiol.2010.199653

Braak, H., and Braak, E. (1976). The pyramidal cells of Betz within the cingulate and precentral gigantopyramidal field in the human brain. Cell Tissue Res. 172, 103-119. doi: 10.1007/bf00226052

Branco, T., Clark, B. A., and Häusser, M. (2010). Dendritic discrimination of temporal input sequences in cortical neurons. Science 329, 1671-1675. doi: 10. 1126/science.1189664

Branco, T., and Häusser, M. (2010). The single dendritic branch as a fundamental functional unit in the nervous system. Curr. Opin. Neurobiol. 20, 494-502. doi: 10.1016/j.conb.2010.07.009

Breton, J.-D., and Stuart, G. J. (2009). Loss of sensory input increases the intrinsic excitability of layer 5 pyramidal neurons in rat barrel cortex. J. Physiol. 587, 5107-5119. doi: 10.1113/jphysiol.2009.180943

Brown, D. A., and Adams, P. R. (1980). Muscarinic suppression of a novel voltage-sensitive K+ current in a vertebrate neurone. Nature 283, 673-676. doi: 10.1038/283673a0

Brown, S. P., and Hestrin, S. (2009). Intracortical circuits of pyramidal neurons reflect their long-range axonal targets. Nature 457, 1133-1136. doi: 10. 1038/nature07658

Burkhalter, A. (1989). Intrinsic connections of rat primary visual cortex: laminar organization of axonal projections. J. Comp. Neurol. 279, 171-186. doi: 10. $1002 /$ cne. 902790202
Caldwell, J. H., Schaller, K. L., Lasher, R. S., Peles, E., and Levinson, S. R. (2000). Sodium channel Nav1.6 is localized at nodes of Ranvier, dendrites and synapses. Proc. Natl. Acad. Sci. U S A 97, 5616-5620. doi: 10.1073/pnas. 090034797

Callaway, E. M., and Katz, L. C. (1993). Photostimulation using caged glutamate reveals functional circuitry in living brain slices. Proc. Natl. Acad. Sci. U S A 90, 7661-7665. doi: 10.1073/pnas.90.16.7661

Cash, S., and Yuste, R. (1998). Input summation by cultured pyramidal neurons is linear and position-independent. J. Neurosci. 18, 10-15.

Chagnac-Amitai, Y., Luhmann, H. J., and Prince, D. A. (1990). Burst generating and regular spiking layer 5 pyramidal neurons of rat neocortex have different morphological features. J. Comp. Neurol. 296, 598-613. doi: 10.1002/cne. 902960407

Chance, F. S., Abbott, L. F., and Reyes, A. D. (2002). Gain modulation from background synaptic input. Neuron 35, 773-782. doi: 10.1016/s08966273(02)00820-6

Chan-Palay, V., Palay, S. L., and Billings-Gagliardi, S. M. (1974). Meynert cells in the primate visual cortex. J. Neurocytol. 3, 631-658. doi: 10.1007/bf010 97628

Chédotal, A., and Richards, L. J. (2010). Wiring the brain: the biology of neuronal guidance. Cold Spring Harb. Perspect. Biol. 2:a001917. doi: 10.1101/cshperspect. a001917

Chu, Z., Galarreta, M., and Hestrin, S. (2003). Synaptic interactions of late-spiking neocortical neurons in layer 1. J. Neurosci. 23, 96-102.

Colbert, C. M., and Pan, E. (2002). Ion channel properties underlying axonal action potential initiation in pyramidal neurons. Nat. Neurosci. 5, 533-538. doi: 10. 1038/nn0602-857

Connors, B. W., and Gutnick, M. J. (1990). Intrinsic firing patterns of diverse neocortical neurons. Trends Neurosci. 13, 99-104. doi: 10.1016/01662236(90)90185-d

Connors, B. W., Gutnick, M. J., and Prince, D. A. (1982). Electrophysiological properties of neocortical neurons in vitro. J. Neurophysiol. 48, 1302-1320.

Constantinople, C. M., and Bruno, R. M. (2013). Deep cortical layers are activated directly by thalamus. Science 340, 1591-1594. doi: 10.1126/science. 1236425

Coombs, J. S., Curtis, D. R., and Eccles, J. C. (1957). The interpretation of spike potentials of motoneurones. J. Physiol. 139, 198-231. doi: 10.1113/jphysiol. 1957.sp005887

Couey, J. J., Meredith, R. M., Spijker, S., Poorthuis, R. B., Smit, A. B., Brussaard, A. B., et al. (2007). Distributed network actions by Nicotine increase the threshold for spike-timing-dependent plasticity in prefrontal cortex. Neuron 54, 73-87. doi: 10.1016/j.neuron.2007.03.006

Crill, W. E. (1996). Persistent sodium current in Mammalian central neurons. Annu. Rev. Physiol. 58, 349-362. doi: 10.1146/annurev.physiol.58.1.349

Dan, Y., and Poo, M. M. (2004). Spike timing-dependent plasticity of neural circuits. Neuron 44, 23-30. doi: 10.1016/j.neuron.2004.09.007

Dan, Y., and Poo, M.-M. (2006). Spike timing-dependent plasticity: from synapse to perception. Physiol. Rev. 86, 1033-1048. doi: 10.1152/physrev.00030.2005

Dayan, P., and Abbott, L. (2001). Theoretical Neuroscience: Computational and Mathematical Modeling of Neural Systems. Cambridge, MA: The MIT Press.

Debanne, D. (2004). Information processing in the axon. Nat. Rev. Neurosci. 5, 304-316. doi: 10.1038/nrn1397

Debanne, D., Campanac, E., Bialowas, A., Carlier, E., and Alcaraz, G. (2011). Axon physiology. Physiol. Rev. 91, 555-602. doi: 10.1152/physrev.00048.2009

DeFelipe, J., and Fariñas, I. (1992). The pyramidal neuron of the cerebral cortex: morphological and chemical characteristics of the synaptic inputs. Prog. Neurobiol. 39, 563-607. doi: 10.1016/0301-0082(92)90015-7

Del Castillo, J., and Katz, B. (1954). Quantal components of the end-plate potential. J. Physiol. 124, 560-573. doi: 10.1113/jphysiol.1954.sp005129

Desai, N. S., Rutherford, L. C., and Turrigiano, G. G. (1999a). Plasticity in the intrinsic excitability of cortical pyramidal neurons. Nat. Neurosci. 2, 515-520. doi: 10.1038/9165

Desai, N. S., Rutherford, L. C., and Turrigiano, G. G. (1999b). BDNF regulates the intrinsic excitability of cortical neurons. Learn. Mem. 6, 284-291.

Destexhe, A., Rudolph, M., Fellous, J.-M., and Sejnowski, T. J. (2001). Fluctuating synaptic conductances recreate in vivo-like activity in neocortical neurons. Neuroscience 107, 13-24. doi: 10.1016/s0306-4522(01)00344-x

Destexhe, A., Rudolph, M., and Paré, D. (2003). The high-conductance state of neocortical neurons in vivo. Nat. Rev. Neurosci. 4, 739-751. doi: 10. 1038/nrn1198 
Di Pasquale, E., Keegan, K. D., and Noebels, J. L. (1997). Increased excitability and inward rectification in layer $\mathrm{V}$ cortical pyramidal neurons in the epileptic mutant mouse stargazer. J. Neurophysiol. 77, 621-631.

Dodt, H.-U., Frick, A., Kampe, K., and Zieglgänsberger, W. (1998). NMDA and AMPA receptors on neocortical neurons are differentially distributed. Eur. J. Neurosci. 10, 3351-3357. doi: 10.1046/j.1460-9568.1998.00338.x

Draguhn, A., Traub, R. D., Schmitz, D., and Jefferys, J. G. (1998). Electrical coupling underlies high-frequency oscillations in the hippocampus in vitro. Nature 394, 189-192. doi: 10.1038/28184

Dudai, Y. (1989). The Neurobiology of Memory: Concepts, Findings, Trends. New York, NY: Oxford University Press.

Dulla, C. G., and Huguenard, J. R. (2009). Who let the spikes out? Nat. Neurosci. 12, 959-960. doi: 10.1038/nn0809-959

Eccles, J. C. (1964). Physiology of Synapses. New York, NY: Academic Press.

Eder, M., Becker, K., Rammes, G., Schierloh, A., Azad, S. C., Zieglgänsberger, W., et al. (2003). Distribution and properties of functional postsynaptic Kainate receptors on neocortical layer V pyramidal neurons. J. Neurosci. 23, 6660-6670.

Elston, G. (2001). Interlaminar differences in the pyramidal cell phenotype in cortical areas $7 \mathrm{~m}$ and STP (the superior temporal polysensory area) of the macaque monkey. Exp. Brain Res. 138, 141-152. doi: 10.1007/s0022101 00705

Elston, G. N., Benavides-Piccione, R., and DeFelipe, J. (2005). A study of pyramidal cell structure in the cingulate cortex of the Macaque Monkey with comparative notes on inferotemporal and primary visual cortex. Cereb. Cortex 15, 64-73. doi: 10.1093/cercor/bhh109

Elston, G. N., Benavides-Piccione, R., Elston, A., Manger, P. R., and DeFelipe, J. (2011). Pyramidal cells in prefrontal cortex of primates: marked differences in neuronal structure among species. Front. Neuroanat. 5:2. doi: 10.3389/fnana. 2011.00002

Elston, G. N., and Jelinek, H. F. (2001). Dendritic branching patterns of pyramidal cells in the visual cortex of the new world marmoset monkey, with comparative notes on the old world macaque monkey. Fractals 09, 297-303. doi: 10. 1142/s0218348x01000841

Fares, T., and Stepanyants, A. (2009). Cooperative synapse formation in the neocortex. Proc. Natl. Acad. Sci. U S A 106, 16463-16468. doi: 10.1073/pnas. 0813265106

Fatt, P. (1957). Electric potentials occurring around a neurone during its antidromic activation. J. Neurophysiol. 20, 27-60.

Feldmeyer, D., Egger, V., Lübke, J., and Sakmann, B. (1999). Reliable synaptic connections between pairs of excitatory layer 4 neurones within a single "barrel" of developing rat somatosensory cortex. J. Physiol. 521, 169-190. doi: 10.1111/j.1469-7793.1999.00169.x

Feldmeyer, D., Lübke, J., Silver, R. A., and Sakmann, B. (2002). Synaptic connections between layer 4 spiny neurone-layer $2 / 3$ pyramidal cell pairs in Juvenile rat Barrel cortex: physiology and anatomy of interlaminar signalling within a cortical column. J. Physiol. 538, 803-822. doi: 10.1113/jphysiol.2001. 012959

Feldmeyer, D., Roth, A., and Sakmann, B. (2005). Monosynaptic connections between Pairs of spiny stellate cells in layer 4 and pyramidal cells in layer $5 \mathrm{~A}$ indicate that Lemniscal and Paralemniscal afferent pathways converge in the infragranular somatosensory cortex. J. Neurosci. 25, 3423-3431. doi: 10. 1523/jneurosci.5227-04.2005

Fleidervish, I. A., and Gutnick, M. J. (1996). Kinetics of slow inactivation of persistent sodium current in layer $\mathrm{V}$ neurons of mouse neocortical slices. $J$. Neurophysiol. 76, 2125-2130.

Fleidervish, I. A., Lasser-Ross, N., Gutnick, M. J., and Ross, W. N. (2010). Na+ imaging reveals little difference in action potential-evoked $\mathrm{Na}+$ influx between axon and soma. Nat. Neurosci. 13, 852-860. doi: 10.1038/nn.2574

Foust, A. J., Yu, Y., Popovic, M., Zecevic, D., and McCormick, D. A. (2011). Somatic membrane potential and Kv1 channels control spike repolarization in cortical axon collaterals and presynaptic boutons. J. Neurosci. 31, 15490-15498. doi: 10.1523/JNEUROSCI.2752-11.2011

Frick, A., Feldmeyer, D., Helmstaedter, M., and Sakmann, B. (2008). Monosynaptic connections between pairs of L5A pyramidal neurons in columns of Juvenile rat somatosensory cortex. Cereb. Cortex 18, 397-406. doi: 10.1093/cercor/bhm074

Frick, A., Zieglgänsberger, W., and Dodt, H.-U. (2001). Glutamate receptors form hot spots on apical dendrites of neocortical pyramidal neurons. J. Neurophysiol. $86,1412-1421$.
Froemke, R. C., Poo, M., and Dan, Y. (2005). Spike-timing-dependent synaptic plasticity depends on dendritic location. Nature 434, 221-225. doi: 10. 1038/nature03366

Fuortes, M. G. F., Frank, K., and Becker, M. C. (1957). Steps in the production of motoneuron spikes. J. Gen. Physiol. 40, 735-752. doi: 10.1085/jgp.40. 5.735

Garey, L. J., Ong, W. Y., Patel, T. S., Kanani, M., Davis, A., Mortimer, A. M., et al. (1998). Reduced dendritic spine density on cerebral cortical pyramidal neurons in schizophrenia. J. Neurol. Neurosurg. Psychiatry 65, 446-453. doi: 10. 1136/jnnp.65.4.446

Gordon, U., Polsky, A., and Schiller, J. (2006). Plasticity compartments in basal dendrites of neocortical pyramidal neurons. J. Neurosci. 26, 12717-12726. doi: 10.1523/jneurosci.3502-06.2006

Gottlieb, J. P., and Keller, A. (1997). Intrinsic circuitry and physiological properties of pyramidal neurons in rat barrel cortex. Exp. Brain Res. 115, 47-60. doi: 10. 1007/pl00005684

Groh, A., Meyer, H. S., Schmidt, E. F., Heintz, N., Sakmann, B., and Krieger, P. (2009). Cell-type specific properties of pyramidal neurons in neocortex underlying a layout that is modifiable depending on the cortical area. Cereb. Cortex 20, 826-836. doi: 10.1093/cercor/bhp152

Gulledge, A. T., and Jaffe, D. B. (1998). Dopamine decreases the excitability of layer V pyramidal cells in the rat prefrontal cortex. J. Neurosci. 18, 9139-9151.

Gulledge, A. T., and Jaffe, D. B. (2001). Multiple effects of dopamine on layer V pyramidal cell excitability in rat prefrontal cortex. J. Neurophysiol. 86, 586-595. doi: 10.1093/cercor/11.5.452

Gulledge, A. T., Kampa, B. M., and Stuart, G. J. (2005). Synaptic integration in dendritic trees. J. Neurobiol. 64, 75-90. doi: 10.1002/neu.20144

Gulledge, A. T., and Stuart, G. J. (2003). Action potential initiation and propagation in layer 5 pyramidal neurons of the rat prefrontal cortex: absence of dopamine modulation. J. Neurosci. 23, 11363-11372.

Gulledge, A. T., and Stuart, G. J. (2005). Cholinergic inhibition of neocortical pyramidal neurons. J. Neurosci. 25, 10308-10320. doi: 10.1523/jneurosci.269705.2005

Gupta, A., Wang, Y., and Markram, H. (2000). Organizing principles for a diversity of GABAergic interneurons and synapses in the neocortex. Science 287, 273-278. doi: 10.1126/science.287.5451.273

Hallermann, S., de Kock, C. P. J., Stuart, G. J., and Kole, M. H. P. (2012). State and location dependence of action potential metabolic cost in cortical pyramidal neurons. Nat. Neurosci. 15, 1007-1014. doi: 10.1038/nn.3132

Hamilton, T. J., Xapelli, S., Michaelson, S. D., Larkum, M. E., and Colmers, W. F. (2013). Modulation of distal calcium electrogenesis by neuropeptide $\mathrm{Y}_{1}$ receptors inhibits neocortical long-term depression. J. Neurosci. 33, 11184-11193. doi: 10.1523/jneurosci.5595-12.2013

Harnett, M. T., Magee, J. C., and Williams, S. R. (2015). Distribution and function of HCN channels in the apical dendritic tuft of neocortical pyramidal neurons. J. Neurosci. 35, 1024-1037. doi: 10.1523/jneurosci.2813-14.2015

Harnett, M. T., Xu, N.-L., Magee, J. C., and Williams, S. R. (2013). Potassium channels control the interaction between active dendritic integration compartments in layer 5 cortical pyramidal neurons. Neuron 79, 516-529. doi: 10.1016/j.neuron.2013.06.005

Hattox, A. M., and Nelson, S. B. (2007). Layer V neurons in mouse cortex projecting to different targets have distinct physiological properties. J. Neurophysiol. 98, 3330-3340. doi: 10.1152/jn.00397.2007

Häusser, M. (2001). Synaptic function: dendritic democracy. Curr. Biol. 11, R10-R12. doi: 10.1016/s0960-9822(00)00034-8

Häusser, M., and Mel, B. (2003). Dendrites: bug or feature? Curr. Opin. Neurobiol. 13, 372-383. doi: 10.1016/s0959-4388(03)00075-8

Häusser, M., and Roth, A. (1997). Estimating the time course of the excitatory synaptic conductance in neocortical pyramidal cells using a novel voltage jump method. J. Neurosci. 17, 7606-7625.

Hay, E., Hill, S., Schürmann, F., Markram, H., and Segev, I. (2011). Models of neocortical layer $5 \mathrm{~b}$ pyramidal cells capturing a wide range of dendritic and perisomatic active properties. PLoS Comput. Biol. 7:e1002107. doi: 10. 1371/journal.pcbi.1002107

Hebb, D. O. (1949). The Organization of Behavior; A Neuropsychological Theory. Oxford, England: Wiley.

Helmchen, F., Imoto, K., and Sakmann, B. (1996). Ca2+ buffering and action potential-evoked Ca2+ signaling in dendrites of pyramidal neurons. Biophys. J. 70, 1069-1081. doi: 10.1016/s0006-3495(96)79653-4 
Helmchen, F., Svoboda, K., Denk, W., and Tank, D. W. (1999). In vivo dendritic calcium dynamics in deep-layer cortical pyramidal neurons. Nat. Neurosci. 2, 989-996. doi: 10.1038/14788

Hill, D. N., Varga, Z., Jia, H., Sakmann, B., and Konnerth, A. (2013). Multibranch activity in basal and tuft dendrites during firing of layer 5 cortical neurons in vivo. Proc. Natl. Acad. Sci. U S A 110, 13618-13623. doi: 10.1073/pnas. 1312599110

Hô, N., and Destexhe, A. (2000). Synaptic background activity enhances the responsiveness of neocortical pyramidal neurons. J. Neurophysiol. 84, 1488-1496.

Holtmaat, A. J. G. D., Trachtenberg, J. T., Wilbrecht, L., Shepherd, G. M., Zhang, X., Knott, G. W., et al. (2005). Transient and persistent dendritic spines in the neocortex in vivo. Neuron 45, 279-291. doi: 10.3410/f.1023545. 270738

Holtmaat, A., Wilbrecht, L., Knott, G. W., Welker, E., and Svoboda, K. (2006). Experience-dependent and cell-type-specific spine growth in the neocortex. Nature 441, 979-983. doi: 10.1038/nature04783

Howard, A., Tamas, G., and Soltesz, I. (2005). Lighting the chandelier: new vistas for axo-axonic cells. Trends Neurosci. 28, 310-316. doi: 10.1016/j.tins.2005.04. 004

Hu, W., Tian, C., Li, T., Yang, M., Hou, H., and Shu, Y. (2009). Distinct contributions of Nav1.6 and Nav1.2 in action potential initiation and backpropagation. Nat. Neurosci. 12, 996-1002. doi: 10.1038/nn.2359

Huguenard, J. R., Hamill, O. P., and Prince, D. A. (1989). Sodium channels in dendrites of rat cortical pyramidal neurons. Proc. Natl. Acad. Sci. U S A 86, 2473-2477. doi: 10.1073/pnas.86.7.2473

Inda, M. C., DeFelipe, J., and Muñoz, A. (2006). Voltage-gated ion channels in the axon initial segment of human cortical pyramidal cells and their relationship with chandelier cells. Proc. Natl. Acad. Sci. U S A 103, 2920-2925. doi: 10. 1073/pnas.0511197103

Jefferys, J. G. (1995). Nonsynaptic modulation of neuronal activity in the brain: electric currents and extracellular ions. Physiol. Rev. 75, 689-723.

Jelinek, H. F., and Elston, G. N. (2001). Pyramidal neurones in macaque visual cortex: interareal phenotypic variation of dendritic branching patterns. Fractals 9, 287-295. doi: 10.1142/s0218348x01000725

Jiang, X., Wang, G., Lee, A. J., Stornetta, R. L., and Zhu, J. J. (2013). The organization of two new cortical interneuronal circuits. Nat. Neurosci. 16, 210-218. doi: 10.1038/nn.3305

Jin, X., Prince, D. A., and Huguenard, J. R. (2006). Enhanced excitatory synaptic connectivity in layer $\mathrm{V}$ pyramidal neurons of chronically injured epileptogenic neocortex in rats. J. Neurosci. 26, 4891-4900. doi: 10.1523/jneurosci.4361-05. 2006

Johnston, D., Magee, J. C., Colbert, C. M., and Christie, B. R. (1996). Active properties of neuronal dendrites. Annu. Rev. Neurosci. 19, 165-186. doi: 10. 1146/annurev.neuro.19.1.165

Jones, E. G., DeFelipe, J., Hendry, S. H., and Maggio, J. E. (1988). A study of tachykinin-immunoreactive neurons in monkey cerebral cortex. J. Neurosci. 8, 1206-1224.

Jones, M. V., and Westbrook, G. L. (1996). The impact of receptor desensitization on fast synaptic transmission. Trends Neurosci. 19, 96-101. doi: 10.1016/s01662236(96)80037-3

Kaiserman-Abramof, I. R., and Peters, A. (1972). Some aspects of the morphology of Betz cells in the cerebral cortex of the cat. Brain Res. 43, 527-546. doi: 10 . 1016/0006-8993(72)90406-4

Kalisman, N., Silberberg, G., and Markram, H. (2005). The neocortical microcircuit as a tabula rasa. Proc. Natl. Acad. Sci. U S A 102, 880-885. doi: 10. 3410/f.1023301.269659

Kampa, B. M., Clements, J., Jonas, P., and Stuart, G. J. (2004). Kinetics of Mg2+ unblock of NMDA receptors: implications for spike-timing dependent synaptic plasticity. J. Physiol. 556, 337-345. doi: 10.1113/jphysiol.2003.058842

Kampa, B. M., Letzkus, J. J., and Stuart, G. J. (2006a). Cortical feed-forward networks for binding different streams of sensory information. Nat. Neurosci. 9, 1472-1473. doi: 10.1038/nn1798

Kampa, B. M., Letzkus, J. J., and Stuart, G. J. (2006b). Requirement of dendritic calcium spikes for induction of spike-timing-dependent synaptic plasticity. J. Physiol. 574, 283-290. doi: 10.1113/jphysiol.2006.111062

Kampa, B. M., Letzkus, J. J., and Stuart, G. J. (2007). Dendritic mechanisms controlling spike-timing-dependent synaptic plasticity. Trends Neurosci. 30, 456-463. doi: 10.1016/j.tins.2007.06.010
Kampa, B. M., and Stuart, G. J. (2006). Calcium spikes in basal dendrites of layer 5 pyramidal neurons during action potential bursts. J. Neurosci. 26, 7424-7432. doi: 10.1523/jneurosci.3062-05.2006

Kandel, E. R. (2007). In Search of Memory: The Emergence of a New Science of Mind. New York: W. W. Norton \& Company.

Kang, J., Huguenard, J. R., and Prince, D. A. (1996a). Development of BK channels in neocortical pyramidal neurons. J. Neurophysiol. 76, 188-198.

Kang, J., Huguenard, J. R., and Prince, D. A. (1996b). Two types of BK channels in immature rat neocortical pyramidal neurons. J. Neurophysiol. 76, 4194-4197.

Kang, J., Huguenard, J. R., and Prince, D. A. (2000). Voltage-gated potassium channels activated during action potentials in layer $\mathrm{V}$ neocortical pyramidal neurons. J. Neurophysiol. 83, 70-80.

Kapfer, C., Glickfeld, L. L., Atallah, B. V., and Scanziani, M. (2007). Supralinear increase of recurrent inhibition during sparse activity in the somatosensory cortex. Nat. Neurosci. 10, 743-753. doi: 10.1038/nn1909

Kasper, E. M., Larkman, A. U., Lübke, J., and Blakemore, C. (1994b). Pyramidal neurons in layer 5 of the rat visual cortex. II. Development of electrophysiological properties. J. Comp. Neurol. 339, 475-494. doi: 10. 1002/cne.903390403

Kasper, E. M., Lübke, J., Larkman, A. U., and Blakemore, C. (1994a). Pyramidal neurons in layer 5 of the rat visual cortex. III. Differential maturation of axon targeting, dendritic morphology and electrophysiological properties. J. Comp. Neurol. 339, 495-518. doi: 10.1002/cne.903390404

Katz, B., and Schmitt, O. H. (1940). Electric interaction between two adjacent nerve fibres. J. Physiol. 97, 471-488. doi: 10.1113/jphysiol.1940.sp003823

Kawaguchi, Y., and Kubota, Y. (1997). GABAergic cell subtypes and their synaptic connections in rat frontal cortex. Cereb. Cortex 7, 476-486. doi: 10 1093/cercor/7.6.476

Keller, A. (1993). Intrinsic synaptic organization of the motor cortex. Cereb. Cortex 3, 430-441. doi: 10.1093/cercor/3.5.430

Kennedy, M. B. (1997). The postsynaptic density at glutamatergic synapses. Trends Neurosci. 20, 264-268. doi: 10.1016/s0166-2236(96)01033-8

Kennedy, M. B. (2000). Signal-processing machines at the postsynaptic density. Science 290, 750-754. doi: 10.1126/science.290.5492.750

Khosravani, H., and Zamponi, G. W. (2006). Voltage-gated calcium channels and idiopathic generalized epilepsies. Physiol. Rev. 86, 941-966. doi: 10. 1152/physrev.00002.2006

Knaus, H. G., Schwarzer, C., Koch, R. O., Eberhart, A., Kaczorowski, G. J., Glossmann, H., et al. (1996). Distribution of high-conductance $\mathrm{Ca}(2+)$ activated $\mathrm{K}+$ channels in rat brain: targeting to axons and nerve terminals. J. Neurosci. 16, 955-963.

Koch, C., and Zador, A. (1993). The function of dendritic spines: devices subserving biochemical rather than electrical compartmentalization. J. Neurosci. 13, 413-422.

Koester, H. J., and Sakmann, B. (1998). Calcium dynamics in single spines during coincident pre- and postsynaptic activity depend on relative timing of back-propagating action potentials and subthreshold excitatory postsynaptic potentials. Proc. Natl. Acad. Sci. U S A 95, 9596-9601. doi: 10.1073/pnas.95. 16.9596

Kole, M. H. P. (2011). First node of ranvier facilitates high-frequency burst encoding. Neuron 71, 671-682. doi: 10.1016/j.neuron.2011.06.024

Kole, M. H., Bräuer, A. U., and Stuart, G. J. (2007a). Inherited cortical HCN1 channel loss amplifies dendritic calcium electrogenesis and burst firing in a rat absence epilepsy model. J. Physiol. 578, 507-525. doi: 10.1113/jphysiol.2006. 122028

Kole, M. H. P., Hallermann, S., and Stuart, G. J. (2006). Single Ih channels in pyramidal neuron dendrites: properties, distribution and impact on action potential output. J. Neurosci. 26, 1677-1687. doi: 10.1523/jneurosci.3664-05. 2006

Kole, M. H. P., Ilschner, S. U., Kampa, B. M., Williams, S. R., Ruben, P. C., and Stuart, G. J. (2008). Action potential generation requires a high sodium channel density in the axon initial segment. Nat. Neurosci. 11, 178-186. doi: 10 1038/nn2040

Kole, M. H. P., Letzkus, J. J., and Stuart, G. J. (2007b). Axon initial segment Kv1 channels control axonal action potential waveform and synaptic efficacy. Neuron 55, 633-647. doi: 10.1016/j.neuron.2007.07.031

Kole, M. H. P., and Stuart, G. J. (2012). Signal processing in the axon initial segment. Neuron 73, 235-247. doi: 10.1016/j.neuron.2012.01.007 
Korn, H., and Faber, D. S. (1991). Quantal analysis and synaptic efficacy in the CNS. Trends Neurosci. 14, 439-445. doi: 10.1016/0166-2236(91) 90042-s

Korngreen, A., and Sakmann, B. (2000). Voltage-gated $\mathrm{K}+$ channels in layer 5 neocortical pyramidal neurones from young rats: subtypes and gradients. J. Physiol. 525, 621-639. doi: 10.1111/j.1469-7793.2000. 00621.x

Książek, A., Ładno, W., Szulczyk, B., Grzelka, K., and Szulczyk, P. (2013). Properties of BK-type $\mathrm{Ca}(+)(+)$-dependent $\mathrm{K}+$ channel currents in medial prefrontal cortex pyramidal neurons in rats of different ages. Front. Cell. Neurosci. 7:185. doi: 10.3389/fncel.2013.00185

Kumar, P., and Ohana, O. (2008). Inter- and intralaminar subcircuits of excitatory and inhibitory neurons in layer 6a of the rat barrel cortex. J. Neurophysiol. 100, 1909-1922. doi: 10.1152/jn.90684.2008

Lai, H. C., and Jan, L. Y. (2006). The distribution and targeting of neuronal voltagegated ion channels. Nat. Rev. Neurosci. 7, 548-562. doi: 10.1038/nrn1938

Larkman, A. U. (1991a). Dendritic morphology of pyramidal neurones of the visual cortex of the rat: I. Branching patterns. J. Comp. Neurol. 306, 307-319. doi: 10.1002/cne.903060207

Larkman, A. U. (1991b). Dendritic morphology of pyramidal neurones of the visual cortex of the rat: III. Spine distributions. J. Comp. Neurol. 306, 332-343. doi: 10.1002/cne.903060209

Larkum, M. E., Kaiser, K. M. M., and Sakmann, B. (1999a). Calcium electrogenesis in distal apical dendrites of layer 5 pyramidal cells at a critical frequency of back-propagating action potentials. Proc. Natl. Acad. Sci. U S A 96, 14600-14604. doi: 10.1073/pnas.96.25.14600

Larkum, M. E., Nevian, T., Sandler, M., Polsky, A., and Schiller, J. (2009). Synaptic integration in tuft dendrites of layer 5 pyramidal neurons: a new unifying principle. Science 325, 756-760. doi: 10.1126/science. 1171958

Larkum, M. E., and Zhu, J. J. (2002). Signaling of layer 1 and whisker-evoked Ca2+ and $\mathrm{Na}+$ action potentials in distal and terminal dendrites of rat neocortical pyramidal neurons in vitro and in vivo. J. Neurosci. 22, 6991-7005.

Larkum, M. E., Zhu, J. J., and Sakmann, B. (1999b). A new cellular mechanism for coupling inputs arriving at different cortical layers. Nature 398, 338-341. doi: $10.1038 / 18686$

Larkum, M. E., Zhu, J. J., and Sakmann, B. (2001). Dendritic mechanisms underlying the coupling of the dendritic with the axonal action potential initiation zone of adult rat layer 5 pyramidal neurons. J. Physiol. 533, 447-466. doi: 10.1111/j.1469-7793.2001.0447a.x

Le Bé, J.-V., and Markram, H. (2006). Spontaneous and evoked synaptic rewiring in the neonatal neocortex. Proc. Natl. Acad. Sci. U S A 103, 13214-13219. doi: 10.1073/pnas.0604691103

Lee, A. J., Wang, G., Jiang, X., Johnson, S. M., Hoang, E. T., Lanté, F., et al. (2014). Canonical organization of layer 1 neuron-led cortical inhibitory and disinhibitory interneuronal circuits. Cereb. Cortex doi: 10.1093/cercor/bhu020 [Epub ahead of print].

le Gros Clark, W. E. (1942). The cells of Meynert in the visual cortex of the monkey. J. Anat. 76, 369-376.1.

Letzkus, J. J., Kampa, B. M., and Stuart, G. J. (2006). Learning rules for spike timing-dependent plasticity depend on dendritic synapse location. J. Neurosci. 26, 10420-10429. doi: 10.1523/jneurosci.2650-06.2006

Lisman, J. E. (1997). Bursts as a unit of neural information: making unreliable synapses reliable. Trends Neurosci. 20, 38-43. doi: 10.1016/s01662236(96)10070-9

Lisman, J., and Spruston, N. (2005). Postsynaptic depolarization requirements for LTP and LTD: a critique of spike timing-dependent plasticity. Nat. Neurosci. 8, 839-841. doi: 10.1038/nn0705-839

Loebel, A., Silberberg, G., Helbig, D., Markram, H., Tsodyks, M., and Richardson, M. J. E. (2009). Multiquantal release underlies the distribution of synaptic efficacies in the neocortex. Front. Comput. Neurosci. 3:27. doi: 10.3389/neuro. 10.027.2009

London, M., and Häusser, M. (2005). Dendritic computation. Annu. Rev. Neurosci. 28, 503-532. doi: 10.1146/annurev.neuro.28.061604.135703

London, M., and Segev, I. (2001). Synaptic scaling in vitro and in vivo. Nat. Neurosci. 4, 853-854. doi: 10.1038/nn0901-853

Lörincz, A., Notomi, T., Tamás, G., Shigemoto, R., and Nusser, Z. (2002). Polarized and compartment-dependent distribution of HCN1 in pyramidal cell dendrites. Nat. Neurosci. 5, 1185-1193. doi: 10.1038/nn962
Lörincz, A., and Nusser, Z. (2010). Molecular identity of dendritic voltage-gated sodium channels. Science 328, 906-909. doi: 10.1126/science.1187958

Lübke, J., and Feldmeyer, D. (2007). Excitatory signal flow and connectivity in a cortical column: focus on barrel cortex. Brain Struct. Funct. 212, 3-17. doi: 10. 1007/s00429-007-0144-2

Lübke, J. H. R., and Feldmeyer, D. (2010). "The axon of excitatory neurons in the neocortex: projection patterns and target specificity," in New Aspects of Axonal Structure and Function, eds D. Feldmeyer and J. H. R. Lübke (US: Springer), 157-178.

Lübke, J., Markram, H., Frotscher, M., and Sakmann, B. (1996). Frequency and dendritic distribution of autapses established by layer 5 pyramidal neurons in the developing rat neocortex: comparison with synaptic innervation of adjacent neurons of the same class. J. Neurosci. 16, 3209-3218.

Luo, L., Callaway, E. M., and Svoboda, K. (2008). Genetic dissection of neural circuits. Neuron 57, 634-660. doi: 10.1016/j.neuron.2008.01.002

Lynch, G. S., Dunwiddie, T., and Gribkoff, V. (1977). Heterosynaptic depression: a postsynaptic correlate of long-term potentiation. Nature 266, 737-739. doi: 10. $1038 / 266737 \mathrm{a} 0$

Lytton, W. W. (2008). Computer modelling of epilepsy. Nat. Rev. Neurosci. 9, 626-637. doi: 10.1038/nrn2416

Magee, J. C. (2000). Dendritic integration of excitatory synaptic input. Nat. Rev. Neurosci. 1, 181-190. doi: 10.1038/35044552

Magee, J. C., and Cook, E. P. (2000). Somatic EPSP amplitude is independent of synapse location in hippocampal pyramidal neurons. Nat. Neurosci. 3, 895-903. doi: $10.1038 / 78800$

Magee, J. C., and Johnston, D. (1997). A synaptically controlled, associative signal for hebbian plasticity in hippocampal neurons. Science 275, 209-213. doi: 10. 1126/science.275.5297.209

Mainen, Z. F., and Sejnowski, T. J. (1996). Influence of dendritic structure on firing pattern in model neocortical neurons. Nature 382, 363-366. doi: 10. 1038/382363a0

Major, G., Larkum, M. E., and Schiller, J. (2013). Active properties of neocortical pyramidal neuron dendrites. Annu. Rev. Neurosci. 36, 1-24. doi: 10. 1146/annurev-neuro-062111-150343

Major, G., Polsky, A., Denk, W., Schiller, J., and Tank, D. W. (2008). Spatiotemporally graded NMDA spike/plateau potentials in basal dendrites of neocortical pyramidal neurons. J. Neurophysiol. 99, 2584-2601. doi: 10.1152/jn. 00011.2008

Markram, H. (1997). A network of tufted layer 5 pyramidal neurons. Cereb. Cortex 7, 523-533. doi: 10.1093/cercor/7.6.523

Markram, H., Helm, P. J., and Sakmann, B. (1995). Dendritic calcium transients evoked by single back-propagating action potentials in rat neocortical pyramidal neurons. J. Physiol. 485, 1-20. doi: 10.1113/jphysiol.1995. sp020708

Markram, H., Lübke, J., Frotscher, M., Roth, A., and Sakmann, B. (1997a). Physiology and anatomy of synaptic connections between thick tufted pyramidal neurones in the developing rat neocortex. J. Physiol. 500, 409-440. doi: 10.1113/jphysiol.1997.sp022031

Markram, H., Lübke, J., Frotscher, M., and Sakmann, B. (1997b). Regulation of synaptic efficacy by coincidence of postsynaptic APs and EPSPs. Science 275, 213-215. doi: 10.1126/science.275.5297.213

Markram, H., and Sakmann, B. (1994). Calcium transients in dendrites of neocortical neurons evoked by single subthreshold excitatory postsynaptic potentials via low-voltage-activated calcium channels. Proc. Natl. Acad. Sci. U S A 91, 5207-5211. doi: 10.1073/pnas.91.11.5207

Markram, H., Toledo-Rodriguez, M., Wang, Y., Gupta, A., Silberberg, G., and Wu, C. (2004). Interneurons of the neocortical inhibitory system. Nat. Rev. Neurosci. 5, 793-807. doi: 10.1038/nrn1519

Markram, H., and Tsodyks, M. (1996). Redistribution of synaptic efficacy between neocortical pyramidal neurons. Nature 382, 807-810. doi: 10.1038/ $382807 \mathrm{a} 0$

Markram, H., Wang, Y., and Tsodyks, M. (1998). Differential signaling via the same axon of neocortical pyramidal neurons. Proc. Natl. Acad. Sci. U S A 95, 5323-5328. doi: 10.1073/pnas.95.9.5323

Marrion, N. V. (1997). Control of M-Current. Annu. Rev. Physiol. 59, 483-504. doi: 10.1146/annurev.physiol.59.1.483

Marx, M., and Feldmeyer, D. (2012). Morphology and physiology of excitatory neurons in layer $6 \mathrm{~b}$ of the somatosensory rat barrel cortex. Cereb. Cortex 23 , 2803-2817. doi: 10.1093/cercor/bhs254 
Mason, A., and Larkman, A. (1990). Correlations between morphology and electrophysiology of pyramidal neurons in slices of rat visual cortex. II. Electrophysiology. J. Neurosci. 10, 1415-1428.

McBain, C. J., and Fisahn, A. (2001). Interneurons unbound. Nat. Rev. Neurosci. 2, 11-23. doi: 10.1038/35049047

McCormick, D. A., Connors, B. W., Lighthall, J. W., and Prince, D. A. (1985). Comparative electrophysiology of pyramidal and sparsely spiny stellate neurons of the neocortex. J. Neurophysiol. 54, 782-806.

McCormick, D. A., Shu, Y., and Yu, Y. (2007). Neurophysiology: Hodgkin and Huxley model-still standing? Nature 445, E1-E2. doi: 10.1038/nature05523

McNaughton, B. L., and Morris, R. G. M. (1987). Hippocampal synaptic enhancement and information storage within a distributed memory system. Trends Neurosci. 10, 408-415. doi: 10.1016/0166-2236(87)90011-7

Mel, B. W. (1993). Synaptic integration in an excitable dendritic tree. J. Neurophysiol. 70, 1086-1101.

Migliore, M., and Shepherd, G. M. (2002). Emerging rules for the distributions of active dendritic conductances. Nat. Rev. Neurosci. 3, 362-370. doi: 10. 1038/nrn810

Milojkovic, B. A., Radojicic, M. S., Goldman-Rakic, P. S., and Antic, S. D. (2004). Burst generation in rat pyramidal neurones by regenerative potentials elicited in a restricted part of the basilar dendritic tree. J. Physiol. 558, 193-211. doi: 10. 1113/jphysiol.2004.061416

Milojkovic, B. A., Wuskell, J. P., Loew, L. M., and Antic, S. D. (2005). Initiation of sodium spikelets in basal dendrites of neocortical pyramidal neurons. J. Membr. Biol. 208, 155-169. doi: 10.1007/s00232-005-0827-7

Mittmann, T., Linton, S. M., Schwindt, P., and Crill, W. (1997). Evidence for persistent $\mathrm{Na}+$ current in apical dendrites of rat neocortical neurons from imaging of Na+-Sensitive dye. J. Neurophysiol. 78, 1188-1192.

Morishima, M., and Kawaguchi, Y. (2006). Recurrent connection patterns of corticostriatal pyramidal cells in frontal cortex. J. Neurosci. 26, 4394-4405. doi: 10.1523/jneurosci.0252-06.2006

Muralidhar, S., Wang, Y., and Markram, H. (2014). Synaptic and cellular organization of layer 1 of the developing rat somatosensory cortex. Front. Neuroanat. 7:52. doi: 10.3389/fnana.2013.00052

Murayama, M., Pérez-Garci, E., Lüscher, H.-R., and Larkum, M. E. (2007). Fiberoptic system for recording dendritic calcium signals in layer 5 neocortical pyramidal cells in freely moving rats. J. Neurophysiol. 98, 1791-1805. doi: 10. 1152/jn.00082.2007

Murayama, M., Pérez-Garci, E., Nevian, T., Bock, T., Senn, W., and Larkum, M. E. (2009). Dendritic encoding of sensory stimuli controlled by deep cortical interneurons. Nature 457, 1137-1141. doi: 10.1038/nature 07663

Naundorf, B., Wolf, F., and Volgushev, M. (2006). Unique features of action potential initiation in cortical neurons. Nature 440, 1060-1063. doi: 10. 1038/nature04610

Nettleton, J. S., and Spain, W. J. (2000). Linear to supralinear summation of AMPA-Mediated EPSPs in neocortical pyramidal neurons. J. Neurophysiol. 83, 3310-3322.

Nevian, T., Larkum, M. E., Polsky, A., and Schiller, J. (2007). Properties of basal dendrites of layer 5 pyramidal neurons: a direct patch-clamp recording study. Nat. Neurosci. 10, 206-214. doi: 10.1038/nn1826

Nicolai, B. (1981). [The postnatal development of the lamina V pyramidal cells in the temporal cortex of the albino rat]. J. Hirnforsch. 22, 351-381.

Nimchinsky, E. A., Sabatini, B. L., and Svoboda, K. (2002). Structure and function of dendritic spines. Annu. Rev. Physiol. 64, 313-353. doi: 10.1146/annurev. physiol.64.081501.160008

Nuñez, A., Domínguez, S., Buño, W., and Fernández de Sevilla, D. (2012). Cholinergic-mediated response enhancement in barrel cortex layer $\mathrm{V}$ pyramidal neurons. J. Neurophysiol. 108, 1656-1668. doi: 10.1152/jn.00156. 2012

O’Donovan, M. J., and Rinzel, J. (1997). Synaptic depression: a dynamic regulator of synaptic communication with varied functional roles. Trends Neurosci. 20, 431-433. doi: 10.1016/s0166-2236(97)01124-7

Ohana, O., and Sakmann, B. (1998). Transmitter release modulation in nerve terminals of rat neocortical pyramidal cells by intracellular calcium buffers. $J$. Physiol. 513, 135-148. doi: 10.1111/j.1469-7793.1998.135by.x

Oláh, S., Füle, M., Komlósi, G., Varga, C., Báldi, R., Barzó, P., et al. (2009). Regulation of cortical microcircuits by unitary GABA-mediated volume transmission. Nature 461, 1278-1281. doi: 10.1038/nature08503
Oláh, S., Komlósi, G., Szabadics, J., Varga, C., Tóth, E., Barzó, P., et al. (2007). Output of neurogliaform cells to various neuron types in the human and rat cerebral cortex. Front. Neural Circuits 1:4. doi: 10.3389/neuro.04.004.2007

Oviedo, H. V., and Reyes, A. D. (2012). Integration of subthreshold and suprathreshold excitatory barrages along the somatodendritic axis of pyramidal neurons. PLoS One 7:e33831. doi: 10.1371/journal.pone.0033831

Palay, S. L., Sotelo, C., Peters, A., and Orkand, P. M. (1968). The axon hillock and the initial segment. J. Cell Biol. 38, 193-201. doi: 10.1083/jcb.38. 1.193

Palmer, L., Murayama, M., and Larkum, M. (2012a). Inhibitory regulation of dendritic activity in vivo. Front. Neural Circuits 6:26. doi: 10.3389/fncir.2012. 00026

Palmer, L. M., Schulz, J. M., Murphy, S. C., Ledergerber, D., Murayama, M., and Larkum, M. E. (2012b). The cellular basis of GABAB-Mediated interhemispheric inhibition. Science 335, 989-993. doi: 10.1126/science. 1217276

Palmer, L. M., and Stuart, G. J. (2006). Site of action potential initiation in layer 5 pyramidal neurons. J. Neurosci. 26, 1854-1863. doi: 10.1523/jneurosci.4812-05. 2006

Palmer, L. M., and Stuart, G. J. (2009). Membrane potential changes in dendritic spines during action potentials and synaptic input. J. Neurosci. 29, 6897-6903. doi: 10.1523/JNEUROSCI.5847-08.2009

Paré, D., Shink, E., Gaudreau, H., Destexhe, A., and Lang, E. J. (1998). Impact of spontaneous synaptic activity on the resting properties of cat neocortical pyramidal neurons in vivo. J. Neurophysiol. 79, 1450-1460.

Parikh, V., Kozak, R., Martinez, V., and Sarter, M. (2007). Prefrontal acetylcholine release controls cue detection on multiple timescales. Neuron 56, 141-154. doi: 10.1016/j.neuron.2007.08.025

Pérez-Garci, E., Gassmann, M., Bettler, B., and Larkum, M. E. (2006). The GABAB1b isoform mediates long-lasting inhibition of dendritic $\mathrm{Ca} 2+$ spikes in layer 5 somatosensory pyramidal neurons. Neuron 50, 603-616. doi: 10.1016/j. neuron.2006.04.019

Perin, R., Berger, T. K., and Markram, H. (2011). A synaptic organizing principle for cortical neuronal groups. Proc. Natl. Acad. Sci. U S A 108, 5419-5424. doi: $10.1073 /$ pnas. 1016051108

Peters, A. (1987). "Number of neurons and synapses in primary visual cortex," in Cereb. Cortex, eds E. G. Jones and A. Peters (US: Springer), 267-294.

Peters, A., and Kaiserman-Abramof, I. R. (1970). The small pyramidal neuron of the rat cerebral cortex. The perikaryon, dendrites and spines. Am. J. Anat. 127, 321-355. doi: 10.1002/aja.1001270402

Peters, A., and Kara, D. A. (1985). The neuronal composition of area 17 of rat visual cortex. I: the pyramidal cells. J. Comp. Neurol. 234, 218-241. doi: 10. 1002/cne.902340208

Peters, A., Proskauer, C. C., and Kaiserman-Abramof, I. R. (1968). The small pyramidal neuron of the rat cerebral cortex the axon hillock and initial segment. J. Cell Biol. 39, 604-619. doi: 10.1083/jcb.39.3.604

Pfeffer, C. K., Xue, M., He, M., Huang, Z. J., and Scanziani, M. (2013). Inhibition of inhibition in visual cortex: the logic of connections between molecularly distinct interneurons. Nat. Neurosci. 16, 1068-1076. doi: 10.1038/ nn.3446

Phillips, C. G. (1956). Intracellular records from betz cells in the cat. Q. J. Exp. Physiol. Cogn. Med. Sci. 41, 58-69. doi: 10.1113/expphysiol.1956.sp001163

Poirazi, P., Brannon, T., and Mel, B. W. (2003). Pyramidal neuron as two-layer neural network. Neuron 37, 989-999. doi: 10.1016/s0896-6273(03)00149-1

Polsky, A., Mel, B. W., and Schiller, J. (2004). Computational subunits in thin dendrites of pyramidal cells. Nat. Neurosci. 7, 621-627. doi: 10.1038/nn1253

Polsky, A., Mel, B., and Schiller, J. (2009). Encoding and decoding bursts by NMDA spikes in basal dendrites of layer 5 pyramidal neurons. J. Neurosci. 29, 11891-11903. doi: 10.1523/JNEUROSCI.5250-08.2009

Poorthuis, R. B., Bloem, B., Schak, B., Wester, J., de Kock, C. P. J., and Mansvelder, H. D. (2013). Layer-specific modulation of the prefrontal cortex by nicotinic acetylcholine receptors. Cereb. Cortex 23, 148-161. doi: 10.1093/cercor/bhr390

Potez, S., and Larkum, M. E. (2008). Effect of common anesthetics on dendritic properties in layer 5 neocortical pyramidal neurons. J. Neurophysiol. 99, 1394-1407. doi: 10.1152/jn.01126.2007

Ramaswamy, S., Hill, S. L., King, J. G., Schürmann, F., Wang, Y., and Markram, H. (2012). Intrinsic morphological diversity of thick-tufted layer 5 pyramidal neurons ensures robust and invariant properties of in silico synaptic connections. J. Physiol. 590, 737-752. doi: 10.1113/jphysiol.2011.219576 
Rasband, M. N. (2010). The axon initial segment and the maintenance of neuronal polarity. Nat. Rev. Neurosci. 11, 552-562. doi: 10.1038/nrn2852

Reimann, M. W., Anastassiou, C. A., Perin, R., Hill, S. L., Markram, H., and Koch, C. (2013). A biophysically detailed model of neocortical local field potentials predicts the critical role of active membrane currents. Neuron 79, 375-390. doi: 10.1016/j.neuron.2013.05.023

Ren, M., Yoshimura, Y., Takada, N., Horibe, S., and Komatsu, Y. (2007). Specialized inhibitory synaptic actions between nearby neocortical pyramidal neurons. Science 316, 758-761. doi: 10.1126/science.1135468

Reuveni, I., Friedman, A., Amitai, Y., and Gutnick, M. J. (1993). Stepwise repolarization from $\mathrm{Ca} 2+$ plateaus in neocortical pyramidal cells: evidence for nonhomogeneous distribution of HVA Ca2+ channels in dendrites. J. Neurosci. $13,4609-4621$.

Reyes, A. (2001). Influence of dendritic conductances on the input-output properties of neurons. Annu. Rev. Neurosci. 24, 653-675. doi: 10.1146/annurev. neuro.24.1.653

Reyes, A., Lujan, R., Rozov, A., Burnashev, N., Somogyi, P., and Sakmann, B. (1998). Target-cell-specific facilitation and depression in neocortical circuits. Nat. Neurosci. 1, 279-285.

Reyes, A., and Sakmann, B. (1999). Developmental switch in the short-term modification of unitary EPSPs evoked in layer 2/3 and layer 5 pyramidal neurons of rat neocortex. J. Neurosci. 19, 3827-3835.

Rhodes, P. (2006). The properties and implications of NMDA spikes in neocortical pyramidal cells. J. Neurosci. 26, 6704-6715. doi: 10.1523/jneurosci.3791-05. 2006

Rhodes, P. A., and Gray, C. M. (1994). Simulations of intrinsically bursting neocortical pyramidal neurons. Neural Comput. 6, 1086-1110. doi: 10. 1162/neco.1994.6.6.1086

Rhodes, P. A., and Llinás, R. R. (2001). Apical tuft input efficacy in layer 5 pyramidal cells from rat visual cortex. J. Physiol. 536, 167-187. doi: 10.1111/j. 1469-7793.2001.00167.x

Rinaldi, T., Kulangara, K., Antoniello, K., and Markram, H. (2007a). Elevated NMDA receptor levels and enhanced postsynaptic long-term potentiation induced by prenatal exposure to valproic acid. Proc. Natl. Acad. Sci. U S A 104, 13501-13506. doi: 10.1073/pnas.0704391104

Rinaldi, T., Silberberg, G., and Markram, H. (2007b). Hyperconnectivity of local neocortical microcircuitry induced by prenatal exposure to valproic acid. Cereb. Cortex 18, 763-770. doi: 10.1093/cercor/bhm117

Rivara, C.-B., Sherwood, C. C., Bouras, C., and Hof, P. R. (2003). Stereologic characterization and spatial distribution patterns of Betz cells in the human primary motor cortex. Anat. Rec. A Discov. Mol. Cell. Evol. Biol. 270, 137-151. doi: 10.1002/ar.a.10015

Rochester, N., Holland, J., Haibt, L., and Duda, W. (1956). Tests on a cell assembly theory of the action of the brain, using a large digital computer. IRE Trans. Inf. Theory 2, 80-93. doi: 10.1109/tit.1956.1056810

Rockland, K. S. (1996). Two types of corticopulvinar terminations: round (type 2) and elongate (type 1). J. Comp. Neurol. 368, 57-87.

Romand, S., Wang, Y., Toledo-Rodriguez, M., and Markram, H. (2011). Morphological development of thick-tufted layer v pyramidal cells in the rat somatosensory cortex. Front. Neuroanat. 5:5. doi: 10.3389/fnana.2011.00005

Rosenblatt, F. (1962). Principles of Neurodynamics. Washington: Spartan Book.

Roth, G., and Dicke, U. (2005). Evolution of the brain and intelligence. Trends Cogn. Sci. 9, 250-257. doi: 10.1016/j.tics.2005.03.005

Rubenstein, J. L. R., and Merzenich, M. M. (2003). Model of autism: increased ratio of excitation/inhibition in key neural systems. Genes Brain Behav. 2, 255-267. doi: 10.1034/j.1601-183x.2003.00037.x

Rudolph, M., and Destexhe, A. (2003). A fast-conducting, stochastic integrative mode for neocortical neurons in vivo. J. Neurosci. 23, 2466-2476.

Rumsey, C. C., and Abbott, L. F. (2006). Synaptic democracy in active dendrites. J. Neurophysiol. 96, 2307-2318. doi: 10.1152/jn.00149.2006

Sala, C., and Segal, M. (2014). Dendritic spines: the locus of structural and functional plasticity. Physiol. Rev. 94, 141-188. doi: 10.1152/physrev.00012. 2013

Santoro, B., and Baram, T. Z. (2003). The multiple personalities of h-channels. Trends Neurosci. 26, 550-554. doi: 10.1016/j.tins.2003.08.003

Schaefer, A. T., Helmstaedter, M., Schmitt, A. C., Bar-Yehuda, D., Almog, M., BenPorat, H., et al. (2007). Dendritic voltage-gated $\mathrm{K}+$ conductance gradient in pyramidal neurones of neocortical layer 5B from rats. J. Physiol. 579, 737-752. doi: $10.1113 /$ jphysiol.2006.122564
Schiller, J., Helmchen, F., and Sakmann, B. (1995). Spatial profile of dendritic calcium transients evoked by action potentials in rat neocortical pyramidal neurones. J. Physiol. 487, 583-600. doi: 10.1113/jphysiol.1995. sp020902

Schiller, J., Major, G., Koester, H. J., and Schiller, Y. (2000). NMDA spikes in basal dendrites of cortical pyramidal neurons. Nature 404, 285-289. doi: 10. $1038 / 35005094$

Schiller, J., Schiller, Y., Stuart, G., and Sakmann, B. (1997). Calcium action potentials restricted to distal apical dendrites of rat neocortical pyramidal neurons. J. Physiol. 505, 605-616. doi: 10.1111/j.1469-7793.1997.605ba.x

Schubert, D., Kötter, R., and Staiger, J. F. (2007). Mapping functional connectivity in barrel-related columns reveals layer- and cell type-specific microcircuits. Brain Struct. Funct. 212, 107-119. doi: 10.1007/s00429-0070147-z

Schubert, D., Staiger, J. F., Cho, N., Kötter, R., Zilles, K., and Luhmann, H. J. (2001). Layer-specific intracolumnar and transcolumnar functional connectivity of layer $\mathrm{V}$ pyramidal cells in rat barrel cortex. J. Neurosci. 21, 3580-3592.

Schwindt, P. C., and Crill, W. E. (1995). Amplification of synaptic current by persistent sodium conductance in apical dendrite of neocortical neurons. $J$. Neurophysiol. 74, 2220-2224.

Schwindt, P., and Crill, W. (1999). Mechanisms underlying burst and regular spiking evoked by dendritic depolarization in layer 5 cortical pyramidal neurons. J. Neurophysiol. 81, 1341-1354.

Schwindt, P., O'Brien, J. A., and Crill, W. (1997). Quantitative analysis of firing properties of pyramidal neurons from layer 5 of rat sensorimotor cortex. J. Neurophysiol. 77, 2484-2498.

Segev, I., and London, M. (2000). Untangling dendrites with quantitative models. Science 290, 744-750. doi: 10.1126/science.290.5492.744

Sejnowski, D. T. J. (1977). Storing covariance with nonlinearly interacting neurons. J. Math. Biol. 4, 303-321. doi: 10.1007/bf00275079

Sherwood, C. C., Lee, P. W. H., Rivara, C.-B., Holloway, R. L., Gilissen, E. P. E., Simmons, R. M. T., et al. (2003). Evolution of specialized pyramidal neurons in primate visual and motor cortex. Brain Behav. Evol. 61, 28-44. doi: 10. $1159 / 000068879$

Shu, Y., Duque, A., Yu, Y., Haider, B., and McCormick, D. A. (2007). Properties of action-potential initiation in neocortical pyramidal cells: evidence from whole cell axon recordings. J. Neurophysiol. 97, 746-760. doi: 10.1152/jn.00922.2006

Silberberg, G. (2008). Polysynaptic subcircuits in the neocortex: spatial and temporal diversity. Curr. Opin. Neurobiol. 18, 332-337. doi: 10.1016/j.conb. 2008.08.009

Silberberg, G., and Markram, H. (2007). Disynaptic inhibition between neocortical pyramidal cells mediated by martinotti cells. Neuron 53, 735-746. doi: 10 . 1016/j.neuron.2007.02.012

Silva, L. R., Amitai, Y., and Connors, B. W. (1991). Intrinsic oscillations of neocortex generated by layer 5 pyramidal neurons. Science 251, 432-435. doi: $10.1126 /$ science. 1824881

Silver, R. A. (2010). Neuronal arithmetic. Nat. Rev. Neurosci. 11, 474-489. doi: 10. 1038/nrn2864

Sjöström, P. J., and Häusser, M. (2006). A cooperative switch determines the sign of synaptic plasticity in distal dendrites of neocortical pyramidal neurons. Neuron 51, 227-238. doi: 10.1016/j.neuron.2006.06.017

Sjöström, P. J., Rancz, E. A., Roth, A., and Häusser, M. (2008). Dendritic excitability and synaptic plasticity. Physiol. Rev. 88, 769-840. doi: 10 1152/physrev.00016.2007

Sjöström, P. J., Turrigiano, G. G., and Nelson, S. B. (2001). Rate, timing and cooperativity jointly determine cortical synaptic plasticity. Neuron 32 , 1149-1164. doi: 10.1016/s0896-6273(01)00542-6

Sjöström, P. J., Turrigiano, G. G., and Nelson, S. B. (2007). Multiple forms of longterm plasticity at unitary neocortical layer 5 synapses. Neuropharmacology 52 , 176-184. doi: 10.1016/j.neuropharm.2006.07.021

Somogyi, P. (1977). A specific "axo-axonal" interneuron in the visual cortex of the rat. Brain Res. 136, 345-350. doi: 10.1016/0006-8993(77)90808-3

Somogyi, P., Freund, T. F., and Cowey, A. (1982). The axo-axonic interneuron in the cerebral cortex of the rat, cat and monkey. Neuroscience 7, 2577-2607. doi: 10.1016/0306-4522(82)90086-0

Somogyi, P., Tamás, G., Lujan, R., and Buhl, E. H. (1998). Salient features of synaptic organisation in the cerebral cortex. Brain Res. Brain Res. Rev. 26, 113-135. 
Song, S., Sjöström, P. J., Reigl, M., Nelson, S., and Chklovskii, D. B. (2005). Highly nonrandom features of synaptic connectivity in local cortical circuits. PLoS Biol. 3:e68. doi: 10.3410/f.1024459.287955

Spruston, N. (2008). Pyramidal neurons: dendritic structure and synaptic integration. Nat. Rev. Neurosci. 9, 206-221. doi: 10.1038/nrn2286

Stafstrom, C. E., Schwindt, P. C., Chubb, M. C., and Crill, W. E. (1985). Properties of persistent sodium conductance and calcium conductance of layer V neurons from cat sensorimotor cortex in vitro. J. Neurophysiol. 53, $153-170$.

Stent, G. S. (1973). A physiological mechanism for Hebb's postulate of learning. Proc. Natl. Acad. Sci. U S A 70, 997-1001. doi: 10.1073/pnas.70. 4.997

Stepanyants, A., Hof, P. R., and Chklovskii, D. B. (2002). Geometry and structural plasticity of synaptic connectivity. Neuron 34, 275-288. doi: 10.1016/s08966273(02)00652-9

Stepanyants, A., Tamás, G., and Chklovskii, D. B. (2004). Class-specific features of neuronal wiring. Neuron 43, 251-259. doi: 10.1016/j.neuron.2004.06.013

Steriade, M. (2004). Neocortical cell classes are flexible entities. Nat. Rev. Neurosci. 5, 121-134. doi: 10.1038/nrn1325

Stiefel, K. M., Tennigkeit, F., and Singer, W. (2005). Synaptic plasticity in the absence of backpropagating spikes of layer II inputs to layer V pyramidal cells in rat visual cortex. Eur. J. Neurosci. 21, 2605-2610. doi: 10.1111/j.1460-9568. 2005.04094.x

Strauss, U., Kole, M. H. P., Brauer, A. U., Pahnke, J., Bajorat, R., Rolfs, A., et al. (2004). An impaired neocortical Ih is associated with enhanced excitability and absence epilepsy. Eur. J. Neurosci. 19, 3048-3058. doi: 10.1111/j.0953-816x. 2004.03392.x

Stuart, G. J., Dodt, H. U., and Sakmann, B. (1993). Patch-clamp recordings from the soma and dendrites of neurons in brain slices using infrared video microscopy. Pflugers Arch. 423, 511-518. doi: 10.1007/bf003 74949

Stuart, G. J., and Sakmann, B. (1994). Active propagation of somatic action potentials into neocortical pyramidal cell dendrites. Nature 367, 69-72. doi: 10. 1038/367069a0

Stuart, G., Schiller, J., and Sakmann, B. (1997a). Action potential initiation and propagation in rat neocortical pyramidal neurons. J. Physiol. 505, 617-632. doi: $10.1111 /$ j.1469-7793.1997.617ba.x

Stuart, G., and Spruston, N. (1998). Determinants of voltage attenuation in neocortical pyramidal neuron dendrites. J. Neurosci. 18, 3501-3510.

Stuart, G., Spruston, N., Sakmann, B., and Häusser, M. (1997b). Action potential initiation and backpropagation in neurons of the mammalian CNS. Trends Neurosci. 20, 125-131. doi: 10.1016/s0166-2236(96)10075-8

Svoboda, K., Denk, W., Kleinfeld, D., and Tank, D. W. (1997). In vivo dendritic calcium dynamics in neocortical pyramidal neurons. Nature 385, 161-165. doi: $10.1038 / 385161 \mathrm{a} 0$

Szabadics, J., Varga, C., Molnár, G., Oláh, S., Barzó, P., and Tamás, G. (2006). Excitatory effect of GABAergic axo-axonic cells in cortical microcircuits. Science 311, 233-235. doi: 10.1126/science.1121325

Szentágothai, J. (1975). The 'module concept' in cerebral cortex architecture. Brain Res. 95, 475-496. doi: 10.1016/0006-8993(75)90122-5

Tamás, G., Lorincz, A., Simon, A., and Szabadics, J. (2003). Identified sources and targets of slow inhibition in the neocortex. Science 299, 1902-1905. doi: 10. 1126/science. 1082053

Taylor, C. P., and Dudek, F. E. (1982). Synchronous neural afterdischarges in rat hippocampal slices without active chemical synapses. Science 218, 810-812. doi: 10.1126/science.7134978

Thomson, A., and Bannister, A. (1998). Postsynaptic pyramidal target selection by descending layer III pyramidal axons: dual intracellular recordings and biocytin filling in slices of rat neocortex. Neuroscience 84, 669-683. doi: 10.1016/s03064522(97)00557-5

Thomson, A. M., and Bannister, A. P. (2003). Interlaminar connections in the neocortex. Cereb. Cortex 13, 5-14. doi: 10.1093/cercor/13.1.5

Thomson, A. M., and Deuchars, J. (1994). Temporal and spatial properties of local circuits in neocortex. Trends Neurosci. 17, 119-126. doi: 10.1016/01662236(94)90121-x

Thomson, A. M., and Deuchars, J. (1997). Synaptic interactions in neocortical local circuits: dual intracellular recordings in vitro. Cereb. Cortex 7, 510-522. doi: 10. $1093 /$ cercor/7.6.510
Thomson, A. M., Deuchars, J., and West, D. C. (1993). Single axon excitatory postsynaptic potentials in neocortical interneurons exhibit pronounced paired pulse facilitation. Neuroscience 54, 347-360. doi: 10.1016/0306-4522(93) 90257-g

Thomson, A. M., and Lamy, C. (2007). Functional maps of neocortical local circuitry. Front. Neurosci. 1, 19-42. doi: 10.3389/neuro.01.1.1.002.2007

Thomson, A. M., and Morris, O. T. (2002). Selectivity in the inter-laminar connections made by neocortical neurones. J. Neurocytol. 31, 239-246. doi: 10. 1023/A:1024117908539

Thomson, A. M., and West, D. C. (1993). Fluctuations in pyramid-pyramid excitatory postsynaptic potentials modified by presynaptic firing pattern and postsynaptic membrane potential using paired intracellular recordings in rat neocortex. Neuroscience 54, 329-346. doi: 10.1016/0306-4522(93)90256-f

Thomson, A. M., West, D. C., Hahn, J., and Deuchars, J. (1996). Single axon IPSPs elicited in pyramidal cells by three classes of interneurones in slices of rat neocortex. J. Physiol. 496, 81-102. doi: 10.1113/jphysiol.1996.sp021667

Thomson, A. M., West, D. C., Wang, Y., and Bannister, A. P. (2002). Synaptic connections and small circuits involving excitatory and inhibitory neurons in layers 2-5 of adult rat and cat neocortex: triple intracellular recordings and biocytin labelling in vitro. Cereb. Cortex 12, 936-953. doi: 10.1093/cercor/12. 9.936

Trachtenberg, J. T., Chen, B. E., Knott, G. W., Feng, G., Sanes, J. R., Welker, E., et al. (2002). Long-term in vivo imaging of experience-dependent synaptic plasticity in adult cortex. Nature 420, 788-794. doi: 10.1038/nature01273

Traub, R. D., Contreras, D., Cunningham, M. O., Murray, H., LeBeau, F. E., Roopun, A., et al. (2005). Single-column thalamocortical network model exhibiting gamma oscillations, sleep spindles, and epileptogenic bursts. J. Neurophysiol. 93, 2194-2232. doi: 10.1152/jn.00983.2004

Trimmer, J. S., and Rhodes, K. J. (2004). Localization of voltage-gated ion channels in mammalian brain. Annu. Rev. Physiol. 66, 477-519. doi: 10.1146/annurev. physiol.66.032102.113328

Trussell, L. O., and Fischbach, G. D. (1989). Glutamate receptor desensitization and its role in synaptic transmission. Neuron 3, 209-218. doi: 10.1016/08966273(89)90034-2

Tsay, D., and Yuste, R. (2002). Role of dendritic spines in action potential backpropagation: a numerical simulation study. J. Neurophysiol. 88, 2834-2845. doi: 10.1152/jn.00781.2001

Tsodyks, M. V., and Markram, H. (1997). The neural code between neocortical pyramidal neurons depends on neurotransmitter release probability. Proc. Natl. Acad. Sci. U S A 94, 719-723. doi: 10.1073/pnas.94.2.719

Ulrich, D. (2002). Dendritic resonance in rat neocortical pyramidal cells. $J$. Neurophysiol. 87, 2753-2759.

van Aerde, K. I., and Feldmeyer, D. (2015). Morphological and physiological characterization of pyramidal neuron subtypes in rat medial prefrontal cortex. Cereb. Cortex 25, 788-805. doi: 10.1093/cercor/bht278

Van Der Loos, H., and Glaser, E. M. (1972). Autapses in neocortex cerebri: synapses between a pyramidal cell's axon and its own dendrites. Brain Res. 48 , 355-360. doi: 10.1016/0006-8993(72)90189-8

Vetter, P., Roth, A., and Häusser, M. (2001). Propagation of action potentials in dendrites depends on dendritic morphology. J. Neurophysiol. 85, 926-937.

Walshe, F. M. R. (1942). The giant cells of betz, the motor cortex and the pyramidal tract: a critical review. Brain 65, 409-461. doi: 10.1093/brain/65.4.409

Wang, Y., Gupta, A., Toledo-Rodriguez, M., Wu, C. Z., and Markram, H. (2002). Anatomical, physiological, molecular and circuit properties of nest basket cells in the developing somatosensory cortex. Cereb. Cortex 12, 395-410. doi: 10. $1093 /$ cercor/12.4.395

Wang, Y., Markram, H., Goodman, P. H., Berger, T. K., Ma, J., and GoldmanRakic, P. S. (2006). Heterogeneity in the pyramidal network of the medial prefrontal cortex. Nat. Neurosci. 9, 534-542. doi: 10.1038/nn1670

Wang, Z., and McCormick, D. A. (1993). Control of firing mode of corticotectal and corticopontine layer $\mathrm{V}$ burst-generating neurons by norepinephrine, acetylcholine and 1S,3R-ACPD. J. Neurosci. 13, 2199-2216.

Waters, J., Schaefer, A., and Sakmann, B. (2005). Backpropagating action potentials in neurones: measurement, mechanisms and potential functions. Prog. Biophys. Mol. Biol. 87, 145-170. doi: 10.1016/j.pbiomolbio.2004.06.009

Williams, S. R. (2004). Spatial compartmentalization and functional impact of conductance in pyramidal neurons. Nat. Neurosci. 7, 961-967. doi: 10 $1038 / \mathrm{nn} 1305$ 
Williams, S. R. (2005). Encoding and decoding of dendritic excitation during active states in pyramidal neurons. J. Neurosci. 25, 5894-5902. doi: 10.1523/jneurosci. 0502-05.2005

Williams, S. R., and Stuart, G. J. (1999). Mechanisms and consequences of action potential burst firing in rat neocortical pyramidal neurons. J. Physiol. 521, 467-482. doi: 10.1111/j.1469-7793.1999.00467.x

Williams, S. R., and Stuart, G. J. (2000). Site independence of EPSP time course is mediated by dendritic $\mathrm{I}(\mathrm{h})$ in neocortical pyramidal neurons. J. Neurophysiol. $83,3177-3182$.

Williams, S. R., and Stuart, G. J. (2002). Dependence of EPSP efficacy on synapse location in neocortical pyramidal neurons. Science 295, 1907-1910. doi: 10. 1126/science. 1067903

Williams, S. R., and Stuart, G. J. (2003a). Role of dendritic synapse location in the control of action potential output. Trends Neurosci. 26, 147-154. doi: 10. 1016/s0166-2236(03)00035-3

Williams, S. R., and Stuart, G. J. (2003b). Voltage- and site-dependent control of the somatic impact of dendritic IPSPs. J. Neurosci. 23, 7358-7367.

Williams, S. R., and Wozny, C. (2011). Errors in the measurement of voltageactivated ion channels in cell-attached patch-clamp recordings. Nat. Commun. 2:242. doi: $10.1038 /$ ncomms1225

Wise, S. P., Fleshman, J. W. Jr., and Jones, E. G. (1979). Maturation of pyramidal cell form in relation to developing afferent and efferent connections of rat somatic sensory cortex. Neuroscience 4, 1275-1297. doi: 10.1016/03064522(79)90157-X

Wise, S. P., and Jones, E. G. (1976). The organization and postnatal development of the commissural projection of the rat somatic sensory cortex. J. Comp. Neurol. 168, 313-343. doi: 10.1002/cne.9016 80302

Yang, J., Ye, M., Tian, C., Yang, M., Wang, Y., and Shu, Y. (2013). Dopaminergic modulation of axonal potassium channels and action potential waveform in pyramidal neurons of prefrontal cortex. J. Physiol. 591, 3233-3251. doi: 10. 1113/jphysiol.2013.251058

Yu, Y., Maureira, C., Liu, X., and McCormick, D. (2010). P/Q and N channels control baseline and spike-triggered calcium levels in neocortical axons and synaptic boutons. J. Neurosci. 30, 11858-11869. doi: 10.1523/JNEUROSCI. 2651-10.2010
Yuste, R., and Denk, W. (1995). Dendritic spines as basic functional units of neuronal integration. Nature 375, 682-684. doi: 10.1038/375682a0

Yuste, R., Gutnick, M. J., Saar, D., Delaney, K. R., and Tank, D. W. (1994). Ca2+ accumulations in dendrites of neocortical pyramidal neurons: an apical band and evidence for two functional compartments. Neuron 13, 23-43. doi: 10. 1016/0896-6273(94)90457-x

Yuste, R., Majewska, A., and Holthoff, K. (2000). From form to function: calcium compartmentalization in dendritic spines. Nat. Neurosci. 3, 653-659. doi: 10. $1038 / 76609$

Zarrinpar, A., and Callaway, E. M. (2014). Functional local input to layer 5 pyramidal neurons in the rat visual cortex. Cereb. Cortex doi: 10. 1093/cercor/bhu268 [Epub ahead of print].

Zhang, Z. W. (2004). Maturation of layer V pyramidal neurons in the rat prefrontal cortex: intrinsic properties and synaptic function. J. Neurophysiol. 91, 1171-1182. doi: 10.1152/jn.00855.2003

Zhu, J. J. (2000). Maturation of layer 5 neocortical pyramidal neurons: amplifying salient layer 1 and layer 4 inputs by $\mathrm{Ca} 2+$ action potentials in adult rat tuft dendrites. J. Physiol. 526, 571-587. doi: 10.1111/j.1469-7793.2000.00571.x

Zhu, J., Jiang, M., Yang, M., Hou, H., and Shu, Y. (2011). Membrane potentialdependent modulation of recurrent inhibition in rat neocortex. PLoS Biol. 9:e1001032. doi: 10.1371/journal.pbio.1001032

Zhu, Y., and Zhu, J. J. (2004). Rapid arrival and integration of ascending sensory information in layer 1 nonpyramidal neurons and tuft dendrites of layer 5 pyramidal neurons of the neocortex. J. Neurosci. 24, 1272-1279. doi: 10. 1523/jneurosci.4805-03.2004

Conflict of Interest Statement: The authors declare that the research was conducted in the absence of any commercial or financial relationships that could be construed as a potential conflict of interest.

Copyright (c) 2015 Ramaswamy and Markram. This is an open-access article distributed under the terms of the Creative Commons Attribution License (CC BY). The use, distribution and reproduction in other forums is permitted, provided the original author(s) or licensor are credited and that the original publication in this journal is cited, in accordance with accepted academic practice. No use, distribution or reproduction is permitted which does not comply with these terms. 